\title{
WestVirginiaUniversity
}

THE RESEARCH REPOSITORY @ WVU

Graduate Theses, Dissertations, and Problem Reports

2005

\section{The design, construction and "optimization" of a binder pitch refining unit}

Kevin D. Whiteman

West Virginia University

Follow this and additional works at: https://researchrepository.wvu.edu/etd

\section{Recommended Citation}

Whiteman, Kevin D., "The design, construction and "optimization" of a binder pitch refining unit" (2005).

Graduate Theses, Dissertations, and Problem Reports. 3223.

https://researchrepository.wvu.edu/etd/3223

This Thesis is protected by copyright and/or related rights. It has been brought to you by the The Research Repository @ WVU with permission from the rights-holder(s). You are free to use this Thesis in any way that is permitted by the copyright and related rights legislation that applies to your use. For other uses you must obtain permission from the rights-holder(s) directly, unless additional rights are indicated by a Creative Commons license in the record and/ or on the work itself. This Thesis has been accepted for inclusion in WVU Graduate Theses, Dissertations, and Problem Reports collection by an authorized administrator of The Research Repository @ WVU. For more information, please contact researchrepository@mail.wvu.edu. 
The Design, Construction and "Optimization" of a Binder Pitch Refining Unit

Kevin D. Whiteman

Thesis submitted to the

College of Engineering and Mineral Resources

at West Virginia University

in partial fulfillment of the requirements

for the degree of

Master of Science

in

Mechanical Engineering

W. Scott Wayne, Ph.D., Chair

Alfred H. Stiller, Ph.D.

Eric K. Johnson, Ph.D.

Department of Mechanical and Aerospace Engineering

\author{
Morgantown, West Virginia \\ 2005
}

Keywords: Pitch, Binder Pitch, Wiped Film Evaporators, Pilot Plant, Carbon Products

Copyright 2005 Kevin D. Whiteman 


\section{Abstract \\ The Design, Construction, and "Optimization" of a Binder Pitch Refining Unit}

\section{Kevin D. Whiteman}

Pitches have been important to mankind for hundreds of years. One of the most important pitches used in industry today is binder pitch. Binder pitch is used to make anodes for the aluminum industry. The supply of high quality binder pitch has been steadily decreasing. A process has been developed to produce binder pitch from coal at West Virginia University, but this pitch in this process requires refining.

The focus of this thesis was to design, and construct a bench top wiped film evaporator system to refine that pitch. From the data collected in this thesis, the process was scaled up to a pilot plant sized wiped film evaporator. The research focused on two operating parameters, flow rate into the wiped film evaporator, and the speed of the wiper blades in the wiped film evaporator.

The data indicated that the system was more sensitive to the speed of the wiper blades than the flow rate of material. The best results were obtained with a maximum wiper speed and a minimum flow rate. The operating parameters defined in the bench top system, when applied to the pilot scale unit, resulted in insufficient production to meet contractual obligations. As a direct result of this research, the refining of the pitch was contracted out to Koppers. 


\section{Acknowledgments}

I would like to thank the members of my committee that made this defense possible. I would especially like to thank Dr. Stiller for everything that he has done for me.

Without his help and support this thesis would still be blank sheets of paper. I would like to thank my parents for their continued support. I would also like to thank my wife for her support and patience and for everything that she does. 
$1 \quad$ Introduction

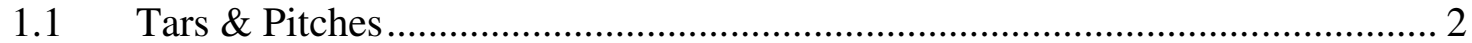

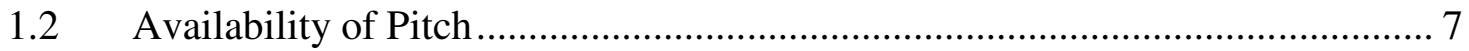

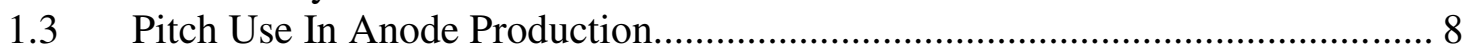

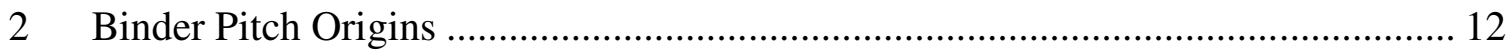

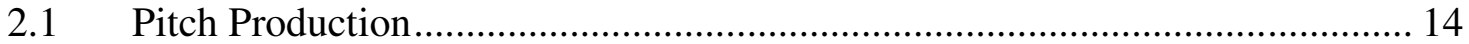

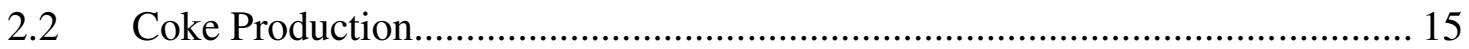

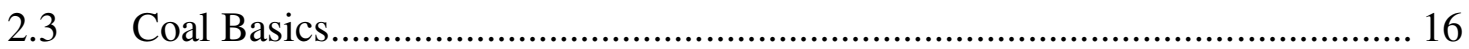

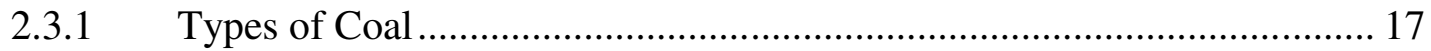

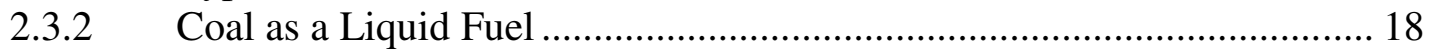

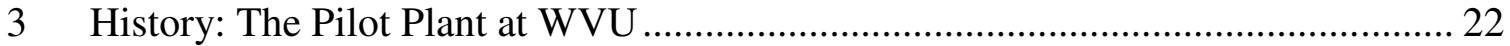

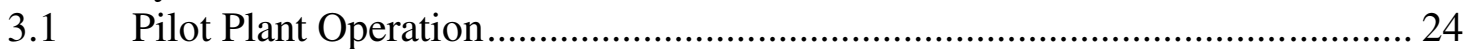

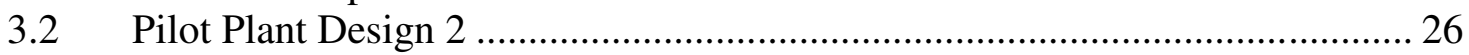

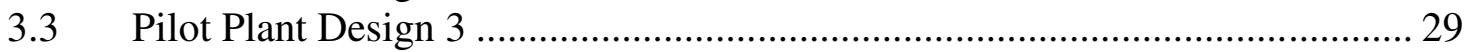

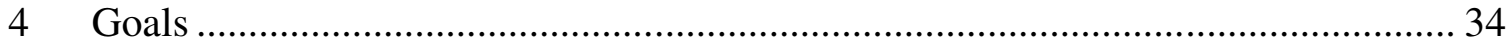

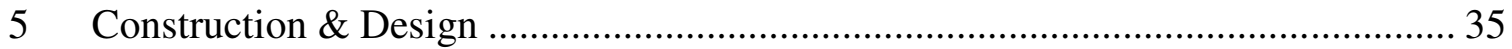

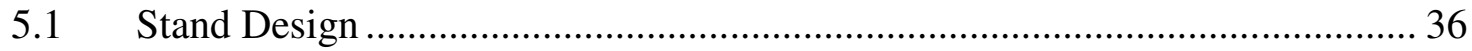

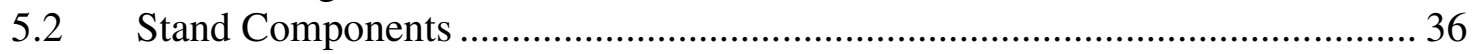

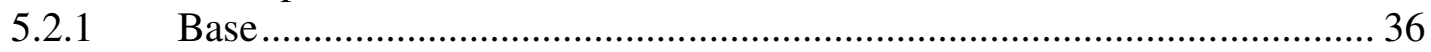

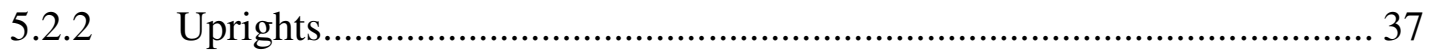

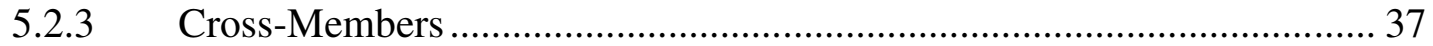

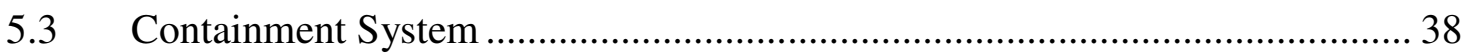

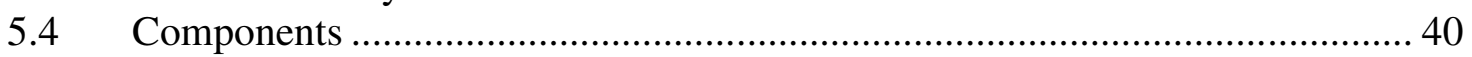

5.4.1 WFE .

5.4.2 WFE Comparison..................................................................................... 41

5.5 Variables for Performance of the WFE ..................................................... 46

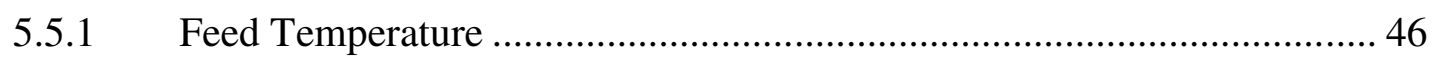

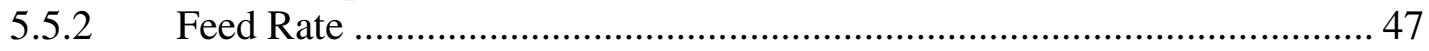

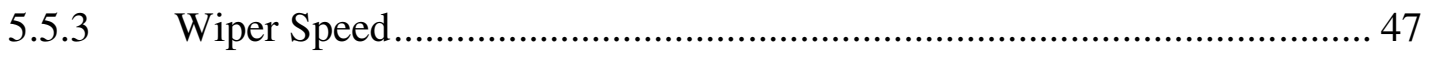

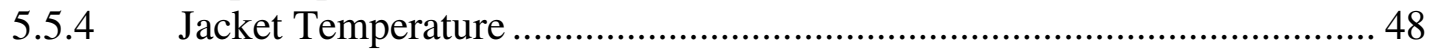

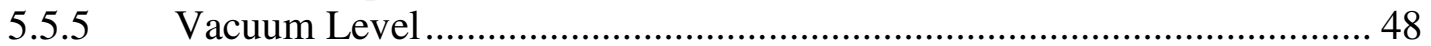

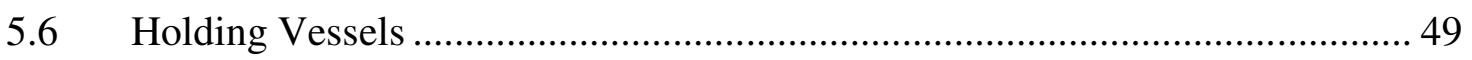

5.6.1 Containment Vessels for Products .......................................................... 51

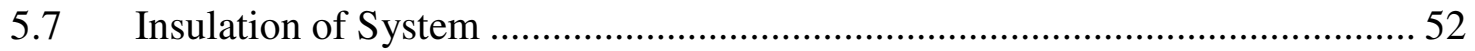

5.8 Heat Exchanger Design and Construction ..................................................... 53

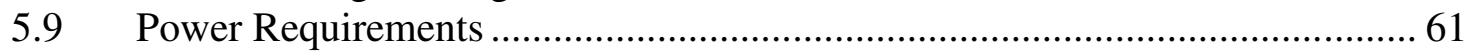

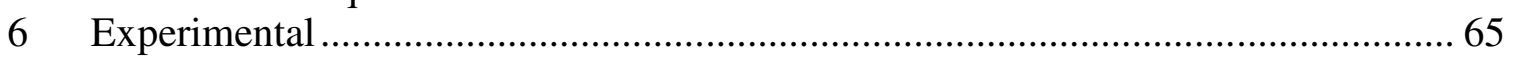

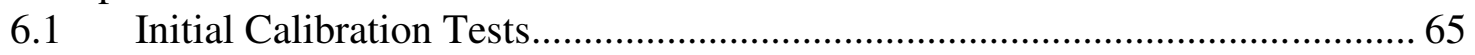

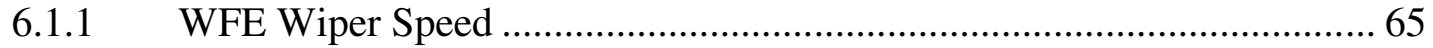

6.1.2 Calibration of Temperature Control......................................................... 70

6.1.3 Calibration of Stirred Vessel Heaters .................................................... 71

6.1.4 Calibration of Pressure Control System................................................... 74

6.2 Modeling and Calibration of Flow Rate …………........................................... 74

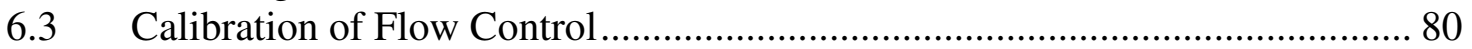

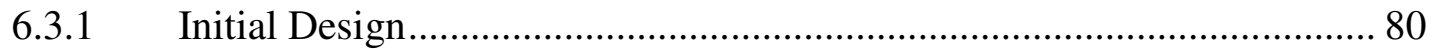




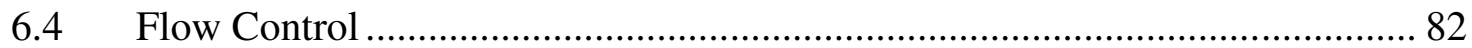

6.4.1 Second Design ............................................................................ 82

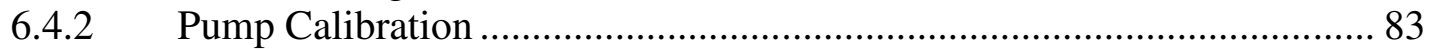

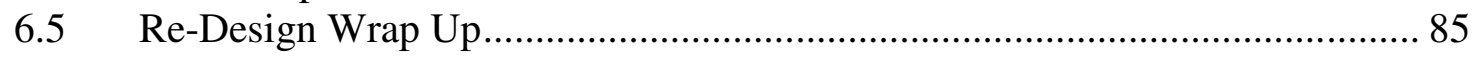

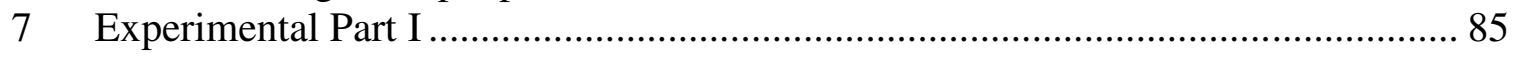

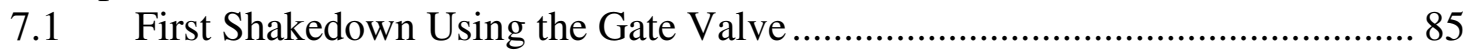

7.2 Second Flow Control Design Using the Gate Valve .................................... 87

Experimental Part II ............................................................................... 90

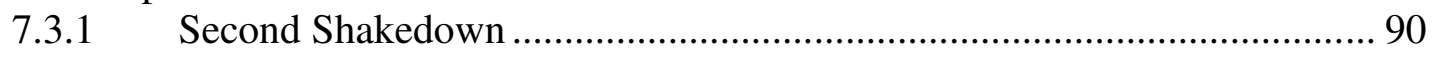

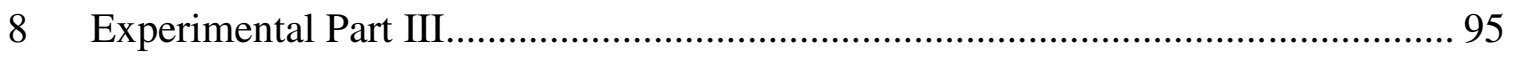

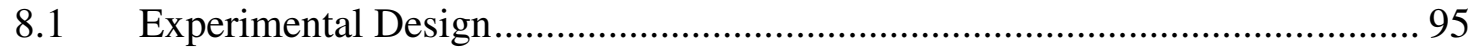

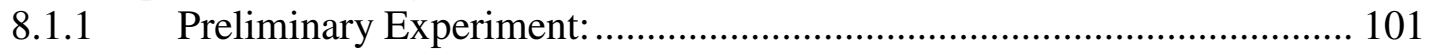

8.1.2 The Two Level Factorial Experiments ............................................... 102

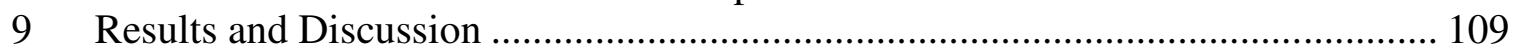

10 Recommendations for Further Research......................................................... 111

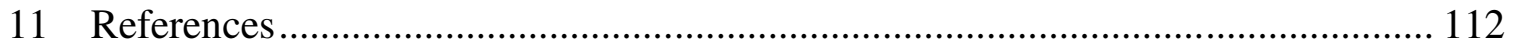

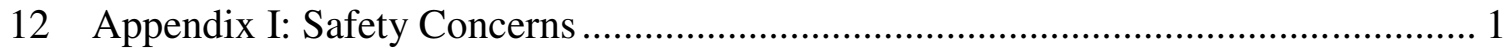

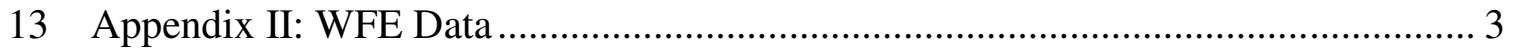

14 Appendix III: MSDS Carbon Black Base ..................................................... 5

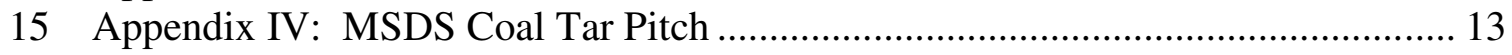

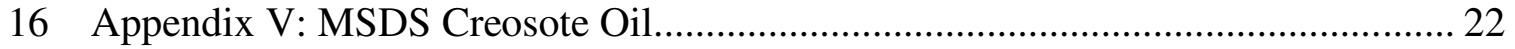




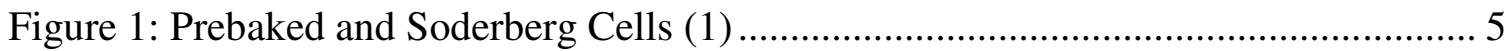

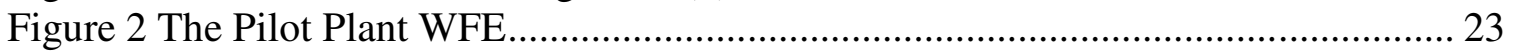

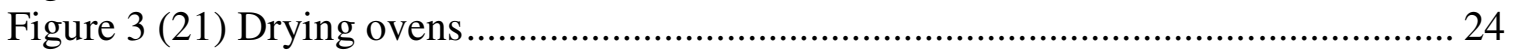

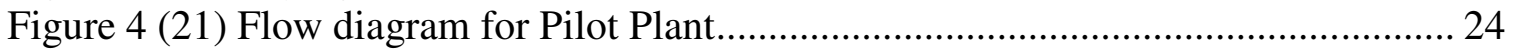

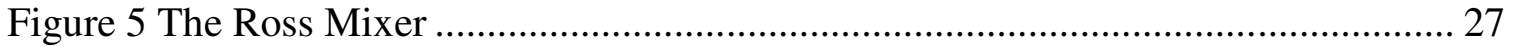

Figure 6 Chrome Plated Tank ................................................................................... 31

Figure 7 The Centrifuge Fume Hood ........................................................................ 33

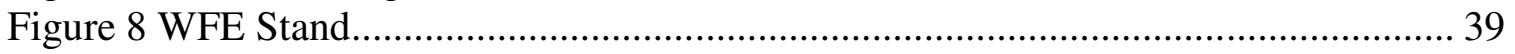

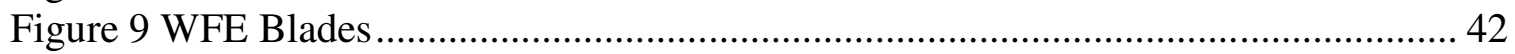

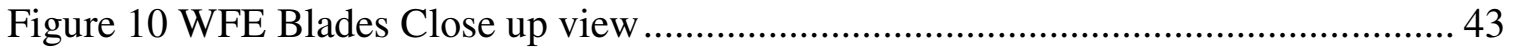

Figure 11 Flow diagram for bench top unit .......................................................... 44

Figure 12 Bench top WFE Blades .......................................................................... 45

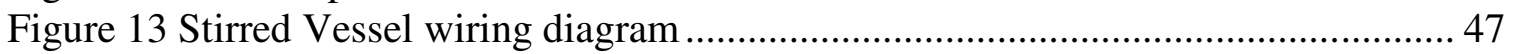

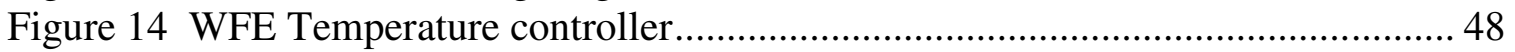

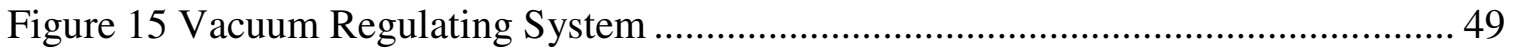

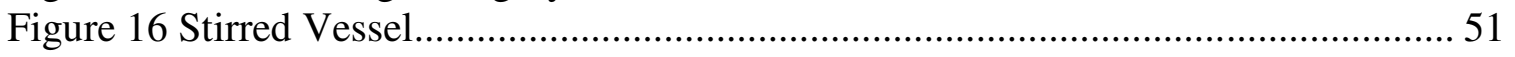

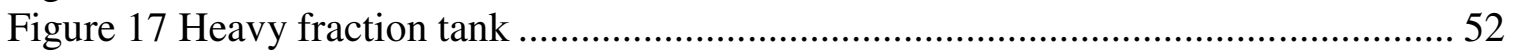

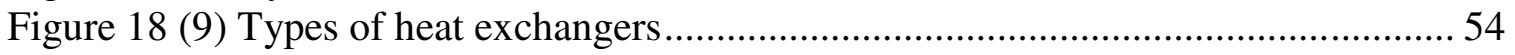

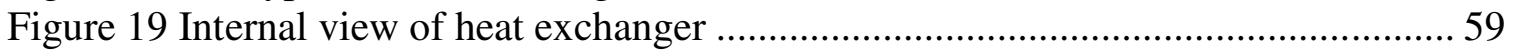

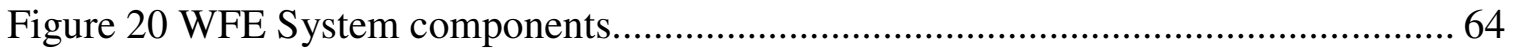

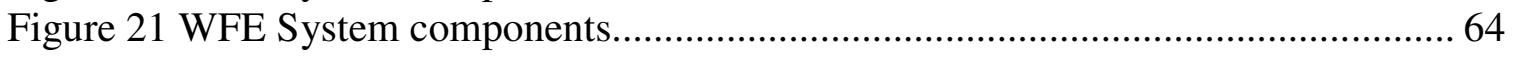

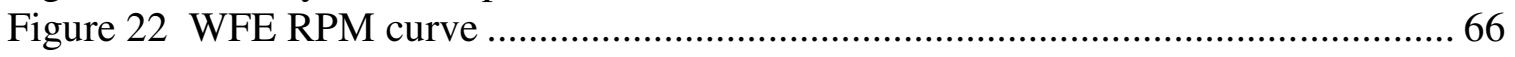

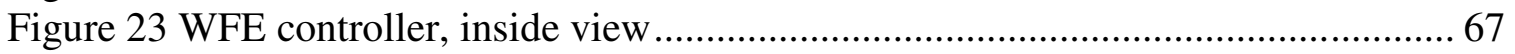

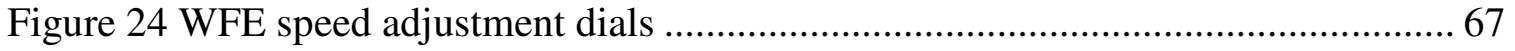

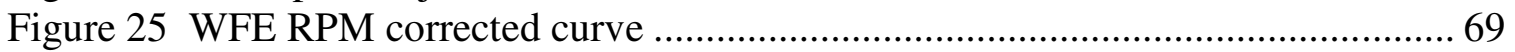

Figure 26 Stirred vessel heater voltage draw .......................................................... 72

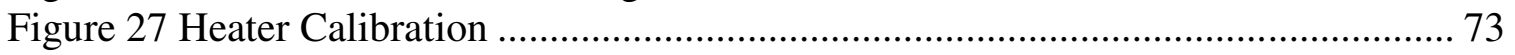

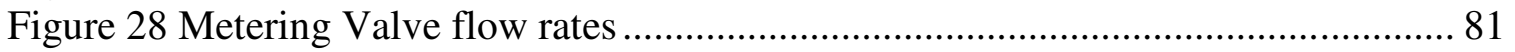

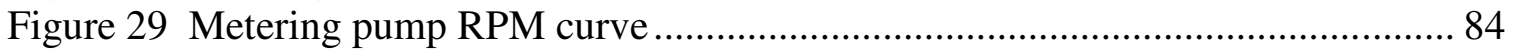

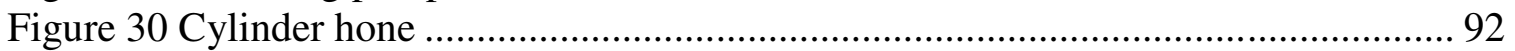

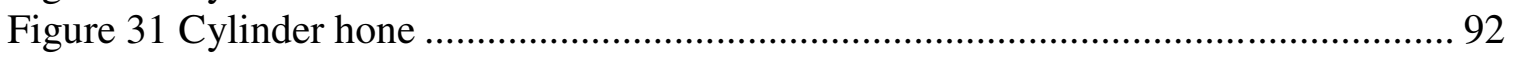

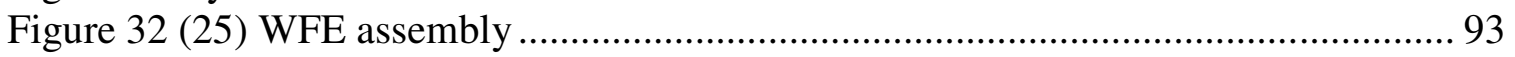

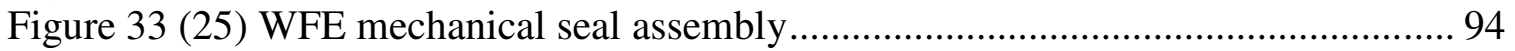

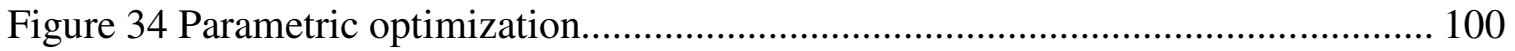

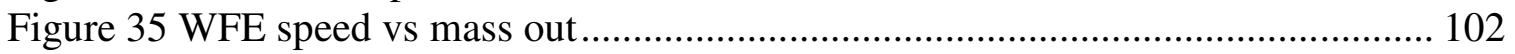

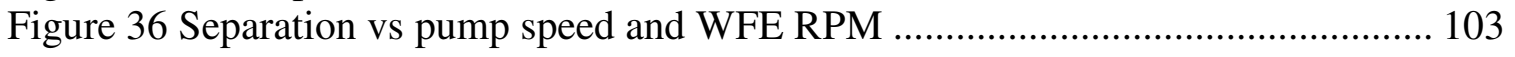

Figure 37 Separation vs pump speed and WFE RPM ............................................... 105

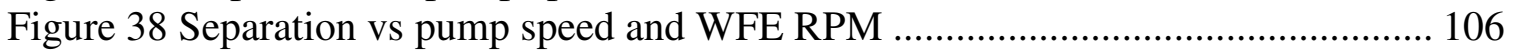

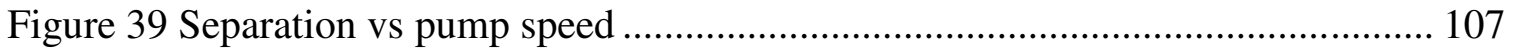

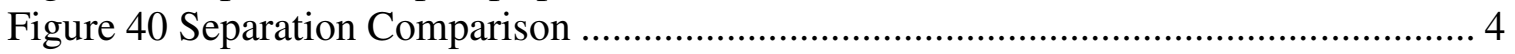

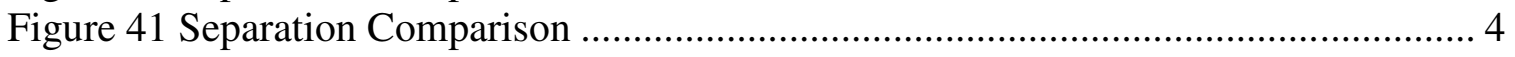




\section{Introduction}

Pitches are complex mixtures of high molecular weight organic compounds that generally are solids at room temperature but become liquids at higher temperatures. For thousands of years, pitches have been used by mankind. These uses have ranged from sealing sailing ships to pouring boiling pitch on soldiers assaulting a castle.

Natural pitch was probably used to seal Noah's ark (22). In the colonial times, wood derived pitches were used to tar the bottom of ships (22). The commercial use of coal derived pitches dates back to British patent \#214 in 1681 (22). In America, it was not

until the American Revolution, during which time the supply of wood tars became scarce, that an interest in replacing wood tar with coal tar developed (22).

Power companies use a type of pitch, known as creosote, to coat the portion of the utility poles that are placed in the ground. In this case, the pitch is used as a wood preservative. Farmers used the same approach to extending the life of fence posts. Although power companies continue this practice, the use of creosote in this manner is now regulated by the EPA. Other industries also use creosote as a wood preserver, and insecticide, although these uses are limited to companies or individuals that have been properly trained to use this material in a safe manner.

Pitches have also been used in the health industry. The health risks associated with coal derived material, such as creosote, have been known for some time. Even though some of these materials have health risks associated with them, they can be found in products used to treat certain skin conditions such as psoriasis, eczema, and dandruff. 
It is generally thought that the exposure level to people in these applications is not high enough to cause long term health risks.

Another selective use of pine tar, also by the agricultural industry, involves chickens. Chickens instinctively pick at one another. When chickens see blood on another chicken, they will pick at the blood causing serious injury. The end result, if left untreated, is that the chickens will pick the bleeding chicken to death. This scenario can be prevented by applying pine tar to the bleeding wound on the chicken. It helps to stop the bleeding and the other chickens will not pick at the sticky substance.

\subsection{Tars \& Pitches}

An appreciation of the proposed research can only be obtained by understanding the difference between tar and pitch. Unfortunately the terms are frequently used interchangeably. This can lead to confusion. Pitch, according to the Merriam-Webster Dictionary (26), is defined as "a black or dark viscous substance obtained as a residue in the distillation of organic materials and especially tars", and by the Oxford Advanced Learner's Dictionary (27) as “a black sticky substance made from oil or coal, used on roofs or the wooden boards of a ship to stop water from coming through." The accepted industry connotation defines tar as the starting material and pitch as a refined product whose properties have been tailored to certain specifications.

The volatile compounds can be removed from tar by distillation. The bottoms or residue remaining after the distillation is generally a solid at room temperature but at liquid at distillation temperatures. This is generically defined as a pitch. Tars tend to be

fluids at room temperatures while pitches are solids at this condition. Tar can come from 
several different sources. The two most common sources are coal and petroleum, but other sources include pine and other conifers.

Pitches can be processed to yield certain properties. For example, the most common specifications for pitch used by the aluminum industry are melting (softening) point and "stickiness". The degree of distillation is the normal method of controlling these properties. This pitch is commonly called binder pitch. It must be able to glue the components, coke and anode butts, used to make anodes together and maintain that bond during the life of the anode.

Other kinds of pitch can be derived from conifers, but these are not important in this research which focuses on pitches distilled from coal and petroleum. The pitch used in this experiment is a blend of Kopper's Coal Tar Pitch and a coal distillate liquid. In general the goal of this research is to blend these two substances and then control the separation of the two materials to produce a product with the desired characteristics, i.e. softening point suitable for use as a binder pitch for the aluminum industry.

The largest use of pitch in the U.S. is the aluminum industry. It accounts for $75 \%$ of the pitch market (17). This industry consumes $0.45 \mathrm{lbs}$ of anode carbon for each pound of aluminum produced (15). In fact, the aluminum industry uses more carbon, as anodes, than all of the other consumers of carbon and graphite put together. The aluminum industry uses a material known as binder pitch to make the anodes needed to refine the aluminum. These anodes can be quite large and consist of three main components, coke, binder pitch, and anode butts. Anode butts are the remaining pieces of a consumed anode. These ingredients are blended together, put in a mold and baked for a specified period of time depending on the size of the anode. The properties of the anodes 
will vary according to the blend ratios of the three ingredients. The method of anode production depends on the type of aluminum reduction cell used to produce the aluminum.

The method of producing aluminum was developed in 1886 simultaneously, but independently by Hall and Heroult in America and Europe respectively (15). The process remains nearly the same now as when it was invented although there have been a few improvements to increase productivity. In brief aluminum is reduced from its oxide state electrolytically using consumable carbon anodes. The stoichiometric reaction is below.

$$
2 \mathrm{Al}_{2} \mathrm{O}_{3}+3 \mathrm{C} \quad 3 \mathrm{CO}_{2}+4 \mathrm{Al}
$$

The $\mathrm{C}$ on the reactant side of the equation is the carbon anode structure.

There are two different types of reduction cell anodes, prebaked and Soderberg. The difference between the two anodes is the method in which they are baked. Prebaked anodes are baked in a separate furnace, whereas the Soderberg anode is formed in place and baked as it is used. The following is an illustration of the two types of anodes. 


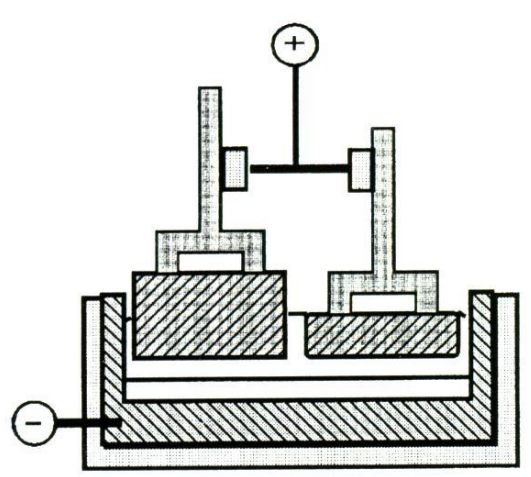

Electrolysis cell with prebaked anodes

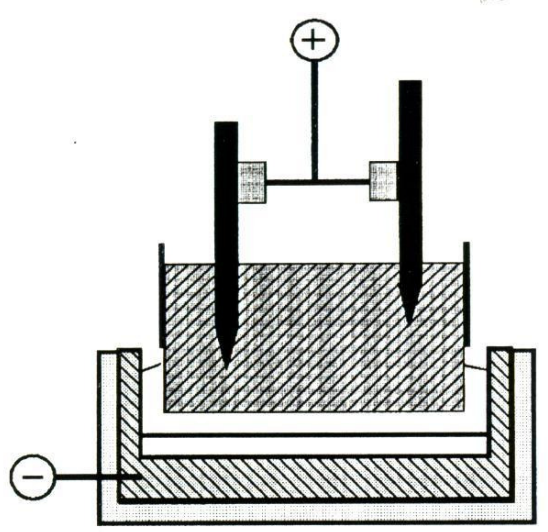

Söderberg cell

Figure 1: Prebaked and Soderberg Cells (1)

The smelters built today use the prebaked anode technology (1). It is expected in the next thirty years the Soderberg cells will be phased out because of environmental issues inherent in the process (1). The environmental issues will become escalated because aluminum production is projected to increase at a rate of $1.5 \%$ a year (1). This growth is fueled by several factors, one of which is the increase in world population. As more countries become developed the demand for aluminum increases as well.

Aluminum has also found many more uses on the automotive industry, from engine blocks and heads, to body panels.

Of the industrial countries of the world, the United States has one of the highest costs per pound of aluminum (1). As the demand for Aluminum increased throughout the world, cost had become a very important issue. The two factors effecting cost are electricity and anode materials. 
Anodes are an essential part of the aluminum smelting process. High quality, minimal impurity anodes are desired in the smelting process. This is necessary for two reasons. The first is that the quality of the aluminum can be affected by impurities in the anode, such as vanadium and nickel. These metals alloy with aluminum in the final product and decrease the overall quality of the metal. Second, since the anode is consumed not only by the reduction of aluminum oxide but by reaction with air and carbon dioxide during the reduction reaction, maximizing the life of the anode by making high purity anodes are needed. The metals in the ash of coke and binder pitch are gasification catalysts and cause the anode to burn in air. Carbon burned in air produces no aluminum.

There are several factors that determine the consumption of the anode, one of which is the quality of the anode (7). Two of the others are electrolysis cell characteristics and operating parameters (7). Determining the quality of the anode is a rather complex problem, but most of the failures of an anode can be attributed to three things; the anode is attacked by $\mathrm{CO}_{2}$, the anode is attacked by ambient air, and the anode is suffering from thermal shock (7).

Ultimately the quality of the components in the mixture used to make the anode is the determining factor for the anode properties (16). There is an optimum blend of the three ingredients, coke, binder pitch, and recycled anode butts. Adjusting the level of pitch in the blend will affect the density of the aggregate. (The higher the apparent density of the anode, the better the pitch has "wet" and penetrated the coke matrix.) There is a maximum value for the density, above which the quality of the anode decreases. The quality, as well as the quantity of binder pitch present in the blend will 
affect the density and properties of the final anode. Anodes with too much binder pitch are as undesirable as anodes with too little binder pitch. The consensus is that increasing pitch content will initially increase the desired properties of the anode, but then reach an inflection point. These properties include electrical conductivity, resistance to air burn, and resistance to thermal cracking. These inflection points represent the optimum amount of binder pitch (16).

The determination of the optimum amount of binder pitch can be determined in the laboratory by mixing the aggregate with different concentrations of binder pitch, forming and baking the anode and evaluating the properties (16). From this evaluation the proper mixture can be selected. However, there is not always a direct correlation between the laboratory and the plant operating conditions. This adds an additional complexity to the system.

The working theory on pitch concentration is that just enough pitch be present to fill the free space between the coke particles during the baking process (16). As long as the amount of pitch in the blend is optimal, the size of the aggregate in the blend can vary over a wide range before it begins to affect anode properties. The reverse is not true. If the pitch content varies by as little as $1 \%$ from the optimum, the anode properties are negatively affected. The properties of the pitch also affect the anode properties.

\subsection{Availability of Pitch}

The production of coal tar is decreasing in the U.S. as well as the rest of the world (17). The decrease in production is due to the closing of recovery coke ovens (18). These closings are due to environmental pressures inherent in the coking process. As a 
result in the decrease in production, alternative sources of binder pitch are being sought. In principle, it is possible to make a similar binder from various petroleum tars (e.g. vacuum residues, decant oil from fluid catalytic crackers, ethylene steam cracker tar) (15). However, most of the petroleum pitches have not been exposed to severe thermal cracking necessary to produce the binding quality of coal-tar pitch (15).

Koppers Industries has attempted to supplement the supply of coal tar pitch with petroleum derived pitches. However, this approach has met with mixed results. More than seventy-five products were evaluated and only one met the performance criteria (23). The most common shortcoming that was reported with petroleum derived pitches was higher than desirable carbon consumption (18). The ultimate challenge is to develop a process that yields a stable supply of high quality pitches.

\subsection{Pitch Use In Anode Production}

Anode formulation has been regarded as a "black art". This nickname could refer to the color of the material involved, carbon and therefore black, or it could refer to the selection of the right materials, in the proper ratios, to yield the desired properties of the finished product. The selection of these materials and the proper recipe to produce the anode could be seen as "black magic."

The standard binder pitch is made from coal tars (17). This tar is a by product from the coking of bituminous coal used in blast furnaces in iron production. The tars that remain are distilled and produce various fractions of distillates and a residue. The residue after distillation is called coal tar pitch. It is this pitch that is mixed with calcined petroleum coke and recycled anode butts, and pressed, vibrated, or poured into an anode 
mold. This mold is then baked for an extended period of time depending on the size of the anode. This process is simulated in the experiments conducted by Suriyapraphadilok et al (17). A 15 gram sample of a specific composition was heated to $1075{ }^{\circ} \mathrm{C}$ over a period of 5-6 days. The heating rate for the sample was $25^{\circ} \mathrm{C}$ per hour from $25-575{ }^{\circ} \mathrm{C}$, and $3.5^{\circ} \mathrm{C}$ an hour from $575-1075{ }^{\circ} \mathrm{C}$. The anode samples were held at the maximum temperature for six hours and then allowed to cool in the furnace. The results of these experiments are used to formulate the optimal blends in molded anodes.

As an anode is baked, the binder pitch begins to coke. It is this coking of the binder pitch that glues the anode together. For this glue to be effective, the binder pitch must contain some quinoline insoluble material. It is believed that the material penetrates the out flow of pitch from the pores of the coke and therefore increases the adherence of the binder pitch and other components. One of the largest differences between coal and petroleum derived pitches is the concentration of QI's, or quinoline insoluble. The QI's contain the largest binder molecules (15). The presence of the QI's in the range of 10$25 \%$ increases the bond-coke quality. In coal-tar pitch, the QI's are near $13.1 \mathrm{wt} \%$, and in petroleum pitch the weight percentage is $0 \%$. Since the QI's play an important role in the binding process, using a petroleum derived pitch will not have the desired properties needed in a binder pitch. The importance of QI's in the binder pitch have been well established, however, the ideal amount of QI's needed to produce the "best" anode has not been determined (17). It is worthwhile to mention that European pitch users and consumers have used pitches, with success, that contain lower concentrations of QI's than their North American counterparts (23). 
The shortcoming of petroleum pitches that is most commonly cited is the higher than desirable consumption of carbon. A current strategy to overcome this shortcoming is to blend a coal-tar pitch with a carefully selected petroleum pitch so that the final product has the properties required in a binder pitch, and extends the supply of coal-tar pitch.

Wombles et al (18), project the coal tar deficit to increase from 140,000 metric tons in 1997 , to 543,000 metric tons in 2003 . These estimations are based on no new smelters being built and the current smelters that have idle capacity remaining idle. They also put forth several strategies to overcome this shortfall.

1.) Import coal tar

2.) Import coal-tar pitch

3.) Using petroleum streams to supplement the coal tar pitch supply

4.) Develop processes to improve pitch yield and upgrade non-conventional coal $\operatorname{tars}$

Each of the above mentioned strategies has pros and cons.

\section{Import Coal Tar}

Due to high labor costs and environmental issues in the U.S., the sources of domestic coal tar pitch have been unable to compete with cheaper imports.

Importing coal tar would seem to be an easy solution to the problem. However, once the coal tar pitch is in the U.S., the problem is then transportation (23). The restrictions for transporting materials such as coal tar pitch have gotten more rigid. Increasing fuel costs 
also make this option less feasible as a long term solution to the coal tar pitch deficit. Another concern with transporting coal tar is the yield of pitch from the tar is approximately $50 \%$, so twice as much coal tar would need to be imported.

\section{Import Coal Tar Pitch}

The second option also has its shortfalls. While it would be advantageous in certain instances, transportation would once again become a concern. Due to external pressures, both labor and environmental, pitch imports have been forced to change from a solid product to a liquid product (23). Because of this change new facilities would need to be constructed to process the product as a liquid. This would require a large capital investment to build these facilities and a stable supply of coal tar pitch would be necessary to justify the expense.

\section{Petroleum Blending}

As mentioned above, some work has been done on replacing or supplementing coal tar pitch with petroleum pitch. The success of this strategy has been somewhat limited. More than 75 different materials have been evaluated and only one met the performance criteria. Even this selection had slight performance disadvantages in the category of air reactivity (23).

\section{Develop New Processes}

The fourth option is also a longer term solution. This strategy involves treating the coal tar to increase the pitch yield and upgrading "unconventional tars to produce high quality pitch" (23). Koppers has conducted research into this area, and similar work has been conducted at West Virginia University. Specific details cannot be revealed here 
to due to the sensitive nature of $R \& D$ developments. However, some success has been recorded in these endeavors.

\section{Binder Pitch Origins}

As mentioned previously, coal-tar pitch is a by product of the coking process. The typical yield of pitch from one ton of coal is $30-45$ liters or 8-12 gallons. Some confusion can arise from the fact that many petroleum products are also called pitches. While inside the petroleum industry this is not an issue, but when outside the petroleum industry, this can cause problems. The characteristics of the pitch will vary with the feedstock from which the pitch is made. Binders are divided into three classes (19).

The class of a binder is determined by the pitches phase at ordinary, i.e. room temperature. These classes are;

1.) Liquid

(a) Tars

1.) Retort-gas tar

2.) Oven-gas tar

3.) Water-gas tar

2.) Semi-solid

(a) Electrolytic pitch

3.) Solid

(a) Coal-tar pitch 
The following table gives a few of the properties of the various pitches.

\begin{tabular}{|c|c|c|c|c|c|}
\hline Material & Melting Point C & $\begin{array}{l}\text { Viscosity (Mac- } \\
\text { Michael)(seconds/100 } \\
\text { rpm) }\end{array}$ & $\begin{array}{c}\text { Free } \\
\text { Carbon } \\
\%\end{array}$ & $\begin{array}{l}\text { Coking } \\
\text { Value } \\
\%\end{array}$ & $\begin{array}{l}\text { Softening } \\
\text { Point C }\end{array}$ \\
\hline Coal-tar & Liquid & $3-15$ & $7-25$ & $10-30$ & \\
\hline Retort-gas tar & Liquid & $5-30$ & $20-40$ & $40-65$ & \\
\hline Oven-gas tar & Liquid & $3-15$ & $12-20$ & $15-30$ & \\
\hline Water-gas tar & Liquid & $3-8$ & $2-5$ & $10-20$ & \\
\hline $\begin{array}{l}\text { Pintsch or oil-gas } \\
\text { tar }\end{array}$ & Liquid & & $25-30$ & $25-35$ & \\
\hline Electrolytic pitch & Semi-solid & $3-25$ & $15-25$ & $20-35$ & 20 \\
\hline \multicolumn{6}{|l|}{ Pitch } \\
\hline Soft & $50-70$ & $3-35$ & $15-25$ & $20-35$ & $35-60$ \\
\hline Medium & $70-90$ & $15-40$ & $25-35$ & $30-40$ & $50-80$ \\
\hline Hard & $90-140$ & $20-250$ & $30-50$ & $35-55$ & $80-115$ \\
\hline
\end{tabular}

Table 1: Properties of various pitches

According to (19), the best pitch to use as a binder is the one that has the highest coke yield. In terms of the finished electrode, this will be the one that loses the least amount of material during the calcining step (19). This is an important criteria to be met since the function of the binder is to glue together the finely ground particles of coke and recycled anode butts, and it does this by coking. It is obvious that the less material that is lost the more that remains to hold those materials together.

Many materials have been evaluated as binders, from sugar to synthetic resins (19). Out of all those materials, the most successful have been coal tars, coal tar pitches and phenol-formaldehyde or phenol-furfural resins (19). One of the properties that can be used as a measure of the effectiveness of the material as a binder is viscosity, but this property is not the absolute determining factor, merely a guideline. As a general rule, viscosity is a means of estimating the binding power of the material. The higher the viscosity the better the material will be at binding the anode together. Using the 
aforementioned properties, the hard pitch in the table listed above would be good choice in both coking value and viscosity.

The hard pitch is the material that is used in the aluminum industry as a binder. Commercially this material is known as coal tar binder pitch. This pitch is the residue remaining after the distillation of coal tar when all the light oils, intermediate fractions, and heavy oils, such as creosotes, and anthracene have evaporated.

\subsection{Pitch Production}

The process through which coal tar pitch is made is to distill coal tar until a high softening point, $150^{\circ} \mathrm{C}$ or so, solid remains. This material is then blended with a lower softening point material until the desired softening point and/or melting point is reached.

Another method of producing this coal tar pitch is to distill that material under vacuum in a steam still until the desired softening point is reached. The steam assists in the removing the high boiling point materials from the still (19). The steam also helps prevent coke from depositing on the walls of the still.

Another method is to distill the coal tar in a horizontal direct fired still until the desired properties are reached. This type of still is not operated under vacuum so that volatile materials that are driven off are allowed to leave at their own vapor pressure which is generated at the same temperature.

There has been some work done, at WVU and elsewhere, on air blowing pitch to raise the softening point to the desired temperature. Air blowing is done by heating the pitch in a reactor to the desired temperature and blowing air into the reactor through the pitch as the material is being stirred. The variables in the reaction, air flow rate, 
temperature, mixing speed, must be rigidly controlled to give reproducible results (24). The following table lists the properties of the pitch before air blowing compared to the desired properties.

\begin{tabular}{|c|c|c|}
\hline $\begin{array}{l}\text { Softening Point C } \\
\text { Analysis; wt-pct }\end{array}$ & $\begin{array}{c}\text { Typical } \\
90\end{array}$ & $\begin{array}{c}\text { Desired } \\
35-100\end{array}$ \\
\hline Moisture & 0 & 0 \\
\hline Carbon & 83.78 & $92-93$ \\
\hline Hydrogen & 8.27 & $4-4.5$ \\
\hline Sulfur & 1.04 & 1 \\
\hline Nitrogen & 1.06 & 1 \\
\hline Oxygen & 5.71 & $1-2$ \\
\hline Ash & 0.14 & 0.3 \\
\hline $\mathrm{C}-\mathrm{H}$ ratio, atomic & 0.84 & 1.8 \\
\hline \multicolumn{3}{|l|}{ Solubility, wt-pct } \\
\hline Benzene & 87.1 & 60 \\
\hline Petroleum ether & 31.9 & 10 \\
\hline
\end{tabular}

Table 2 Pitch Properties before and after air blowing

While the softening point of the pitch can be raised by air blowing, the hydrogen content was reduced by less than one percent, and the viscosity of the softened pitch was higher than desired (24). Another experiment that involved adding sulfur to the pitch to reduce the amount of hydrogen in the pitch was tried. No definite advantage to this treatment was determined (24).

\subsection{Coke Production}

A recovery coke oven is a large oven used to make metallurgical coke. In this type of oven, the coal is heated to $1100^{\circ} \mathrm{C}$ in the absence of air. It is important that the coal is heated in a reduced oxygen environment because the coal will burn at those 
temperatures in the presence of oxygen. In oxygen free pyrolosis, coal becomes a molten reactive mass. During the reaction, devolitilization and cross linking occur. The smaller molecular side chains break off from the larger molecules and become volatiles, while the large molecules cross link and become a solid. The solid is commonly referred to as coke. The volatile compounds that are driven off from the heated coal are collected and condensed. These compounds are collectively referred to as coal tar. The coal tar is subsequently distilled to various coal chemicals and binder pitch.

\subsection{Coal Basics}

Marco Polo introduced Europe to the Chinese use of coal, where it had been used as a home heating source from around 1000 B.C. (Speight 1983). Since that time coal has been used by blacksmiths to fire their forges, by metallurgists to make steel and power companies to produce steam to turn the generators to make electricity. During WW II, alternative fuel sources, to operate military equipment became sought after by the Germans, and researchers turned to coal conversion. At that time, and in more recent history, efforts have been made to convert coal to liquid fuels. However, once the war was over, the interest in this endeavor declined due to the availability of cheaper sources of fuel (21).

In the early part of the last century, several chemicals were made from coal, such as ammonia, methanol and benzene. Another product that has been produced from coal include rubber products. Again, once the war was over, these products were produced using petroleum feed stocks. With the current state of the oil industry, alternative sources 
of fuel are once again becoming a concern. As was done in Germany in WW II, coal could once again become an important part of a potential solution.

Coal is a fossil fuel that is mined from the ground, either by strip mining or underground deep mining. Coal is an organic rock. It is called a fossil fuel because it was formed in a process that took place over millions of years. The decomposing plants and animals of millions of years ago were the precursors to coal. The layers of organic matter were altered over time by pressure, heat and chemical changes. The end result of this time intensive process is the substance that we refer to today as coal. The greatest coal-forming time in geologic history was during the Carboniferous era (280 to 345 million years ago) (20).

\subsubsection{Types of Coal}

Coal comes in three main classifications, anthracite, bituminous and lignite. Anthracite is the hardest of the three types and accounts for roughly half of the exagram $\left(1 \times 10^{15} \mathrm{~kg}\right)$ of coal remaining that is economically accessible. Anthracite coal is primarily used for residential and commercial heating and has a moisture content that is usually lower than $15 \%$ (20). Anthracite coal has little to no mineral matter- Anthracite coal is a metamorphic rock because it was subject to much higher temperature and pressure than the other types of coal. It is non reactive and cannot be used for coke production. It has very a low volatile content about $5 \%$.

Bituminous coal is often referred to as a soft coal and is most commonly used in power plants for steam generation. However, substantial amounts of this type of coal are also used to make coke and coal derived tars and pitches (20). The heating values of 
anthracite and bituminous coal is on the same order of magnitude, 21-30 million BTU/ton (20). Bituminous coal has a slightly higher mineral matter content than anthracite, but much less than the mineral and moisture content of lignite.

Lignite coal is often referred to as brown coal and is of the lowest rank as far as heating value. This coal is used almost exclusively in steam electric power generation. The moisture content of lignite coal can sometimes be as high as $45 \%$. Current estimates are that all coal reserves that remain will last for 300 years.

\subsubsection{Coal as a Liquid Fuel}

In the nineteen seventies America was immersed in a gasoline crises. The cost of gasoline had increased because of a jumping crude oil prices. It was realized that the world would no longer be the same. An assessment of American oil reserves showed that America was dependent on foreign oil suppliers and they could hold us "hostage" over energy. A major effort was started to develop other potential sources of fuel. The logical choice for this attention was coal. America has huge domestic reserves of coal and perhaps this could be converted to meet the nation's energy demand. The only problem was that coal is a rock. It is a solid fuel and society wants a liquid fuel.

During WWII the Germans had converted coal to liquid fuel to support their war effort. One of the original thrusts of research on coal conversion was to duplicate the German processes. Of course the situations were very different. Germany was waging a war with no real domestic fuel sources except coal. To sustain that effort they had to convert coal. America was not in such dire straights. For Germany it was all or nothing. 
For America conversion of coal was a matter of economic relief. There still was oil available that could be purchased.

The German process involved reaction of coal at high temperature, about $450^{\circ} \mathrm{C}$, and high hydrogen pressure, about 2000 psig.; using what is generically known as "red mud" catalysts. Even though the chemistry of German coals is somewhat different than American coals the process could be duplicated. Projects were developed to Project Development Unit (PDU) stages. One of these was at Cresep WVA, another was at Wilsonville Al. The reported purpose was to make de-ashed coal so it could be used in power plants. A larger portion of the ash in coal is pyrite. Pyrite is $50 \%$ sulfur and when that is burned in power plants the sulfur produces sulfur dioxide that becomes sulfur trioxide and ends up as acid rain. The fuel shortage of the 70's was accompanied with an environmental awareness that caused legislation reducing the amount of sulfur in coal burning power plants. So this technology dovetailed into that cause. The challenges to successful development of the technology were the high cost of the equipment and the hydrogen. The conditions were too extreme for the process to be economical. In reality the cost of oil was reduced and the price of gasoline regressed enough for legislators to decrease the effort on coal conversion.

Because it was recognized that one of the major reasons for lack of progress was the extreme reaction conditions the Department of Energy (DOE) started a program to attempt to develop mild condition coal conversion technologies. This was done by a consortium of universities with a group name of Center for Fossil Fuel Liquefaction Science (CFFLS). West Virginia University was a charter member of that group. 
Simultaneously with the formation of that group researchers at WVU were experimenting with the interaction of solvents with coal. It had been established that certain solvents did dissolve larger fractions of coal at mild conditions. Pyridine was commonly used for coal analysis because significant fractions of coal dissolved in it at the solvent boiling point and atmospheric pressure. Researchers at WVU were experimenting with aprotic dipolar solvents such as tetra methyl urea and $\mathrm{N}$ - methyl pyrrlodine. They had shown that these solvents dissolved more organic material from coal at lower temperature but most importantly the solvents could be distilled from the coal. They developed a laboratory scale procedure in which the coal was dissolved in the solvents. The non-soluble portion of the coal was filtered from the solution. The non soluble portion of the coal contained all the ash material. The solvent was distilled from the solution and a dry ash free coal was produced. This duplicated the product from the PDU's developed earlier based on the German technology in that these residues were also ash free.

This research was incorporated into the CFFLS program and studied for several years. It was shown that to be economically effective virtually $100 \%$ of the solvent had to be recovered. Several different procedures were designed to accomplish that objective but only had marginal success. The technology was at a stalemate. A different high value end use for de-ashed coal needed to be found or the technology would be relegated to a scientific curiosity.

That use came to WVU from Oak Ridge National Laboratory. The national laboratory was developing a new type of nuclear reactor. It required significant amounts of nuclear graphite. This particular type of graphite is commonly called isotropic 
graphite. It is made from what is called reactive precursors. The precursors are from petroleum resins produced at refineries. Since the oil refined in America is mostly from foreign countries the government decided to find a domestic source for these precursors. Coal had ideal properties but any ash in the coal would prevent its use in this application. The process described above produced ash free coal. The fit was perfect.

Researchers at West Virginia University began a new research effort called the Carbon Products Program. It was funded by DOE through ORNL and its original objective was to produce isotropic graphite from coal. In order to accomplish this task WVU developed an industrial support group called the Carbon Products Consortium. Members of this consortium were carbon companies that had offices in WVA. They included Koppers corp. UCAR, and ALCOA. During the course of this research samples of ash free coal extract were prepared and converted to graphite by UCAR. The properties of the original samples matched the requirements for nuclear graphite, so the coal dissolution technology had new life.

As the research efforts in carbon materials increases the interest in the coal extraction process also increased. The ash free coal extract was being studied for many other potential applications such as electrodes for the steel industry, anodes for the aluminum industry, potential carbon fiber precursors. Requests for more and more material were made. The group had to advance from the bench top stage at which only 600 grams per week could be produced to a system in which pounds per day could be produced. A pilot plant had to be designed, constructed, and operated.

During the course of the next few years, other technologies were developed from the CFFLS program in which coal could be partially hydrogenated using proton donating 
solvents. Researchers at WVU studied these developments but not with the focus on fuels but rather for the production of carbon materials. These researchers showed that blends of some of the partially hydrogenated coal and ash free coal extract could be used to produce a wide range of carbon products. Further the partially hydrogenated coal could be converted into some of the necessary components for carbon composite manufacture. The pilot plant needed above had to be flexible enough to produce those materials also. This started the continuing scale up effort of which this research is just a part.

\section{History: The Pilot Plant at WVU}

The Carbon Product's Pilot Plant was built in 2000 by Brian Bland and Dr. Alfred H. Stiller. This pilot unit was designed to dissolve coal using a super solvent known as n-methyl-2pyrrilodone, NMP. This process was discovered and patented by Dr. Stiller in 1981. There have been many alterations and design modifications to the pilot plant since it was built. It was thought that the coal extract could be used to make pitch. The development of the pilot plant went through several stages. They are reviewed below.

In general, the pilot plant consists of three operations.

1) Dissolution in which the components of the coal are dissolved in a solvent. This is done in a large constant stirred tank reactor (CSTR). The original CSTR was electrically heated using band heaters.

2) Separation in which the insolubles are removed from the solution. This is done in a centrifuge or filter.

3) Solvent separation, this is done by removing the solvent primarily by evaporation using a heated wiped film evaporator followed by a final drying in vacuum ovens. 


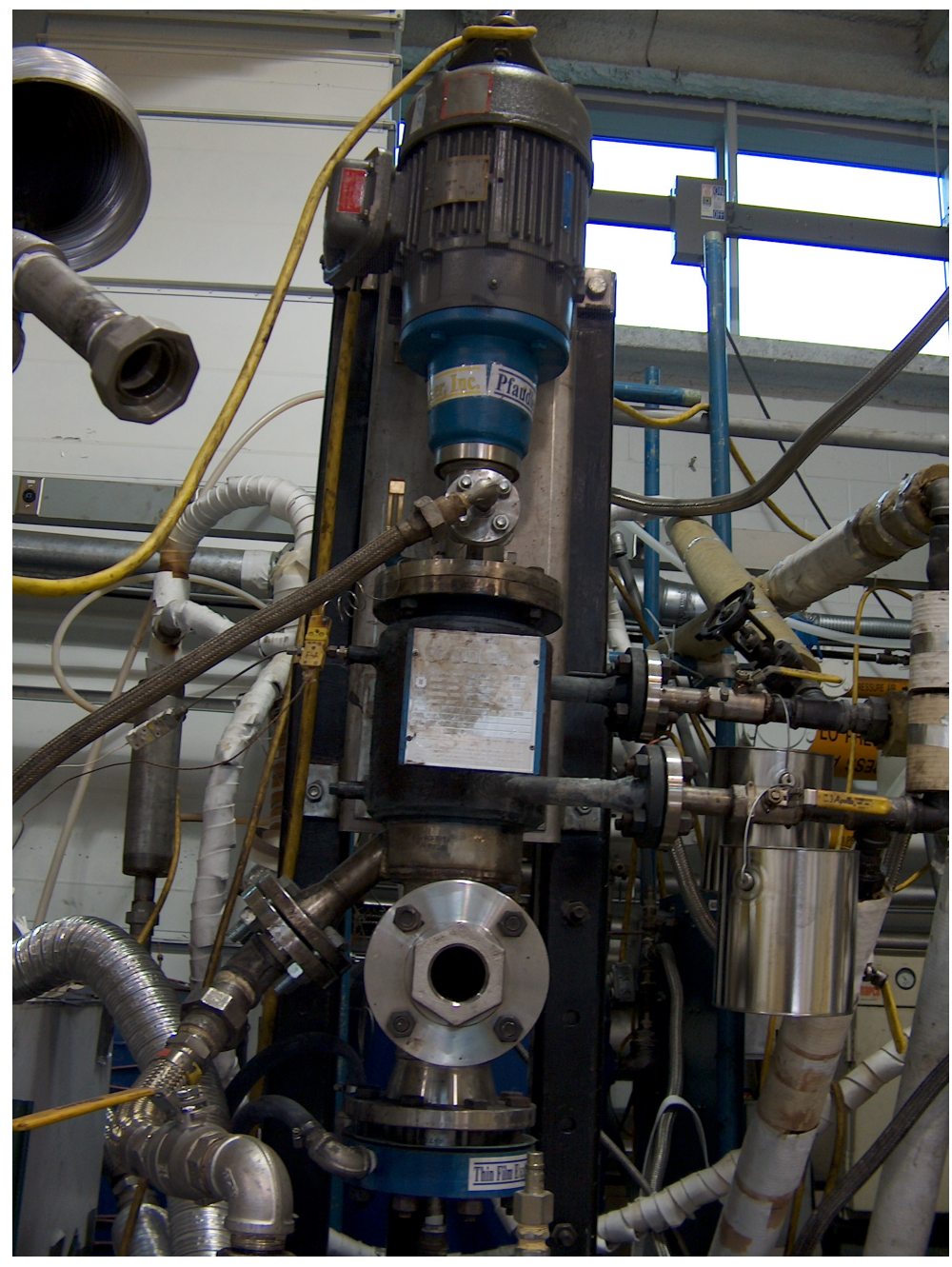

Figure 2 The Pilot Plant WFE 


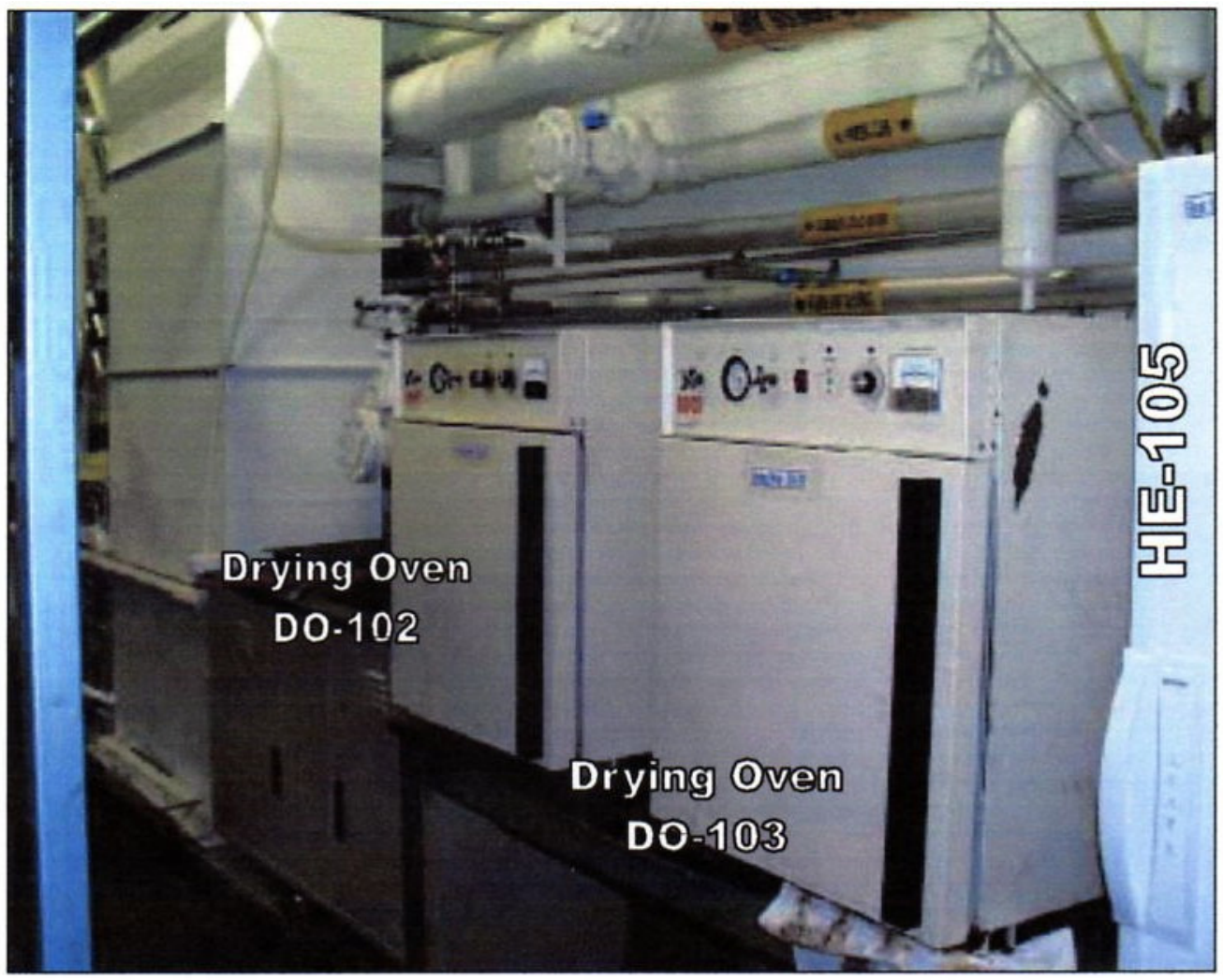

Figure 3 (21) Drying ovens

\subsection{Pilot Plant Operation}

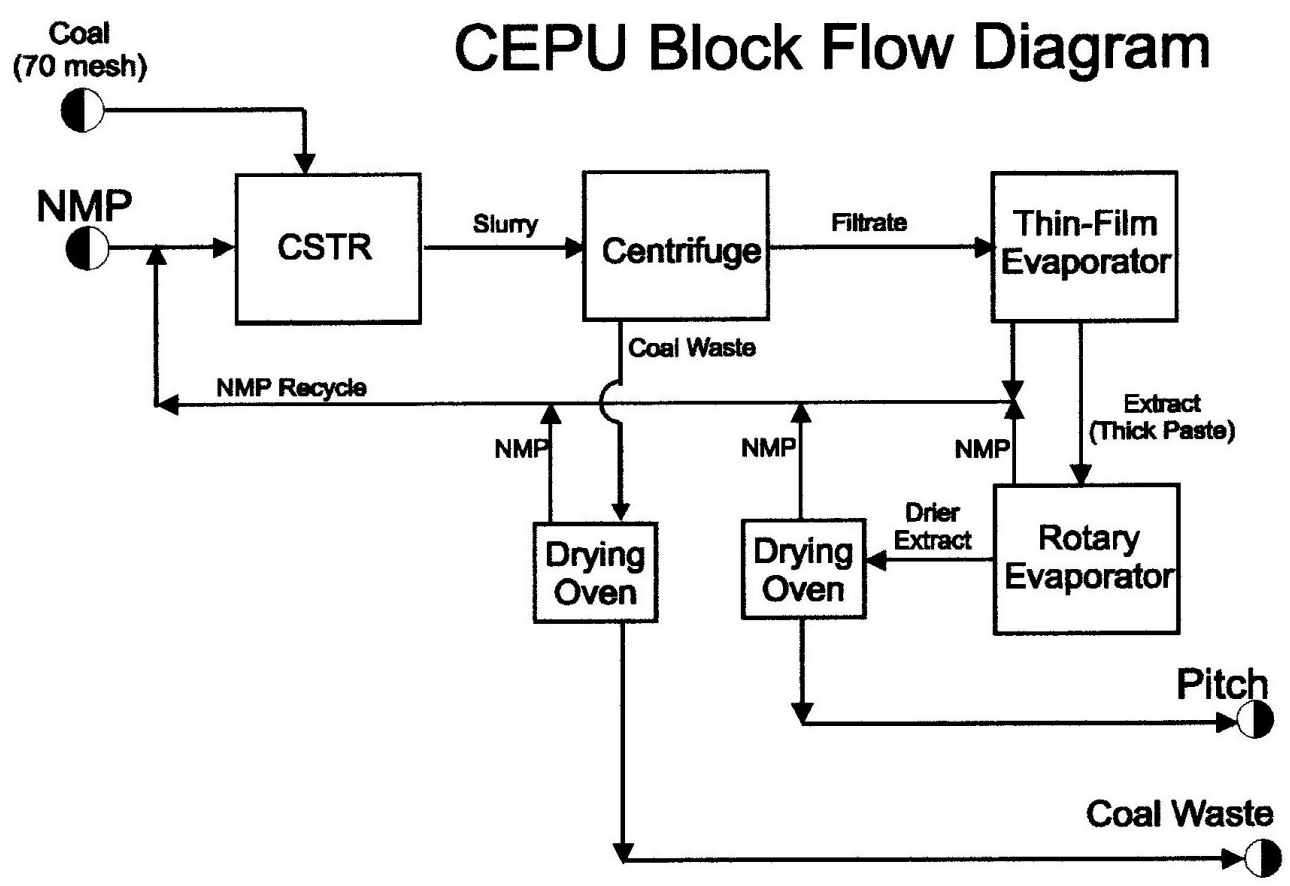

Figure 4 (21) Flow diagram for Pilot Plant 
The first generation pilot plant used a 40 gallon carbon steel, continuously stirred reactor, CSTR, to heat the coal and NMP to the boiling point of the solvent, $202{ }^{\circ} \mathrm{C}$, where the solution was allowed to reflux for a period of one hour, at which time the maximum concentration of coal was shown to dissolve. The feed for the reactor was 100 liters of NMP to 20-22 lbs of coal. Prior to allowing the solution to reflux, water was boiled off and condensed in a glass flask connected to the reactor. It is necessary to remove the moisture content from the coal because the water acts as an anti-solvent and causes the dissolved coal to precipitate. The NMP dissolves preferentially in the water thereby reducing the solvent to solute ratio.

After one hour, the heaters were turned off and the solution was allowed to cool to around $100{ }^{0} \mathrm{C}$. It was necessary to cool the solution because of the temperature restrictions of the centrifuge. The bearings in the centrifuge were not high temperature bearings and therefore could not withstand the high temperature. This cool-down step caused a few problems because at the lower temperatures the dissolved coal precipitated out of solution and caused plugs to form in the plumbing.

The solution was then pumped to a Sharples-Pennwalt centrifuge where the non dissolved coal and ash were separated from the dissolved coal and solvent. This solution was then pumped to a wiped film evaporator, WFE. The WFE was designed as a liquid liquid separator, however. In this application the WFE was actually trying to separate a liquid, the solvent, from a solid, the extracted coal. This was remedied by not taking this step of the process to completion. The separation was halted when the material had the consistency of tar, so it still had significant amounts of solvent. This material was put in a vacuum drying oven where the remainder of the solvent was removed and the extracted coal dried. The objective of this research was to build a 
system that enabled the production of twenty pound batches of dried coal extract. That objective was reached as several hundred pounds of the dried extract were produced.

\subsection{Pilot Plant Design 2}

The second generation of the pilot plant eliminated the WFE from the process. The same reactor and centrifuge were used, but the method of recovering the solvent and extracted coal was altered. The changes were necessary because the tar that the WFE produced was difficult to handle and caused internal problems within the WFE because it was not designed for this type of application.

The WFE was replaced with a Ross planetary mixer. The new method involved pumping the centrate solution into the Ross where it was heated (under reduced pressure) and continuously stirred. Below is a picture of the Ross in the open position, showing the stirring blades. 


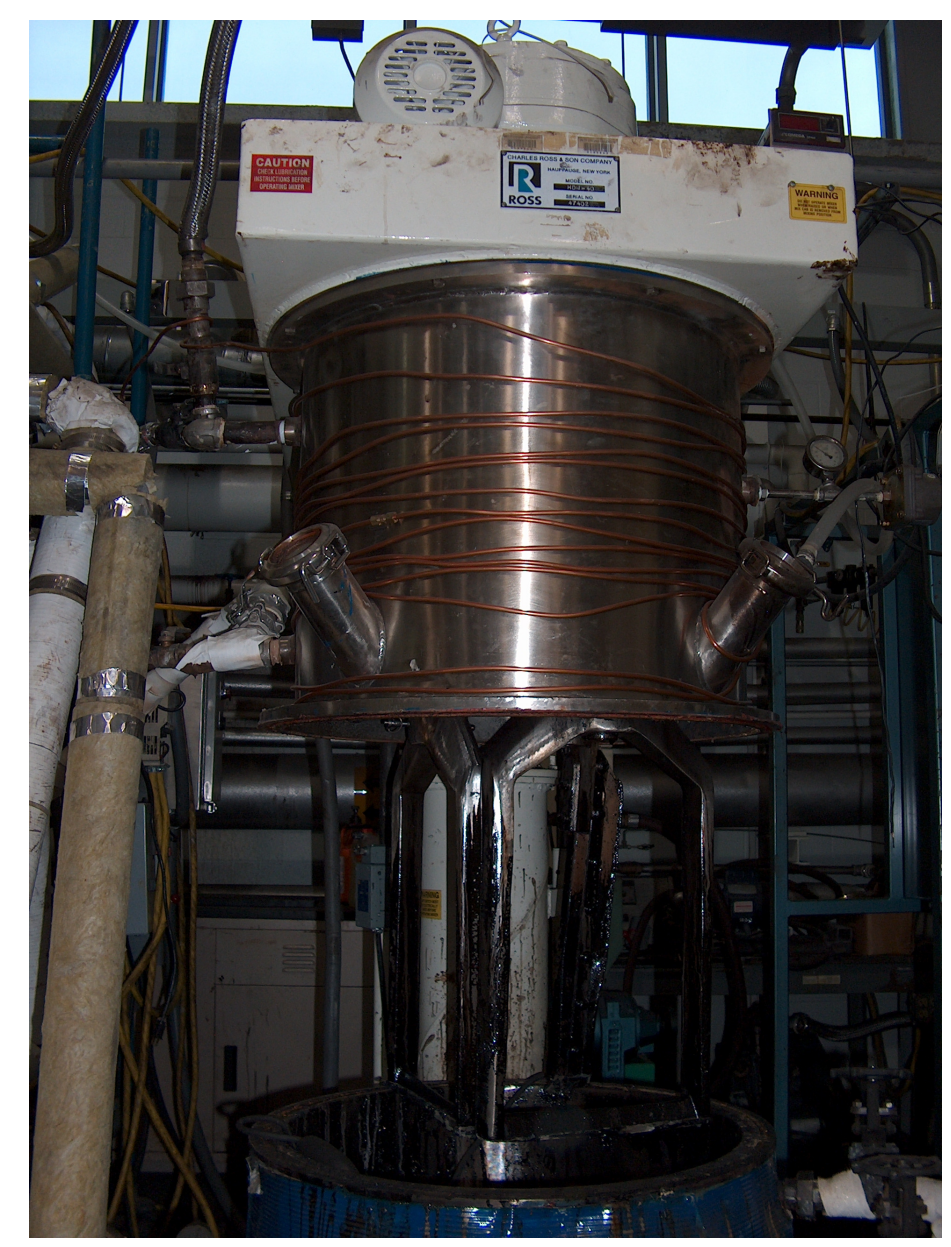

Figure 5 The Ross Mixer

In the first variation of this procedure, $70 \%$ of the solvent was evaporated and the remaining 'thickened' solution was then pumped to a storage tank (55 gallon drum). The recovered solvent was re-used to process another batch of coal. Since $30 \%$ of the solvent remained with the thickened solution, more solvent needed to be added for the next batch. This process was repeated three times to produce a large quantity of thickened solution. After the third run, water was added to the enriched solution to precipitate out the extracted coal. The water acted as an anti-solvent and attracted the NMP and rejecting the coal extract. By this process the extracted coal in the thickened solution precipitated. This solution was then fed into a column filter to separate the liquids from the extracted coal. The extracted coal was dried. 
Although this process produced clean dry extract, it was extremely time consuming, and required several days to process one batch. The filtrate liquids were then pumped to the Ross where the water was evaporated from the NMP and the recovered NMP was added to the recycle stream.

A second variation of the process was developed to reduce the time required to process a batch. It was observed that once the extracted coal was precipitated with water, it would not redissolve in hot NMP. A new procedure was developed to take advantage of that observation. The new procedure eliminated the column filter and sent the precipitated solution directly to the Ross, where it was put under vacuum, heated and stirred. The Ross was put under vacuum to reduce the temperatures needed to boil the water and the solvent. The water was boiled off and the then the temperature was raised and the NMP was boiled off. The material that was left was the extracted coal, already dried and ground to a powder.

The boiling of the water and the solvent provided another problem. When the solution would start to boil, it would foam dramatically. The foam would fill the Ross, and the plumbing going to the water and solvent collection tanks. This issue was resolved by adding small floating plastic spheres to the solution. The addition of the spheres broke up the surface and prevented the foam from developing. However, when the Ross got too hot, it caused the spheres to melt and form one large mass of melted plastic. An attempt was made to use silicon spheres, since the temperatures that were being used would not affect the silicon. However, silicon spheres sink in water and NMP. All attempts to locate hollow silicon spheres failed. Another failed idea was to use wooden spheres. Initially, the wooden balls resolved the over heating issue. The wooden spheres floated, as would be expected, however, they would occasionally get pinched between the wiper blade and the wall of the Ross. Long term use of the spheres was thought to be damaging to the Ross, so the idea was abandoned. A replacement set of plastic spheres was 
eventually found. Even though, the operation range of the spheres was below the temperatures that were being used, some degradation of the spheres was noticed after repeated runs. The damaged spheres were subsequently replaced.

In a forth variation of the process used in this generation of the pilot plant, the water precipitation step was eliminated. Instead the solvent was boiled off directly from the Ross and the extracted coal solids were directly produced. After this process had been proven, the pilot plant was disassembled and a new one was designed and constructed. Several hundred pound quantities of clean, ash free extract were produced using each of the above designs. It is important to understand that this coal extract could not be used to make binder pitch.

\subsection{Pilot Plant Design 3}

When this research was being done the construction and implementation of the pilot plant for phase three had not been completed. The purpose of this research was to evaluate the operation of a version of a WFE to be used in the phase three scale up. The primary purpose of this research was to determine the controlling parameters of the WFE for this application so this knowledge could be transferred to the large scale WFE as it was put into use. The use of WFE's for this purpose had never been attempted before and it was important to have some operational experiences before large scale operations were undertaken.

The purpose of the third modification of the pilot plant was not to produce ash free coal extract, but rather to produce synthetic coal tar binder pitch. The next step was to scale up some bench top experiments that successfully produced synthetic binder pitch. In this process coal 
will be partially hydrogenated in a separate facility and that product will be brought to the pilot plant for purification. The general design of the pilot plant will remain the same.

1) There will be a CSTR to keep the dissolved coal in solution,

2) There will be a separation step. This might be filtration or centrifugation. This step removes the solubles from the insolubles.

3) There will be a refining step. In this case the WFE will be used because the refining involves liquid liquid separation, in which a low boiling liquid, the solvent, is separated from a high boiling point liquid, the pitch.

In the bench top experiments it was shown that a high percentage of the hydrogenated coal will dissolve in the proton donating solvent. The non-soluble portion containing the ash material can be separated by centrifugation. This produces a solution of donor solvent and dissolved hydrogenated coal. By evaporating the donor solvent a solid hydrogenated coal pitch can be produced. The percentage of solvent evaporated from the mixture controls the softening point of the pitch. Bench top experiments have shown that this synthetic hydrogenated coal pitch can be substituted for coal based binder pitch produced by distilling coal tar from a recovery coke oven. It is the goal of this third modification of the pilot plant design to produce larger quantities of the synthetic hydrogenated coal pitch for industrial testing.

\section{The CSTR:}

The new pilot plant replaced the carbon steel reactor with a fifty gallon glass lined Pfaudler reactor. This unit was donated by Alcoa. A stand was designed for this reactor and manufactured by Northco, a local machine shop. The reactor and the stand were contained with in an elevated mezzanine purchased from Grainger Supply. The iron pipe plumbing was all replaced with stainless steel pipe and flex hose. This was needed to reduce the amount iron 
oxide ash, from rust, in the extracted coal. The source of the iron oxide was believed to be rust and scale from the plain carbon steel welds in the vessels and pipes. In addition to replacing the piping, the collection tanks were sent to Swanson Plating and chrome plated to further reduce the potential for picking up iron oxide in the extracted coal. The tank pictured below has been chrome plated inside and out, although it has been painted school colors.

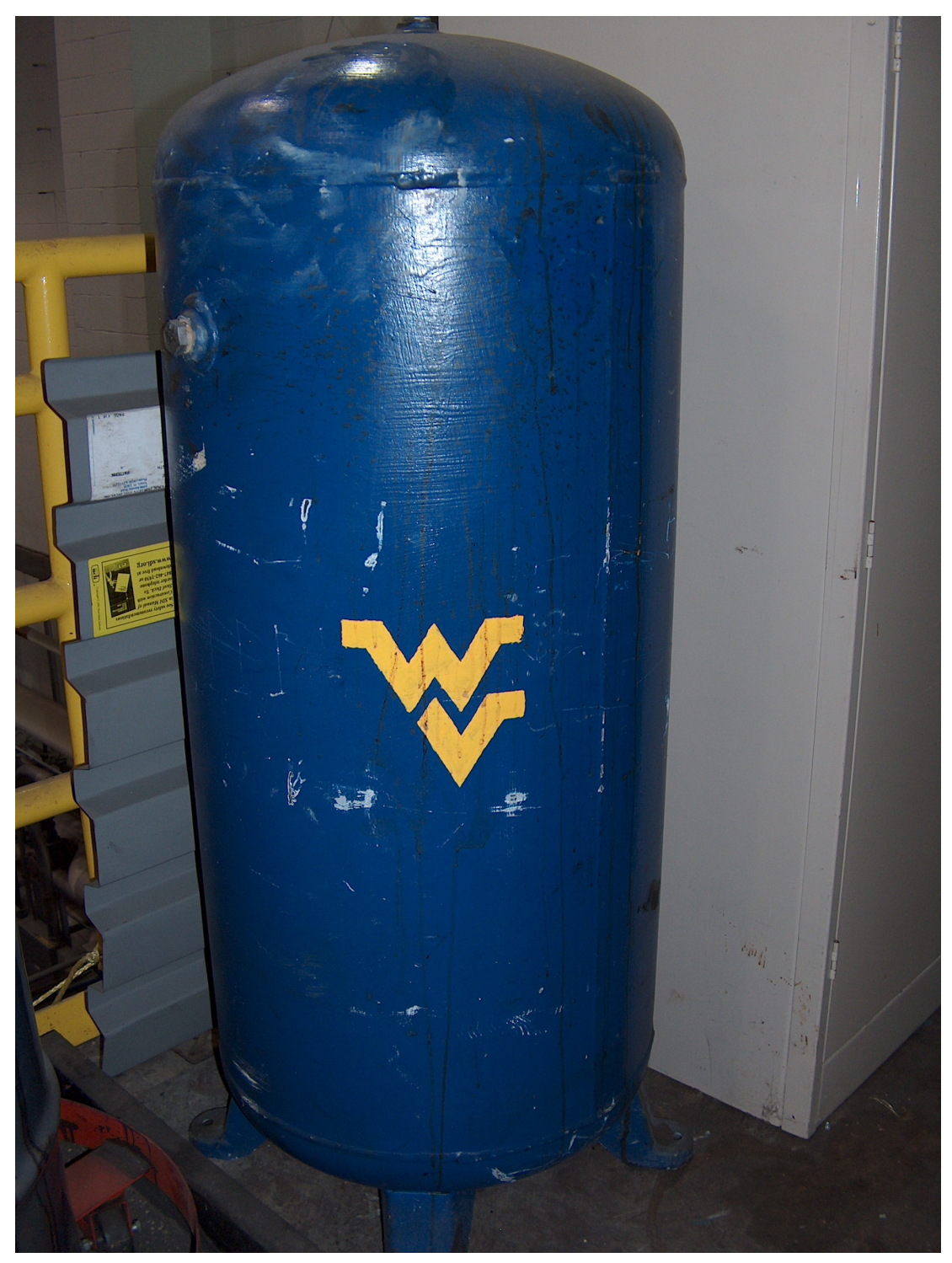

Figure 6 Chrome Plated Tank 


\section{The Separation Step:}

The removal of the non-soluble fraction from the soluble fraction was to be accomplished by the Sharples-Pennwalt centrifuge. The physical arrangement was identical to previous pilot plant designs. The heated mixture from the CSTR was pumped at a controlled rate into the centrifuge. The solid residue was collected in a recovery vessel under the centrifuge and the centrate was collected in a heated collection vessel. Because of the volatility of the heated centrate and solvent which adhered to the solid residue, it was necessary to ventilate the entire centrifuge. A plexiglass box was constructed that enclosed the entire centrifuge. It was plumbed into the exhaust manifold for the system. The bottom of the box was open so a draft could be drawn from the floor level around the centrifuge. A second fan was installed before the exhaust manifold to ensure a high air flow. The box served as a hood and prevented fumes from escaping into the high bay. 


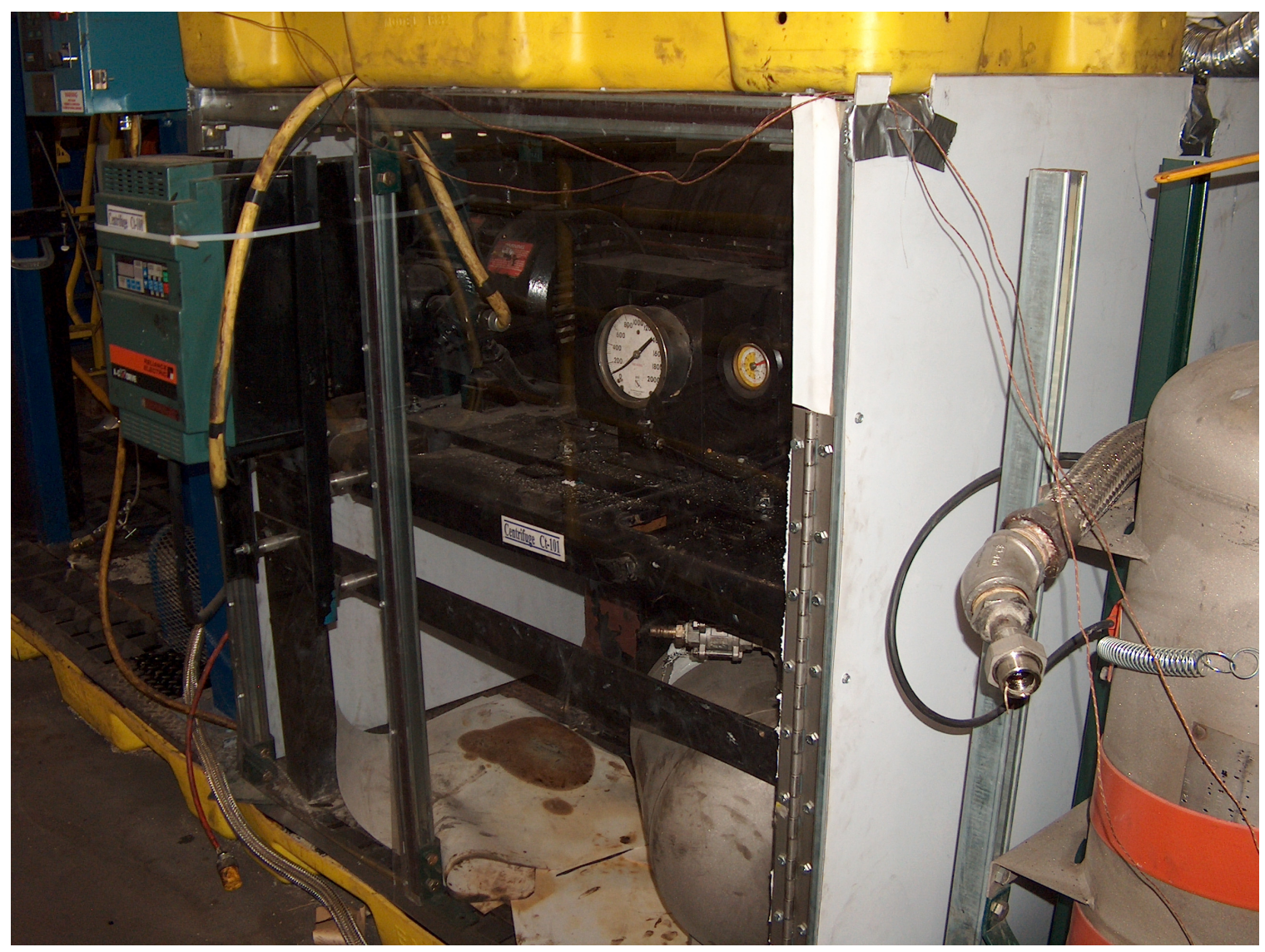

Figure 7 The Centrifuge Fume Hood

The Refining Step:

The WFE was re-integrated into this new design because the products of the synthetic hydrogenated coal pitch are a liquid/liquid separation. The WFE was placed in the system after the centrifuge and could be by-passed if the product did not need to be processed in the WFE. At the time when this research began, no operating parameters had been established for the WFE and no current researchers had used this for a liquid separation unit. Only a single experiment was done to test the WFE. This attempt was to separate coal tar pitch dissolved in NMP and was not successful. Little to no separation occurred. Water was added to the solution with the expectation that the coal tar pitch would precipitate out and the solvent could be recovered. This was also futile and as a result the entire mixture needed to be disposed of as hazardous waste. 
Thus no successful separation of liquid had been accomplished using the WFE by the research group. The necessary parameters for the separation and refining of pitch from hydrogenated coal solvent mixture needed to be established.

A major portion of the research of the Carbon Products Program involves pitch preparation. For this pilot processing in our plant to occur, the WFE needs to be employed. The objective of this thesis is to evaluate the feasibility of a WFE for that purpose. A preliminary evaluation of the operating parameters of a WFE will be done using a small scale WFE. It is anticipated that parameters from these experiments, if successful, can be extrapolated to the pilot scale WFE. This will enable the Carbon Products Program to successfully employ the pilot scale WFE for the production of large quantities of pitch as required by their current contract.

\section{$4 \underline{\text { Goals }}$}

The goal of this research is to design, build and test a mid-scale system employing a small scale WFE to refine blends of coal distillates and hydrogenated coal liquids into high grade binder pitch with properties suitable for use in the aluminum industry. A high grade binder pitch will yield a higher grade anode which will have a longer service life and fewer impurities both in the anode and the final ore product.

The research in this thesis required to complete the goal will be described in the four phases listed below;

- Stand design and construction

- Component Assembly

- Shake down and redesign

- Establishment of operating parameters 
One of the current research focus areas is to create a synthetic binder pitch, known as synpitch, from hydrogenated coal and a coal liquid as a solvent. The softening point of the synpitch can be tailored by controlling the amount of solvent that is evaporated from the mixture after the reaction has taken place. It is anticipated that the WFE in the pilot plant will be the equipment used to perform this separation. This research involves a smaller scale system which should be able to establish conditions for successful operation of the pilot scale system. With the smaller scale WFE, more experiments can be run with less danger and minimal production of hazardous waste. Even though a one-to-one correlation may not exist between the operating parameters of the bench-top version and the larger version in the pilot plant a sensitivity analysis of the operating parameters will provide direction for the pilot plant operation. None of the technicians currently working on the project has any experience operating the WFE in the pilot plant. Any experience gained from this research will increase the understanding of the operation of equipment that will be used on a larger scale in the future.

\section{Construction \& Design}

The following sections describe the original design and construction of each of the components that comprise the WFE test system. These include the stand, the holding vessels, stirred vessel, and heat exchanger. 


\subsection{Stand Design}

Because the mini-WFE, purchased as a unit from LCI, is a bench top scale and could be moved from lab to lab, the stand to hold the WFE and its components must be designed so that the unit can fit through a standard sized doorway. The stand is a rack made from Unistrut that will support the WFE unit, feeding vessel, holding vessels and the drive motor with controller. The stand will consist of three main sections; the base, the vertical uprights and the horizontal cross members. The overall dimensions of the stand are 81 1/2" tall, 25 1/2" deep, and 49 1/4" wide. The design and construction of each will be described below.

\subsection{Stand Components}

There are three main sections of the stand;

1) The base

2) The uprights

3) The horizontal cross-members.

\subsection{1 $\underline{\text { Base }}$}

The base will serve two purposes; as an anchor for the vertical uprights- to support the components of the unit, and part of the spill containment system. The base of the stand is a piece of $1 / 8$ " thick carbon steel, that was bent into the shape of a large tray and welded to seal the seams. The finished base dimensions are $491 / 4$ ' long by $251 \frac{1}{2}$ ' in 
width by 3 1/4" deep. Attached to the base of the stand were plastic castors. The castors were needed to make the stand mobile.

\subsubsection{Uprights}

The vertical uprights were a two piece system. The main component of the uprights will be the c-channel welded to the base.

Bolted to these uprights will be two vertical sections of Unistrut that will serve as the attachment point for the horizontal cross members. Attached to the stand were two uprights. The uprights were three inch wide c-channel, $13 / 8^{\prime \prime}$ deep. To make the stand as versatile as possible, the c-channel was not used to support the cross members that the tanks and the WFE would be attached to. Instead, each of the uprights had a piece of Unistrut attached to it. The Unistrut uprights were five feet eight inches tall. The Unistrut would allow a virtually infinite arrangement of cross members and supports. According to the literature available from Unistrut, the size bolts and spring nuts that will be used have an allowable pull-out strength of 2000lbs and a resistance to slip of $1500 \mathrm{lbs}$. Unistrut also notes that the design loads for the spring nuts includes a safety factor of three. The entire stand could then be supported by one bolt and one spring nut.

\subsubsection{Cross-Members}

There were a total of seven cross members. Six of them were 52"' and the seventh was 34'. The last one was shorter than the others to make room on the base of 
the stand for the vacuum pump. An Additional length of Unistrut was attached to the end of this short piece and the cross member above it by for additional support and strength. The spacing of the cross members was variable and depended on the bolt patterns of the tanks and the WFE.

\subsection{Containment System}

The largest potential safety hazard in the experiment is catastrophic failure resulting in spillage of the liquids in the system. Even though this is a remote possibility, the system had to be designed to accommodate this possibility. The base of the stand

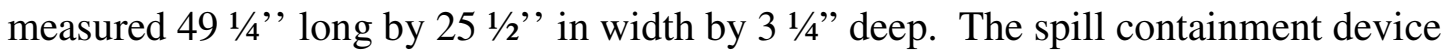
had to accommodate this base. A slotted catch basin, known as a pig, was employed for that purpose. These pigs were purchased from McMaster Carr for use in the first pilot plant. The insert is a perforated high density plastic that is 3'' tall and measures $48^{\prime}$ ' by 24''. The insert fit well into the base of the stand. The volume of that base without the pig insert is 4081 cubic inches, or 66.9 liters. Placing the insert into the base would reduce the available volume of the base by roughly $40 \%$. Even with this reduction volume, the capacity of the insert would exceed the maximum capacity of the system, 17 liters, by a factor of 3. Thus in the event of a catastrophic failure, no chemicals would escape the system which minimized hazard and clean-up problems.

From the picture below, it can be seen that the tanks and the WFE fit onto the stand. The only major component of the system that is not on the stand in this picture is the heat exchanger. The heat exchanger and its construction will be discussed later. 
Suffice to say only that the heat exchanger is also constructed out of a 4.6 gallon tank and will bolt onto the stand with the cross members spaced as they are.

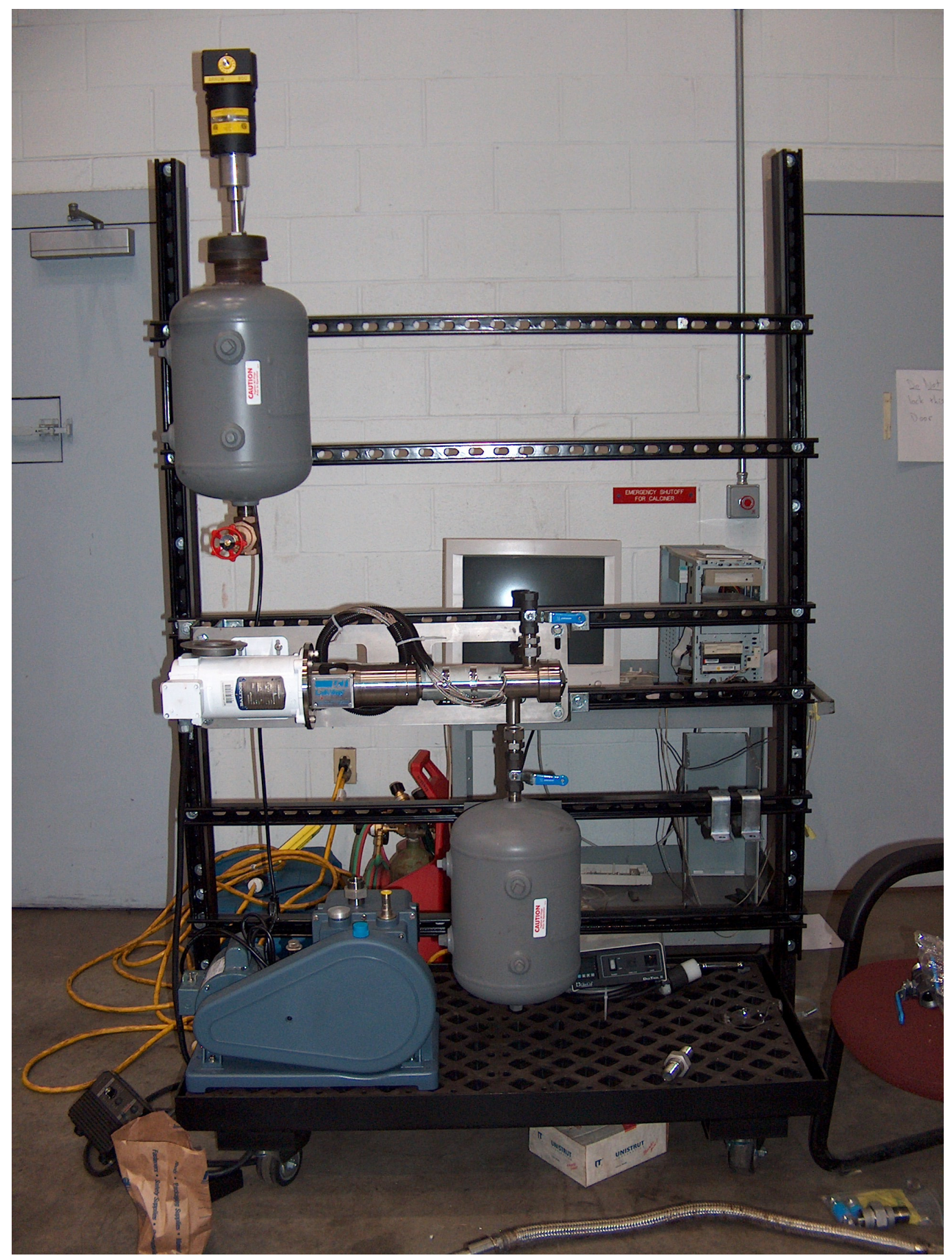

Figure 8 WFE Stand 


\subsection{Components}

\subsection{1 $\quad \underline{\text { WFE }}$}

The wiped film evaporator, WFE, is a classic piece of chemical processing equipment. The WFE is the focus of this system. A WFE system consists of six main components;

- A feed system

- A heated cylindrical surface

- A wiper to spread the feed over the heated surface where the low boiler is evaporated

- A condenser to condense the low boiler

- A recovery vessel for the condensed liquid

- A recovery vessel for the high boiler

In the operation of the WFE, a liquid mixture of at least one high boiling point liquid and one low boiling point liquid is sprayed from the system onto the heated cylindrical surface. The wiper blades spread this spray as a thin film along the hot surface of the cylinder wall. The low boiling point liquid evaporates from the mixture and is condensed and collected in the low boiler receiving vessel. The high boiling point liquid travels along the cylinder and exits through a separate exit port. The surface of the wiper guides the flow of the low boiling point liquid to its port. 


\subsubsection{WFE Comparison}

Wiped film evaporators have several advantages over other separation devices.

First the WFE is run in a continuous process, unlike a rotary evaporator which is a batch process. A distillation column can also be used on a continuous separation process, but these apparatus can be extremely expensive and are used for more exact separations. An advantage of a distillation column is its ability to split the material into more than two fractions. In some applications this is needed, such as refining crude oil, but in this case, only two fractions are needed. A second advantage of a WFE is the short residence time that the material is exposed to heat; typically this is as short as $2-5$ seconds (13). This feature is very important if the material being processed degrades during long term exposure to heat. It is believed that the compounds of the pitch will eventually react on long time exposure to heat. These reactions could change the properties of the pitch and would add an additional complexity to the system. So the short residence time in the heated zone is a distinct advantage over distillation in particular.

There are two different structured WFE's used in this research. The differences are discussed below. (1) The WFE used in this thesis is a bench top version with 0.25 square feet of heated area, compared to a surface area of 1.2 square feet of heated area in the pilot scale unit. (2) The pilot scale WFE that is currently incorporated into the third modification of the pilot plant is a vertical Pfaudler WFE; the bench top WFE is a horizontal model. The primary difference between a vertical and a horizontal WFE is the direction the material travels inside the WFE. In a horizontal WFE, the material will either move left to right, or right to left depending on the location of the inlet and outlet ports. With a vertical unit, the material is fed in the top of the cylinder and flows down 
the cylinder as it is wiped. (3) The material from which the wiper blades are made is different. The wiper blades in the smaller unit are stainless steel. The blades in the larger unit in the pilot plant are made from graphite. (4) The blades differ not only in material, but also in geometry. The geometry of the blades of the larger pilot plant unit is illustrated in the figure below.

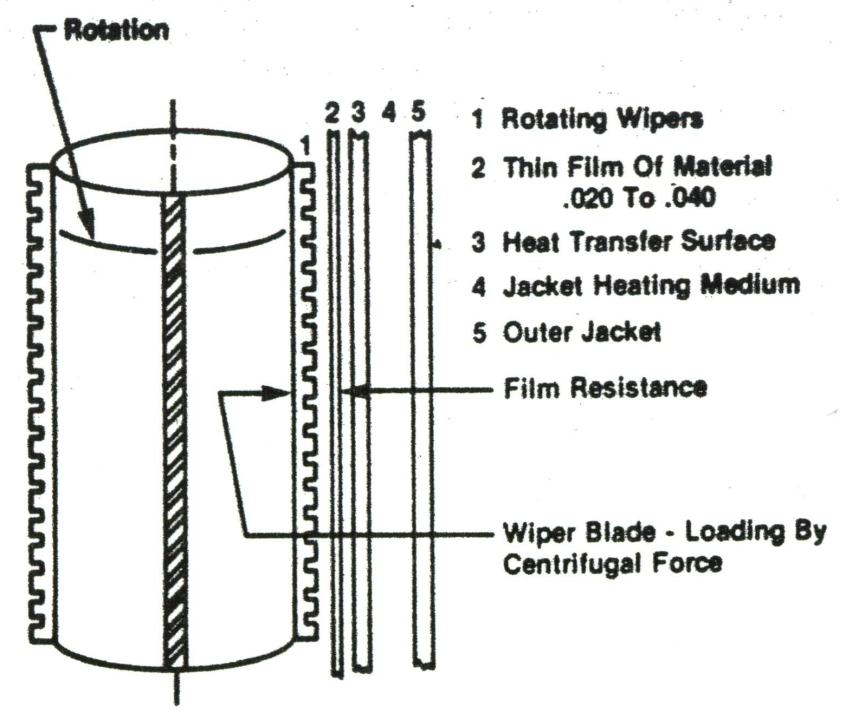

Figure 9 WFE Blades 
As material enters a WFE, the material is wiped along the heated walls of the evaporator. The configuration of a WFE causes the material to spiral its way to the exit ports of the heated section. This flow is facilitated by the grooved channels in the wiper blades.

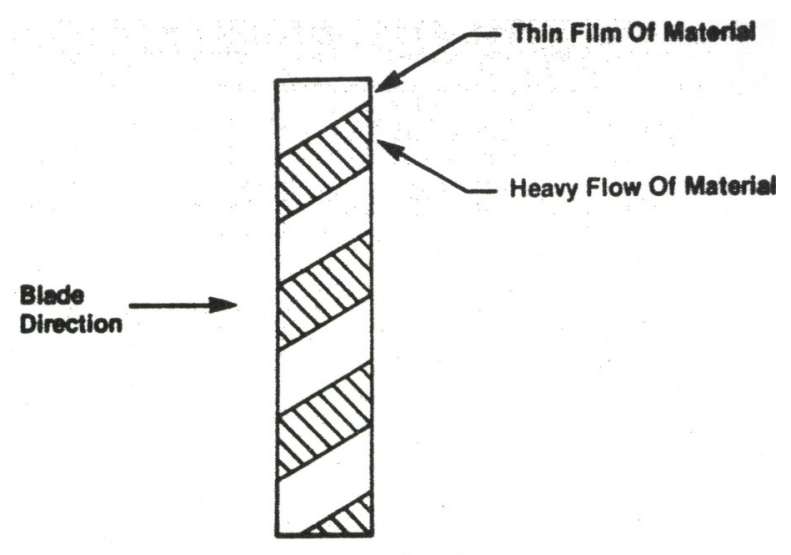

Figure 10 WFE Blades Close up view

One of the outlet ports is for vapor fraction; the other is for the liquid fraction. As the material is wiped by the wiper blades, a turbulent region in the material follows the blades as they turn. The turbulent region facilitates the best heat transfer possible, which is the mechanism responsible for the short residence time required for separation in the apparatus. The difference between the wiping system in the pilot plant WFE and the bench top system can be better understood by comparing the bench top design. Figure 11 below shows the basic bench top system. (5) The method of heating the cylinder walls is different. The bench top heating unit involves electrical resistance tape heaters. The pilot plant used an independent oil heating unit. There is a wider range of heating using the electrical resistance tapes while there is an upper boundary to the oil heater. 
Below is a diagram of the bench top WFE unit used in this research.

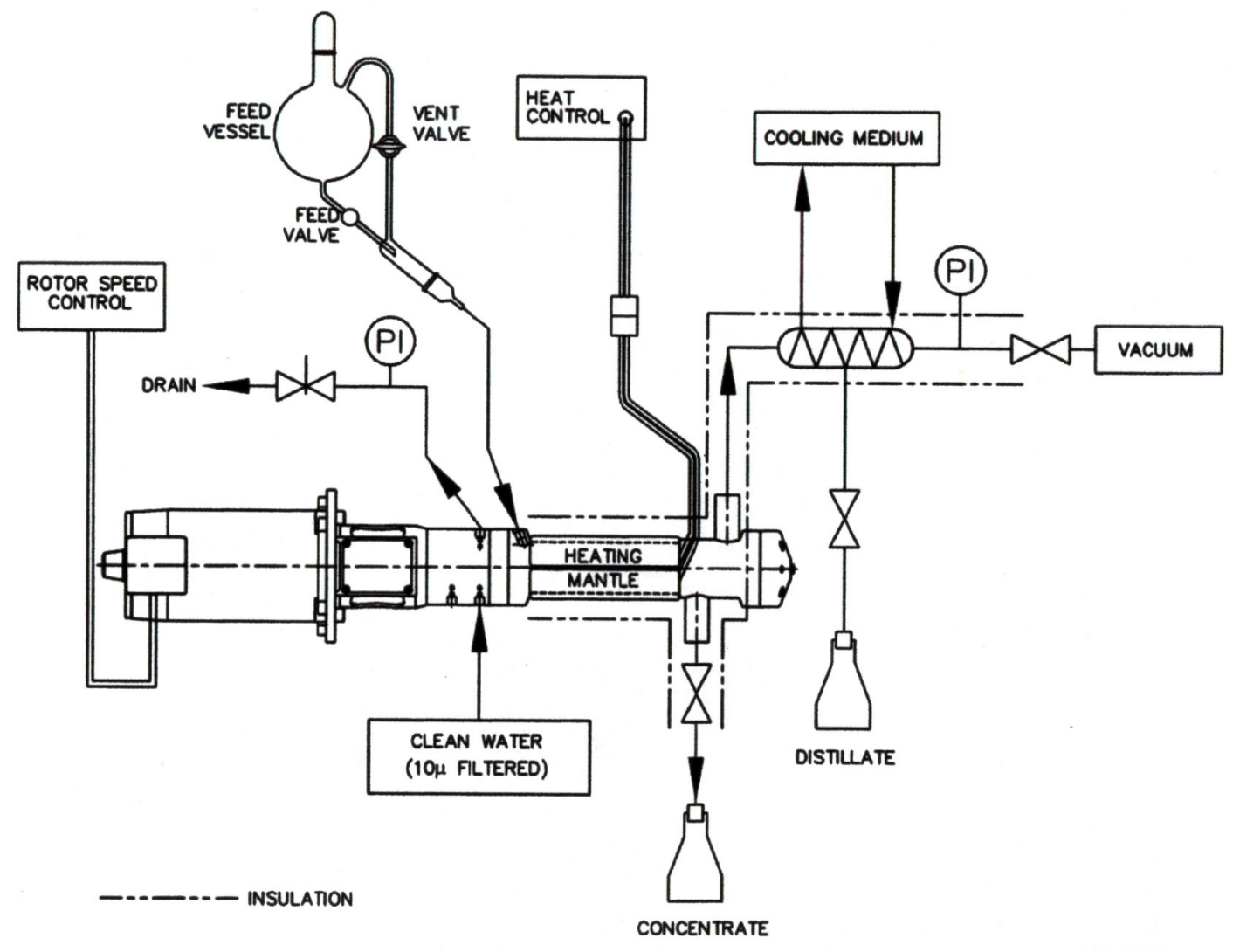

Figure 11 Flow diagram for bench top unit

The labels distillate and concentrate are the light (low boiler) and the heavy (high boiler) holding vessels respectively. The clean water is to cool the mechanical seal around the shaft of the wiper blades. The P1 is to indicate that the water is to be under pressure. The recommended pressure is $15 \mathrm{psi}$, or 1 atm of pressure difference between the water and the internal cavity of the WFE. The seal side must be kept at a higher pressure to keep the seal seated against the shaft.

The WFE has a rotor speed controller and a heating mantle with a controller. 
Below is a picture of the wiper blades from this WFE.

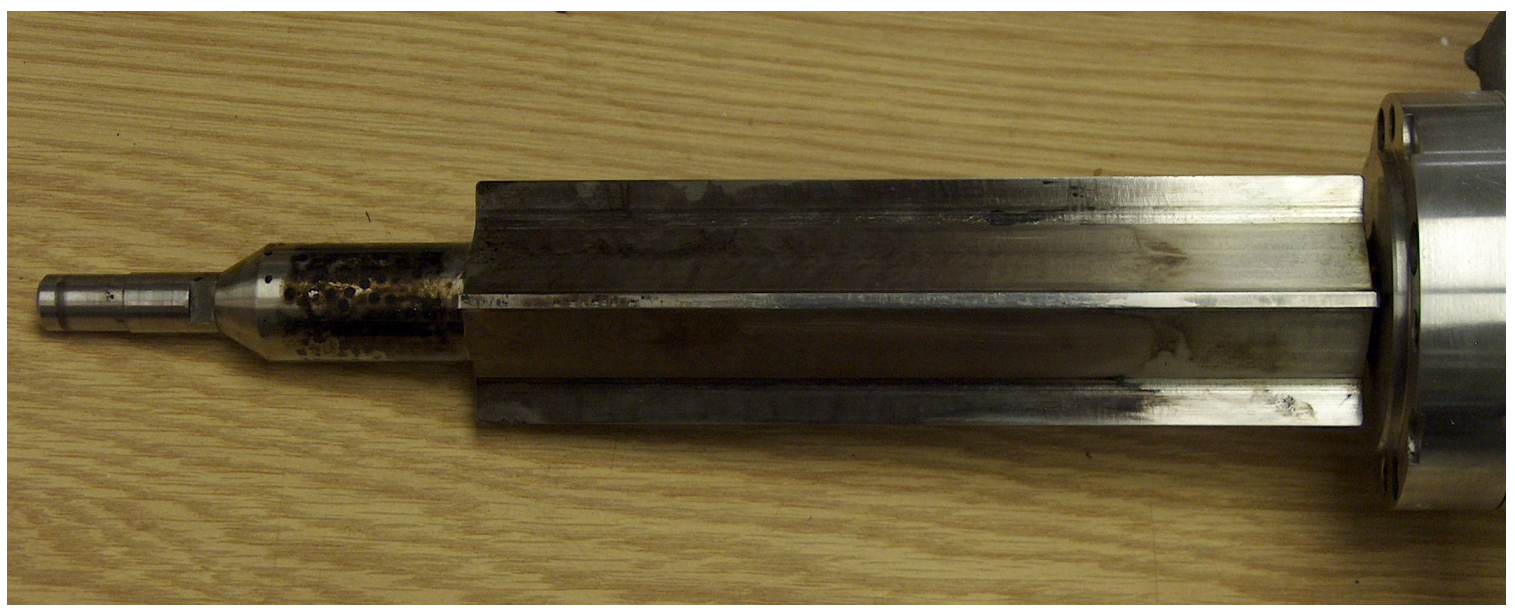

Figure 12 Bench top WFE Blades

It can be seen from Figure 4 that the blades of the bench top model are a different geometry than those from Figure 1, which shows the pilot scale model. In the pilot scale model the thickness of the thin film can be adjusted by altering the set depth of the wipers. This is nearly impossible in the bench top model.

The usual thickness of the material along the walls of the WFE ranges from 0.020-0.040', This thickness can be adjusted on certain models of WFE, but in this case the wiper blades are fixed, so the film thickness cannot be easily adjusted. The only way that the film thickness could be adjusted would be to machine down either the wiper blades, or the inside wall of the WFE. While in theory, this could be done, it is not appropriate here. The parameter that controls the condition is the speed of rotation. The faster the rotation the more turbulent the flow. The more turbulent the flow, the more 
effective the heat transfer, and therefore more effective the evaporation and the separation. The effect of the speed of rotation will be a very important parameter in the research.

\subsection{Variables for Performance of the WFE}

According to Arlidge (13), there are four main process variables that regulate the operation of a WFE. They are 1. feed temperature, 2. feed rate, 3. jacket temperature and 4. vacuum level. Each of these parameters can be varied independently in the design.

\subsubsection{Feed Temperature}

The feed temperature will be controlled by the heat ropes (electrical resistance tapes) on the reactor. A total of four ropes were used, at 500 watts a piece. These heat ropes were connected two to a circuit. Figure 5 illustrates the wiring diagram of the heat rope circuit. 


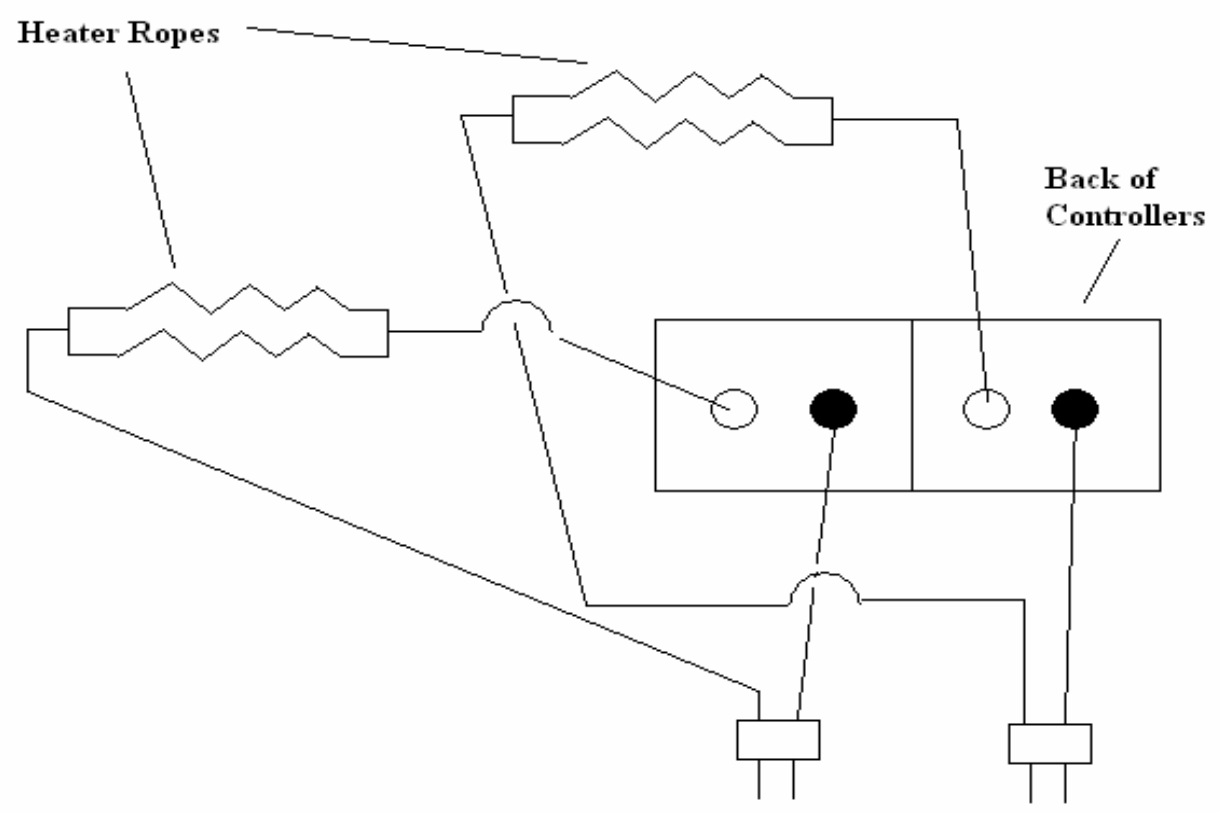

Figure 13 Stirred Vessel wiring diagram

\subsubsection{Feed Rate}

In the original design, it was felt that the feed rate could be controlled by a gate valve system. It was felt that while the gate valve will not provide rigorous control over the flow, the inclusion of quarter inch tubing plumbed in to reduce the flow before entering the WFE should provide adequate control.

\subsubsection{Wiper Speed}

The speed of the wiper blades will be controlled by the controller supplied with the WFE. According to the literature that accompanied the controller, the motor speed is 
linearly related to the potentiometer reading, i.e. $10 \%$ of the motor speed corresponds to a dial setting of $10 \%$.

\subsubsection{Jacket Temperature}

The jacket temperature was easily monitored and controlled. The heater had a built in thermocouple and a digital controller to set the temperature. This system provided a simple means to monitor the temperature.

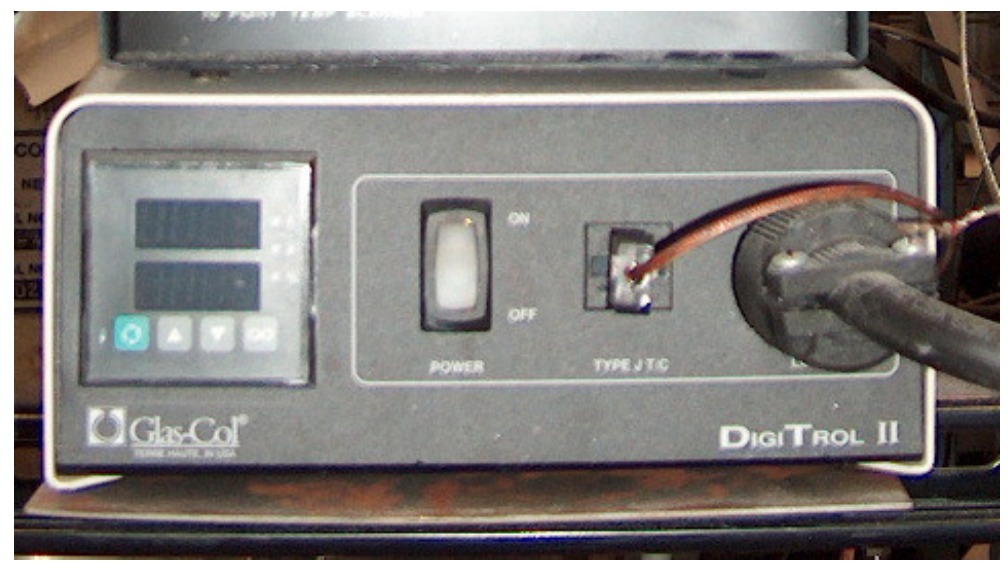

Figure 14 WFE Temperature controller

Figure 14 is a picture of the jacket temperature controller. On the left of the unit is the temperature reading and set point display screens. The on/off switch is in the middle, and the power input is on the far right. The thermocouple that reads the temperature of the jacket is connected via the brown wire on the right of the unit.

\subsubsection{Vacuum Level}

The pressure level in the system will be controlled by a vacuum regulating valve purchased from McMaster Carr. The valve has a threaded adjustment that can be set to 
the desired vacuum level. Figure 15 illustrates the vacuum control system. The vacuum level will be monitored by a pressure/vacuum gauge installed in the vacuum line between the regulating valve and the heat exchanger.

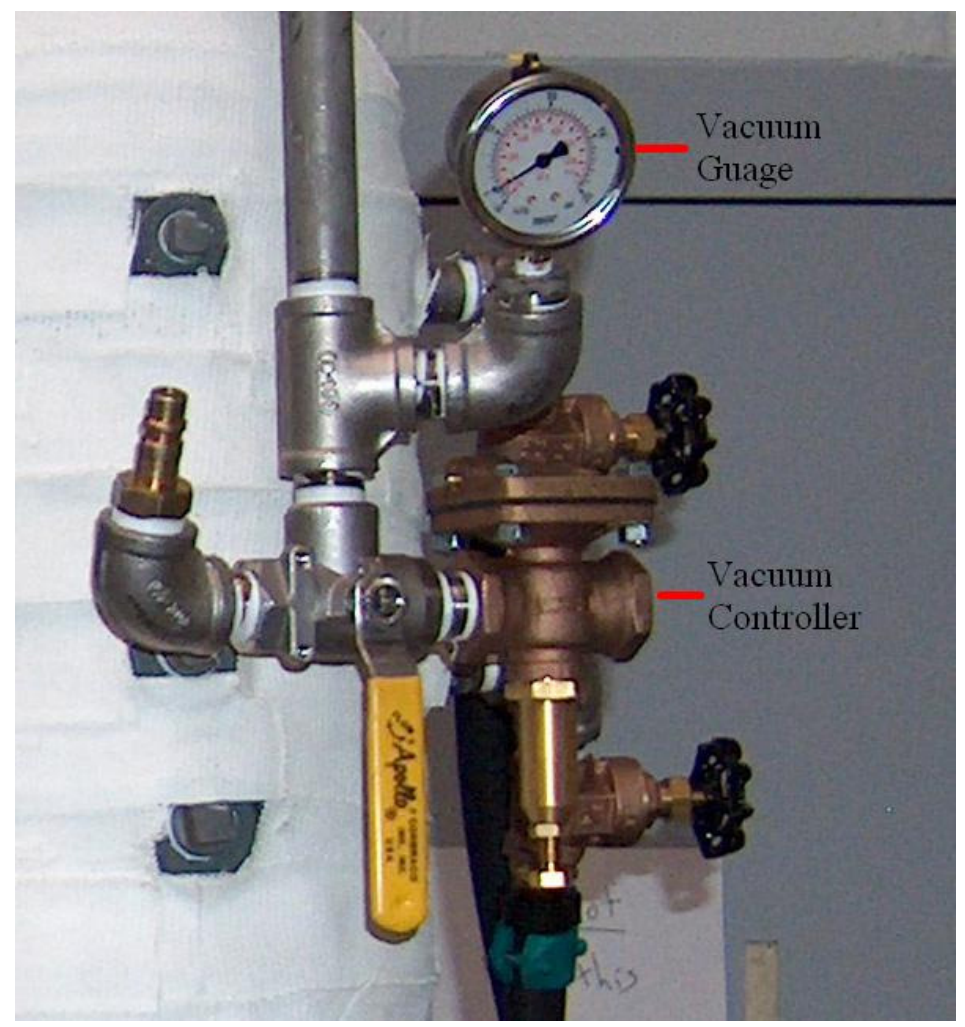

Figure 15 Vacuum Regulating System

The vacuum pump reducing pressure to the system is a Welch Allen vacuum pump.

\subsection{Holding Vessels}

The input holding tank for the WFE stand is based on a 4.6 gallon carbon steel pressure tank. The holding tank needed to be designed so it was capable of being both stirred and heated. In addition it had to have an input port installed so it could be filled 
with the blended materials. There was already an exit port on the tank when purchased. These adaptations had to be leak tight to prevent escape of volatiles from the unit during operation.

A small stirrer was purchased from McMaster Carr. The challenge was to design a system that incorporated the stirrer that has a seal around the shaft to prevent vapors from leaking out of the system. The tank is mounted vertically so it could be fitted with a stirrer. In order for the stirrer to be attached, an opening had to be made in the tank and a three inch fully threaded nipple welded into place. The nipple was used as the template for the hole and was traced around with a soapstone pen. A plasma torch was used to cut an opening into the tank. The nipple was welded into place with a TIG welder. Once this was done, a pipe cap was modified so that the stirring rod could be placed through it. A $3 / 8^{\prime \prime}$ hole was drilled into the cap and then countersunk with a $1 / 2$ ", drill bit. Into the countersink a spring graphite shaft seal was placed. This seal would close against the shaft when tightened and prevent vapors from escaping from the holding tank. The stirrer used was an Arrow Engineering model 850, and has an operating range from 0-1000 rpm, 1/10 horsepower motor and provided a constant torque of $117.6 \mathrm{in}-\mathrm{oz}$ or $7.35 \mathrm{ft}-1 \mathrm{bs}$ to the stirrer.

In order to complete the construction of the holding tank an extra port was needed so that the test material could be transferred into the holding tank. A second three inch pipe nipple was attached to the tank in the same manner about a forty-five degree angle to the stirrer. This would allow the material to be poured into the tank from a separate vessel and also allow the fluid level in the holding tank to be visually monitored. The holding tank would only be opened to check the fluid level after it was certain that the 
holding tank was indeed empty of material. Below is a picture of the stirrer assembly on the holding tank.

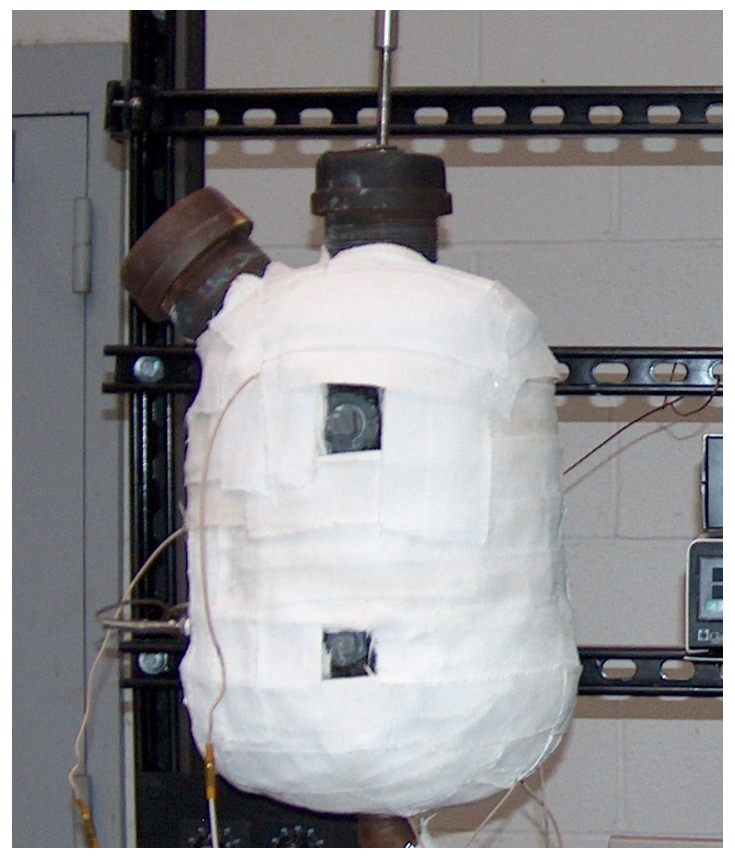

Figure 16 Stirred Vessel

\subsubsection{Containment Vessels for Products}

The light and heavy fractions would also be collected in separate 4.6 gallon tanks. Figure 17 shows the 4.6 gallon tank used as the heavy fraction holding tank before insulation or heaters were installed. 


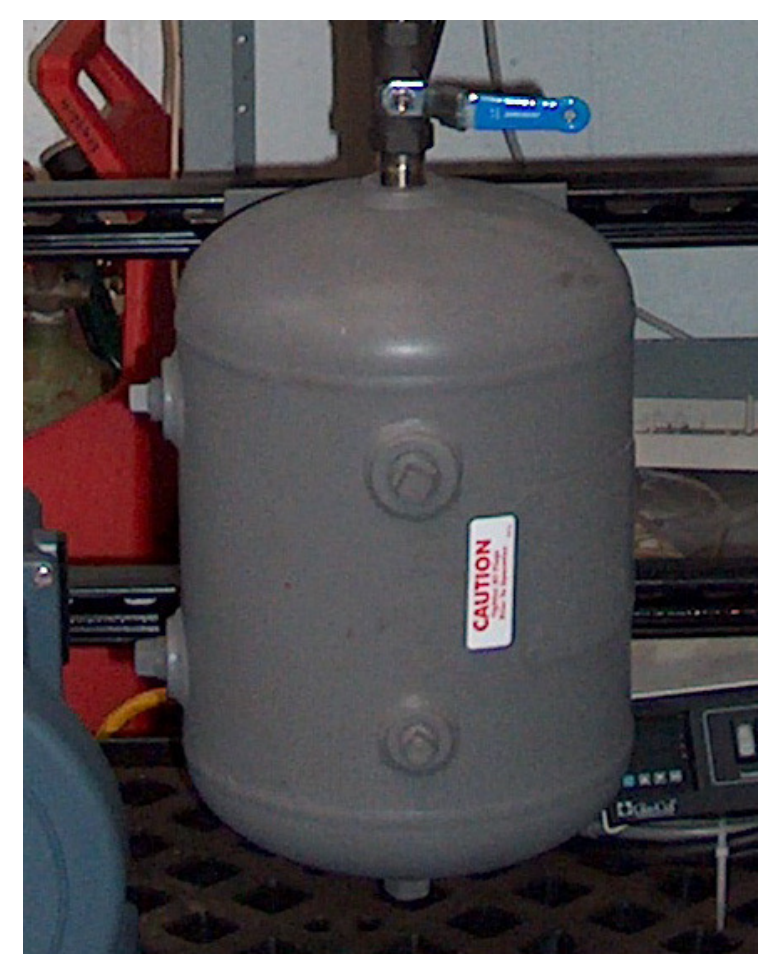

Figure 17 Heavy fraction tank

This was convenient because the bolt patterns of the tanks will all be the same. The tanks will be attached to the cross members of the stand, and since the bolt patterns of the tanks were the same, more than one tank can be mounted on the same cross members instead of adding more cross members. This will save time and material costs. This simplified the assembly of the stand.

\subsection{Insulation of System}

All of the tanks will be insulated. The insulation served two purposes. The first purpose is a safety precaution. The heating mantle of the WFE will be kept at temperatures above $200{ }^{\circ} \mathrm{C}$, which could cause severe burns to the operator on contact. The light fraction tank would be kept warm, approximately $50^{\circ} \mathrm{C}$, to make it easy to drain 
the tank when necessary. The heavy fraction tank will be kept approximately $120^{\circ} \mathrm{C}$ to keep the pitch in a liquid state. The goal of this separation process is to produce a material with a softening point of $110^{\circ} \mathrm{C}$, so the tank will need to be kept at a higher temperature so the pitch will flow out of the tank. The second reason for the insulation was to reduce the rate at which heat was lost from the system.

The plumbing lines running from the reactor into and out from the WFE and to the fraction tanks will also be heated and insulated. These lines are heated to prevent any of the liquid or vapor from condensing and causing a plug. The fittings at the bottom of the tanks were also heated with short sections of silicon heat tape. This was also necessary to prevent solidification and plugs from forming.

\subsection{Heat Exchanger Design and Construction}

On of the components for the WFE system that needed to be designed for this application was the heat exchanger unit. The design of this unit involved several important decisions based on the operating parameters of the unit.

The first decision to be made was the type of heat exchanger to be used. There are many different styles of heat exchangers as seen in the following illustration. 


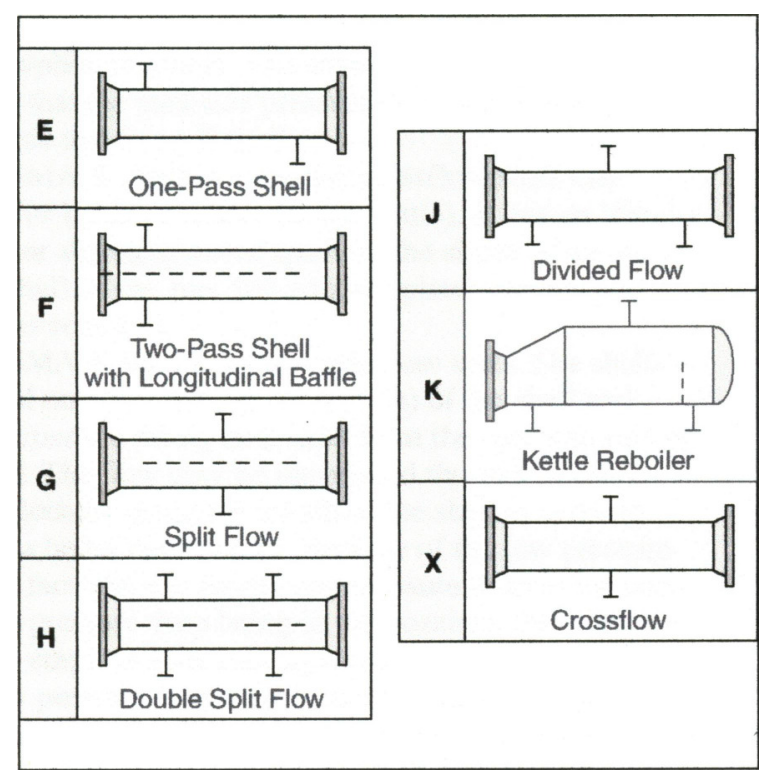

Figure 18 (9) Types of heat exchangers

Each of the types listed above has advantages and disadvantages, and each has specific situations that favor them. For example the E shell is the most common type used in the processing industry (9). A common procedure to increase the efficiency is to combine two E shell heat exchangers in series. This arrangement has several advantages over an F shell. This provides a higher shell side velocity, which leads to a higher heat transfer coefficient (9). This can be an option when space and money are an issue, since this arrangement is smaller and is cheaper to construct (9). This design is also less expensive to operate due to the reduction in fouling (9).

Fouling is a common problem with heat exchangers. Fouling refers to the buildup of material, or sediment on the tubes of the heat exchanger. This buildup reduces the heat transfer coefficient and decreases the efficiency of the exchanger. Fouling is only one of the factors needed to be considered when designing and constructing a heat exchanger. The following is a list of other's feelings needed for proper design or selection of the proper heat exchanger (10) 
-Fluid velocity

-Fouling

-Pressures and temperatures

-Differential thermal expansion between shell and tube

-Susceptibility to vibration

-Piping loads

-Toxic or lethal fluids

-Size and weight for handling

-Space limitations for installation

-Utility and maintenance

-Initial cost vs. operating costs

-Anticipated service life

-Material choice to satisfy environment

Several of these criteria are not applicable for this work, but others are of great importance. For example, the 'size and weight for handling' parameter is one of the more important parameters that needs to be considered. The stand has to be able to fit through a standard sized doorway (with all of the components). This limits the size of the heat exchanger, so it needs to be as compact as possible. In contrast there will be virtually no vibration in the system, so this criterion does not need consideration. 
Thermal expansion, corrosion resistance and cost are factors that need consideration. The heat exchanger will be cooled by tap water at $12.8^{\circ} \mathrm{C}$ and the vapor that will be approximately $225^{\circ} \mathrm{C}$, so thermal expansion could potentially be an issue. To minimize the risk of failure due to thermal expansion, the material exposed to the greatest thermal expansion will be uniform. This is resolved since the only material used for the tubes and the plates in the exchanger will be 316 stainless steel. This material was chosen for it's resistance to corrosion. Due to the expense of a stainless steel shell, the shell material will be plain carbon steel.

The material the heat exchanger will be handling is hazardous, both by inhalation and skin irritant. Therefore the heat exchanger will need to be completely sealed both inside and out. It is imperative that the material does not get into the coolant stream since the coolant stream is not a contained system. The coolant, i.e. water, will be fed from the tap into the exchanger and then sent down the drain. (This was done because this was the easiest solution for a coolant.) Adding a refrigeration unit would have increased the complexity of the system as well as the cost.

The first step of the design process is to determine the type of shell for the heat exchanger. The Tubular Exchanger Manufactures Association Inc, TEMA, lists seven types of shells, E, F, G, H, J, K, and X (9). However, Poddar and Polley (11), list five standard shells, E-J. Poddar and Polley (11), have three suggestions when choosing the shell type. Their suggestion is to initially pick an E shell. If multiple passes are needed then switch to an F shell. It would be possible to stack two or more E shells in series, but the F shell would eliminate the need for multiple shells. If problems still exist with shell side pressure drop, move on to a $\mathrm{J}$ and on to a $\mathrm{G}$ shell. If problems still 
exist use a G shell. Since the heat exchanger would be built in house, keeping the design simple was another important consideration.

Following Poddar and Polley's suggestion, an E shell was selected as the initial shell type. Since the heat exchanger would condense a vapor, a single pass exchanger would be the best, since it is difficult to pump a vapor to re-circulate it for multiple passes.

Starting from the initial shell type as E, the next step would be to decide on the size of the tubing in the heat exchanger. Poddar et. al. (11), offer the following suggestions for selecting a tube size. They recommend starting with a small tube size, and to increase the tube size if problems occur meeting the pressure drop constraints. The starting size they recommend is $0.75^{\prime}$ '. The following points need to be considered when selecting tube size.

- Exchanger volume per unit surface area increases as tube diameter increases

- The film heat-transfer coefficient decreases with increasing tube size

- The sum of the overall heat-transfer coefficient and surface area decreases as diameter increases

- The tube side pressure drop decreases as tube diameter increases

Since this heat exchanger was going to be compact because of the size limitation, there was some concern that the vapor would not have enough residence time in the heat exchanger to be condensed with a large diameter tube. Therefore the $0.75^{\prime}$, recommendation was ignored. Instead, the tube diameter was set at 0.5 ', with a wall 
thickness of $0.0425^{\prime}$. This was the thinnest wall thickness available. The thinner wall allowed a larger surface area for heat transfer and provided the best heat transfer through the walls of the tube. The limiting factor on the length of the tubes was the shell of the exchanger.

The shell of the heat exchanger was made from a 4.6 gallon carbon steel pressure tank purchased from McMaster Carr. This completed the assembly of the stand because the stirred reactor and the fraction storage tanks are also be 4.6 gallon tanks. The first step in the assembly of the heat exchanger was to cut both beveled ends from the 4.6 gallon tank. The middle section of the tank measured 9'" in length and is to be the shell of the heat exchanger. This is used to determine the length and the number of the tubes inside the exchanger.

The arrangement of the tubes within the heat exchanger was based on the available surface area. It was determined by heat balance calculations that this area was more than adequate for this system (the energy balance will be described later in this thesis). The tubes will be arranged out in a square pattern of sixty tubes. This arrangement gives a total surface area of 703.674 square inches, or 4.88 square feet. The picture below shows the top plate of the heat exchanger with the tube arrangement before the assembly. Each tube was welded in place and the system was leak tested. 


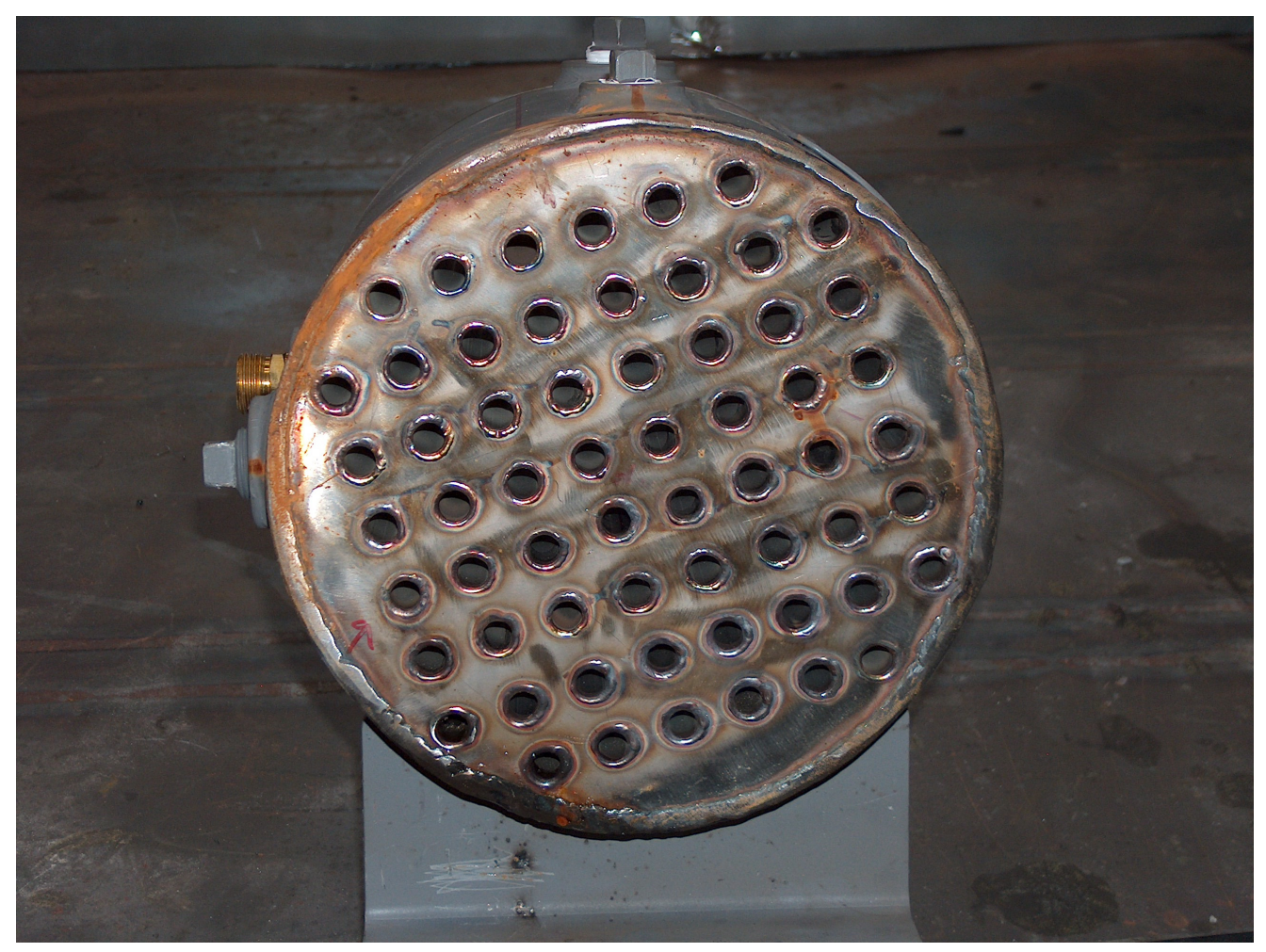

Figure 19 Internal view of heat exchanger

To finalize the assembly, the top bevel and bottom bevel back were welded on.

However, before the bottom bevel was welded back on, the design was altered slightly.

Instead of connecting the heat exchanger to the light fraction tank with a pipe nipple, it was decided to attach the heat exchanger directly to the light fraction tank. This reduced the potential for the material to condense in the nipple and block the flow of vapor, (and also adversely affect the vacuum) and preventing the heat exchanger from functioning properly. This was done by cutting the top bevel off of the light fraction collection tank with a plasma torch and welding the heat exchanger directly to the light fraction tank. With this design change, the system now mimics the larger WFE installed in the pilot plant. The vertical WFE in the pilot plant has a heat exchanger built into the system.

The energy balance over the exchanger was evaluated by the following equation. 


$$
\left(\dot{m} c_{p}\right)_{h}\left(T_{H, \text { in }}-T_{H, \text { out }}\right)=\dot{m}_{c} h_{f g c}
$$

\section{Equation 1}

This equation can be used to determine the maximum heat transfer possible and a given situation (12). This equation can be used to determine the maximum mass flow rate of the material that will be condensed. The inlet and outlet temperatures of the cooling fluid need to be known before this equation can be used. Thermocouples were installed to monitor the temperatures of the inlet and outlet ports of the heat exchanger. Once these temperatures were known, the specific heat of the cooling liquid, water, and the specific of the coal liquid could be obtained from standard tables. The mass flow rate of the water through the exchanger could be estimated by determining the flow rate from the source of the water.

Even with a properly designed heat exchanger, it was desired that a back up to this component be installed in the system to prevent any volatile material from contaminating the vacuum pump system. A dry ice cold trap was purchased to be installed in the vacuum line between the vacuum pump and the heat exchanger to eliminate that possibility. The inlet and outlet ports on the cold trap were designed for tubing of smaller size than what was to be used as the vacuum line. To correct this shortcoming, two NPT fittings were welded unto the inlet and outlet ports to allow barbed fittings of the correct size to be attached to the tubing in use in the system. 


\subsection{Power Requirements}

The next factor to be considered was the power requirements for the heater bands, the vacuum pump, the reactor stirrer and the thermo-couple readers. To determine the heater size for the reactor, the heat mass of the heavy oil needed to be determined.

\section{$2.5 \mathrm{~kJ}$ per kg per deg $\mathrm{C}$}

Density $1.2 \mathrm{~g} / \mathrm{cc}$

18 L of heavy oil

$$
200^{\circ} \mathrm{C} * 2.5 \mathrm{~kJ} * 18 \mathrm{~L} * 1.2 \mathrm{~g} / \mathrm{cc}=10,800 \mathrm{~kJ}
$$

This is the minimum power requirements for the system. In was necessary to balance the power available in the mezzanine against a reasonable heat up time, which will determine the amount of power required. The desired heat up time for the stirred vessel should be less than two hours, therefore, the reactor heaters totaled 2000 watts, four 500 watt heat ropes connected in pairs. This gives an ideal heating time of $5400 \mathrm{sec}$., or 90 minutes.

This time does not reflect the energy required to heat the reactor or the heat conductive putty that coated the reactor. The reactor and the heaters were coated with the heat conductive putty in an attempt to have a uniform temperature profile across the reactor. While the putty added to the thermal mass that needed to be heated, its thermal conductivity is better than steel, so the reactor should "see" one heater instead of numerous hotspots from the contact patches of the rope heaters.

The total power requirement for the system is as follows; 


$\begin{array}{ll}\text { WFE motor } & 3.2 \mathrm{~A} \\ \text { WFE heater } & 6.25 \mathrm{~A} \\ \text { Rope heaters } & 4.17 \mathrm{~A}(\mathrm{x} 4) \\ \text { 1', Heat tape } 10 \mathrm{ft} & 6 \mathrm{~A}(\mathrm{x} \mathrm{3}) \\ \text { 1" Heat tape 2 } \mathrm{ft} & 0.6 \mathrm{~A}(\mathrm{x} 4) \\ \text { Stirrer } & 2 \mathrm{~A} \\ \text { Vacuum pump } & 8.6 \mathrm{~A}\end{array}$

The numbers to the parentheses indicate the circuits that each component is on. The total amperage requirement is $57.13 \mathrm{~A}$. There were three outlets available, numbering two twenty amp and one thirty amp breaker. There was enough power available; the limiting factor was outlet availability.

The limited number of outlets was overcome by wiring four outlet junction boxes on the end of a ten gauge extension cord. On the mezzanine there are the twenty and thirty amp outlets but these require locking plugs. These outlets were located on the bus bar in the mezzanine of the high bay of the NRCCE building. Any alterations to the bar needed to be done by a certified electrician and were therefore to be avoided if at all possible. Using the junction boxes on the extension cords permitted the use of the existing outlets.

The heater ropes for the stirred vessel were wired together, two in a circuit, in parallel so that the voltage requirements of the heaters would be met. By connecting the heaters in parallel, each of the heater ropes in the circuit would receive the same voltage 
across them from the power source, i.e. the outlet. Pictured below is the inside of the heater control box for the stirred vessel's heaters.

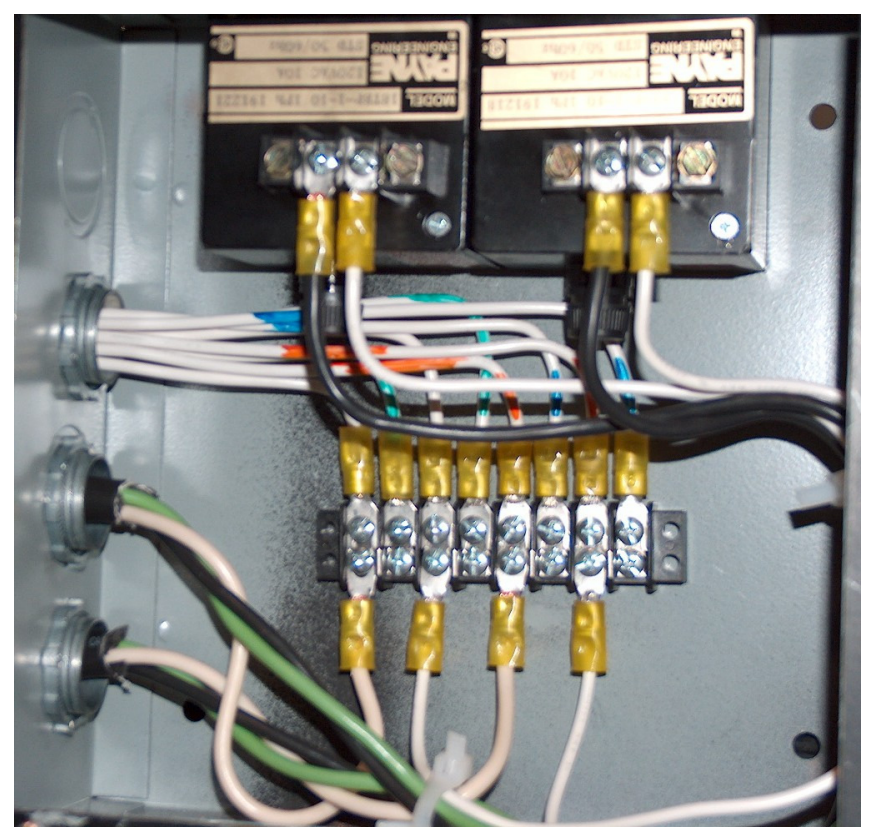

As can be seen from the color coded wires (orange, blue green and white), entering the top of the junction panel, the heaters were connected in pairs. The power lines enter the left of the box and are fed into the junction panel, where each live wire is jumped to the terminal next to it. This is the method by which the power is supplied to the heat ropes in parallel. The return from the heat ropes is similarly jumped so that there is a single wire (white) running to the controller, and then a single black wire returning to the outlet to complete the circuit.

The design and construction phase of the research (based on the original design) is now complete. The next section, Experimental, begins with the calibration of the system components, re-design, and system alterations. Below are two pictures showing the system ready for calibration and system shakedown. 


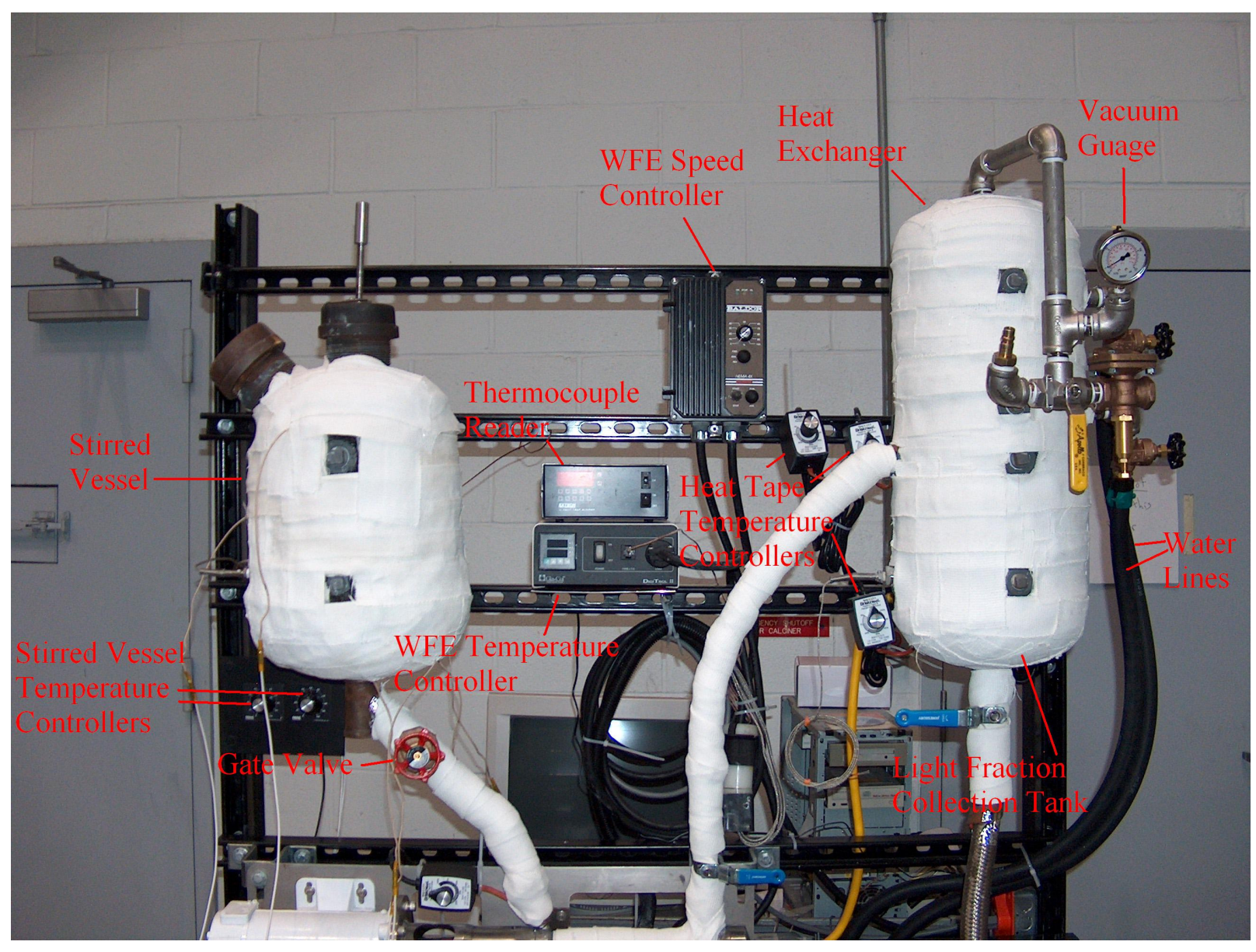

Figure 20 WFE System components

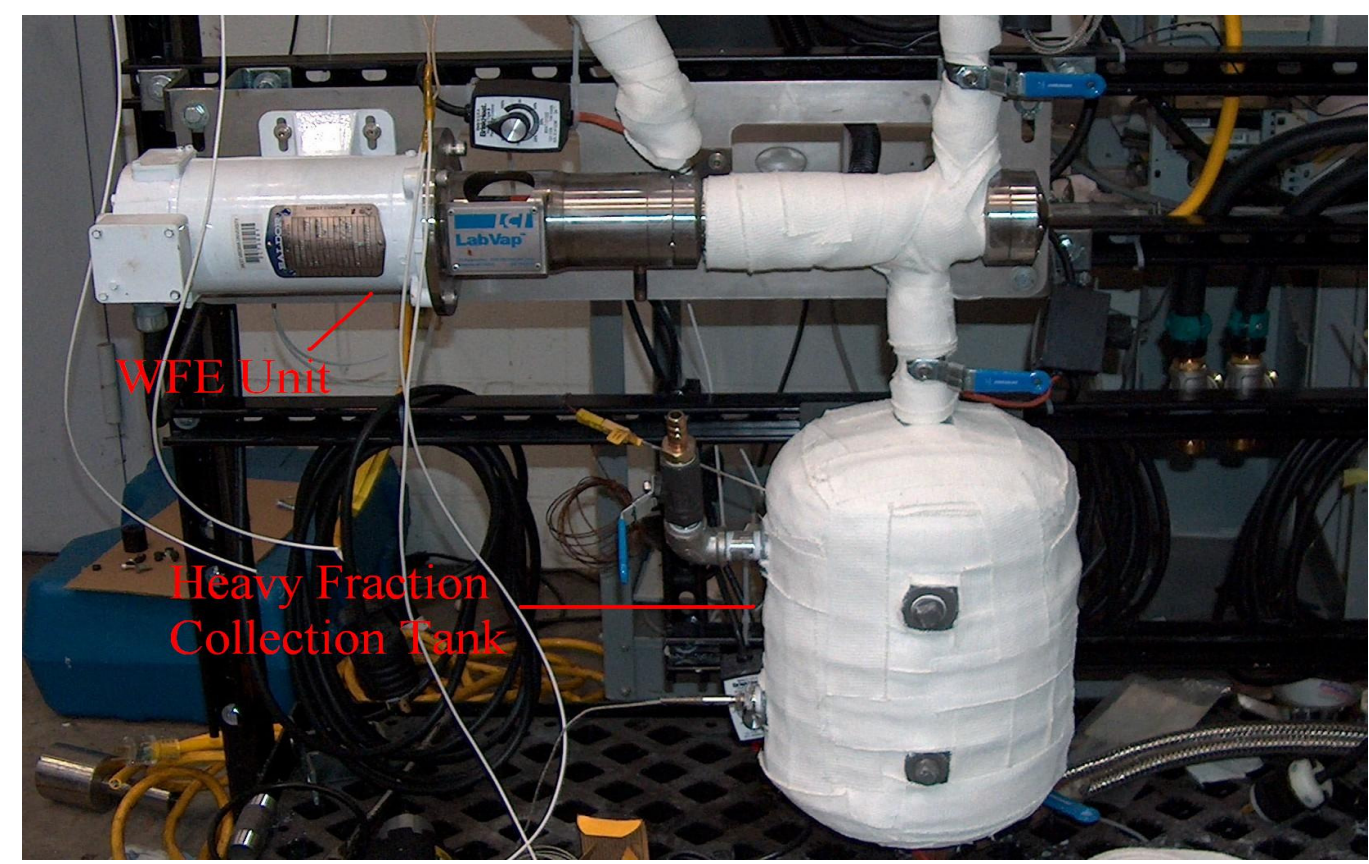

Figure 21 WFE System components 


\section{Experimental}

\subsection{Initial Calibration Tests}

\subsubsection{WFE Wiper Speed}

When the WFE unit was first turned on, the potentiometer needed to be turned to almost $20 \%$ before the motor began to turn the wiper blades of the WFE unit. The literature provided with the unit stated that the wiper speed was linearly related to the potentiometer reading with a zero intercept. The unit needed to be recalibrated so that the correct linear relationship was restored.

The calibration was done by using a photo tachometer made by VWR. This device operates by emitting a light beam and a photo counter counts the frequency at which the beams are reflected. The LCD display produces the results in RPM. The first step in the recalibration was to attach a piece of reflective tape to the coupler between the motor and the WFE. As soon as the reflective tape was applied, the test could commence. The potentiometer was started at zero and increased by $10 \%$ until the potentiometer was at the max setting. The following graph displays the results from two tachometer readings 


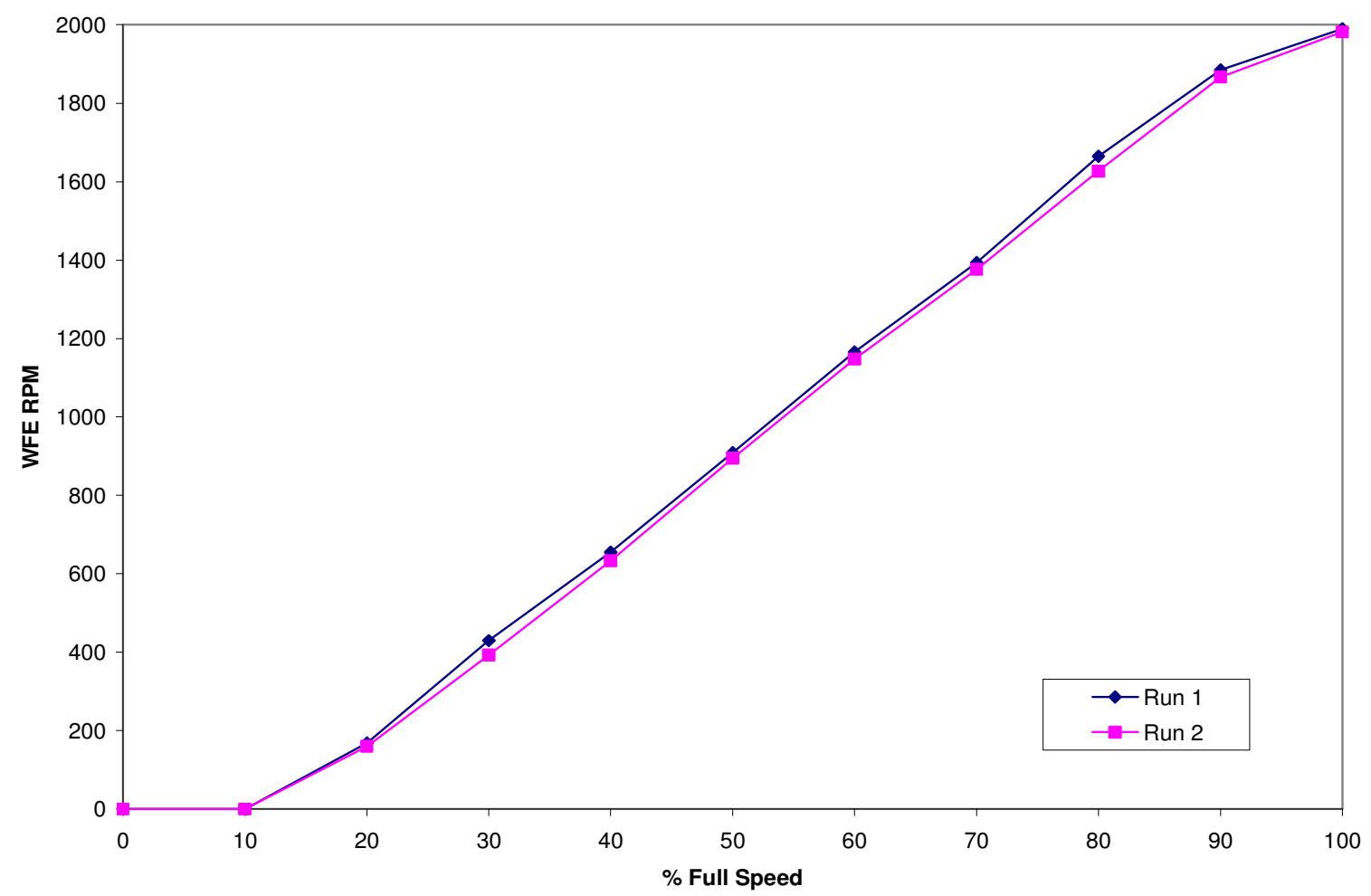

Figure 22 WFE RPM curve

As it can be seen from the graph, the curve can be considered linear, but does not have a zero intercept. The manual for the controller provided detailed information on how to adjust the zero set point for the controller. The following is the diagram of the inside panel of the controller. 


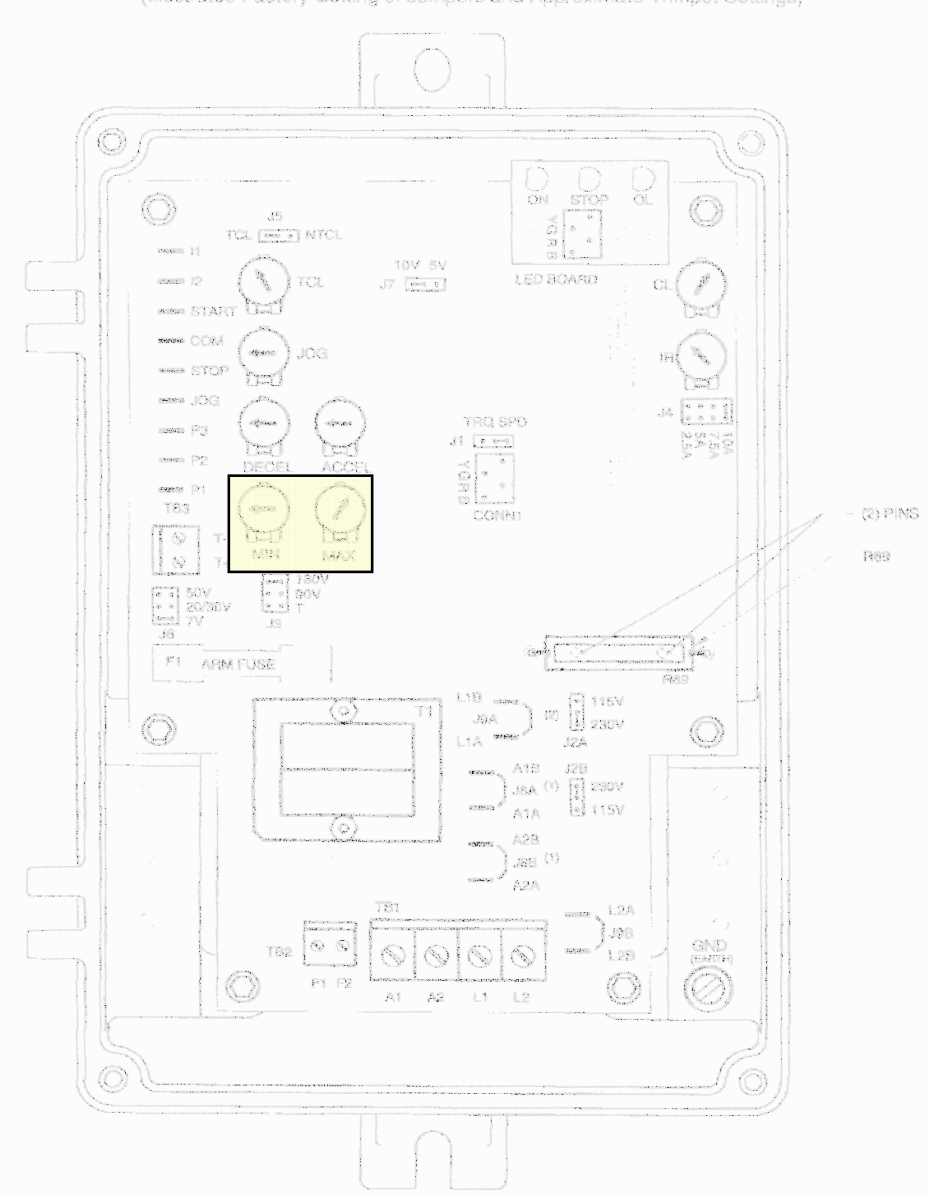

Figure 23 WFE controller, inside view

It is not clear from the illustration, but there are two adjustments that can be made to the speed of the WFE blades. The adjustments can be made with the following two dials.
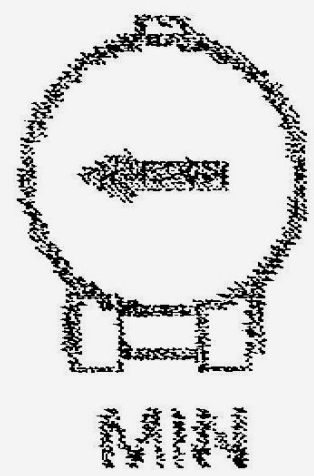

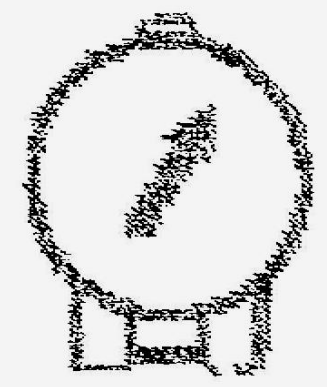

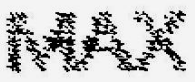

Figure 24 WFE speed adjustment dials 
The illustration is an enlarged section of Figure 6. These two dials adjust the minimum and maximum speed of the WFE motor. The maximum speed was acceptable, but the minimum speed needed to be increased. This was accomplished by turning the dial clockwise with a small screwdriver until the motor started to turn with the potentiometer reading zero. The dial was then backed off just until the motor stopped. The potentiometer was turned to $10 \%$ to verify that the motor would turn at that setting. The motor did indeed turn. After turning the potentiometer back to zero and the motor stopped turning, the adjustment was complete. The new calibration curve of the WFE motor speed is as follows. 


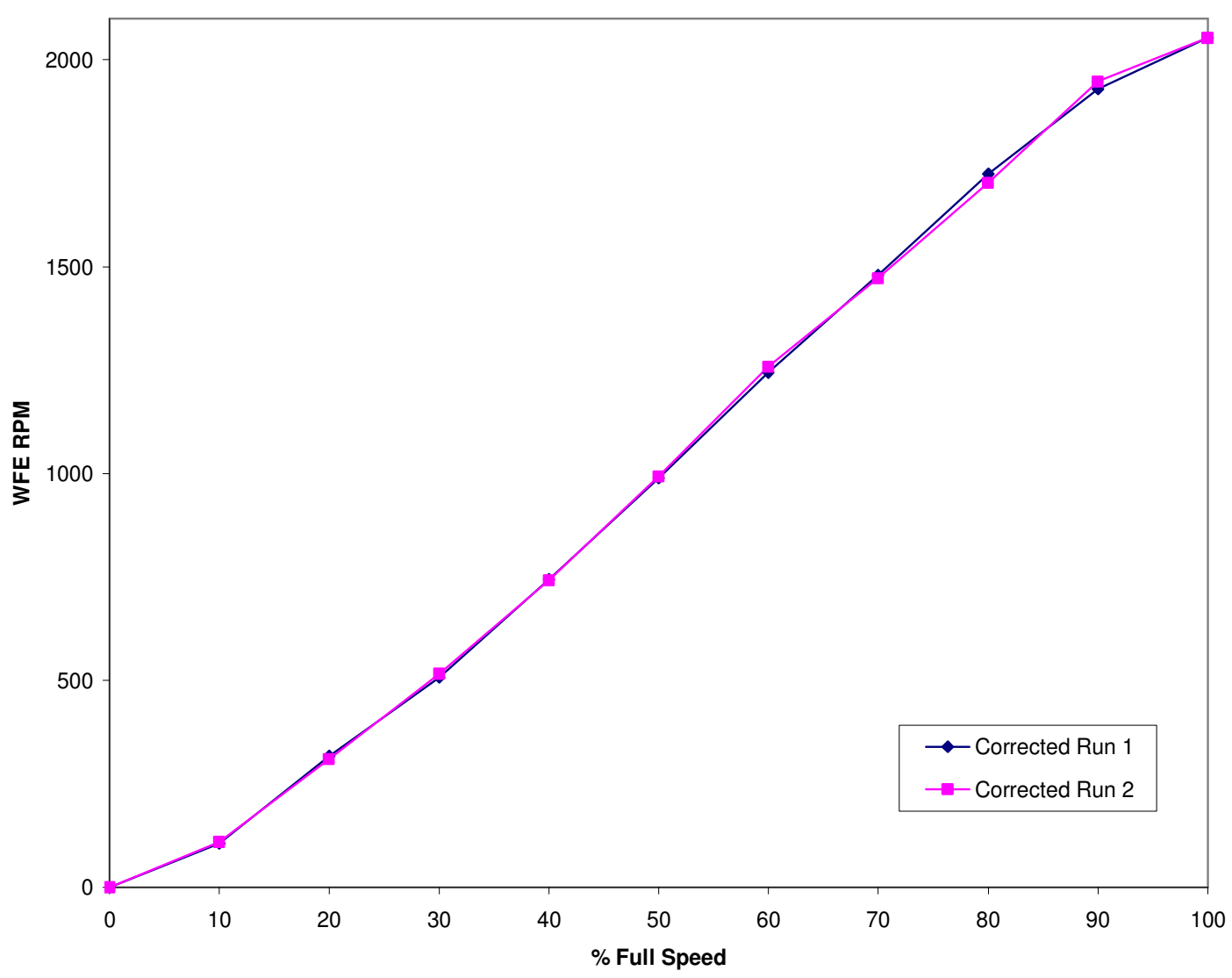

Figure 25 WFE RPM corrected curve

With these adjustments, the relationship between the motor speed and potentiometer reading is now almost linear. While the relationship is not completely linear, some error can be attributed to the dial on the potentiometer. The increment markings on the base of the controller are several times the width of the indicator on the dial. This makes it difficult to ensure that the potentiometer reading is on the indicated reading. However, the linearity of the graph was deemed close enough for the research. 


\subsubsection{Calibration of Temperature Control}

As previously mentioned the heating mantle on the WFE has a built in thermocouple to monitor the temperature of the mantle. The temperature the thermocouple reads is displayed on the controller for the heating mantle. This temperature was compared to the set point input by the user. This controller functions on a binary system, on or off. The input temperature of the thermocouple was compared to the set point on the controller. If the input temperature was less than the set point, the unit continued to supply power to the heating mantle. Once the input and set point temperatures matched, the mantle was deactivated. The only problem with this arrangement was that the heater would over shoot, sometimes twenty degrees or more. During the calibration of the heating mantle, the mantle became discolored and after several trials, ceased to function. It was hypothesized that the insulation on the heat tape caused this failure.

Two steps were taken to prevent the heating mantle from failing again. The first precaution was to leave the heating mantle un-insulated. While this would cause more heat to be lost the surroundings, the loss should not affect the system dramatically. The second precaution was to adjust the set point thirty degrees below the desired temperature and then increased incrementally until the desired temperature was reached. A replacement heater jacket was ordered from LCI, the manufacture of the WFE. However the replacement was six weeks back ordered. As a safe guard against extended downtime in the future, two heating jackets were ordered. 


\subsubsection{Calibration of Stirred Vessel Heaters}

The heaters on the stirred vessel, while rated for 500 watts each, needed to be calibrated. Unlike the motor speed controller on the WFE, the potentiometers for the heaters had no zero adjustment. In order to relate the potentiometer reading to a corresponding temperature, a calibration exercise was needed.

The calibration run was simply a matter of increasing the value of the potentiometer reading and allowing the system to hold at the reading for one hour. Holding the vessel for one hour allowed the system to come to equilibrium. The following graphs show the potentiometer reading versus the increase in voltage, and the potentiometer reading versus the temperature. 


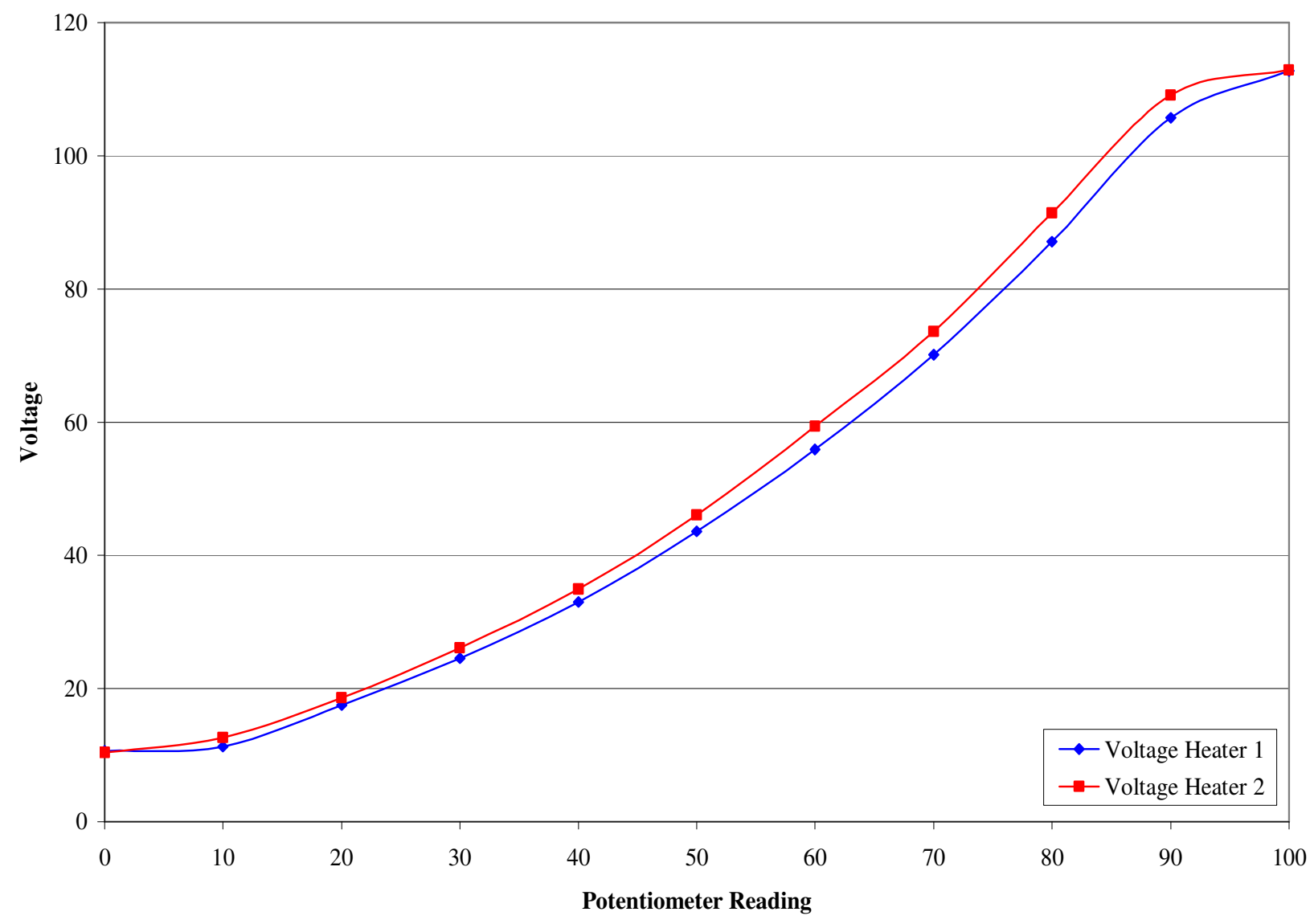

Figure 26 Stirred vessel heater voltage draw

Four heaters were used to heat the stirred vessel. The heaters were connected in parallel, in pairs so the red and blue lines correspond to each pair of heaters. There was a slight discrepancy between the two heaters. This was not unexpected due to the inherent inaccuracies of the control units. It can also been seen from the graph that even when the control units were set to zero, there was a small voltage being applied to the heaters. This was important because it shows that leaving the control dials set to zero will not mean that the heaters are off. The only way to insure the heaters are off was to turn them off at the breaker. 


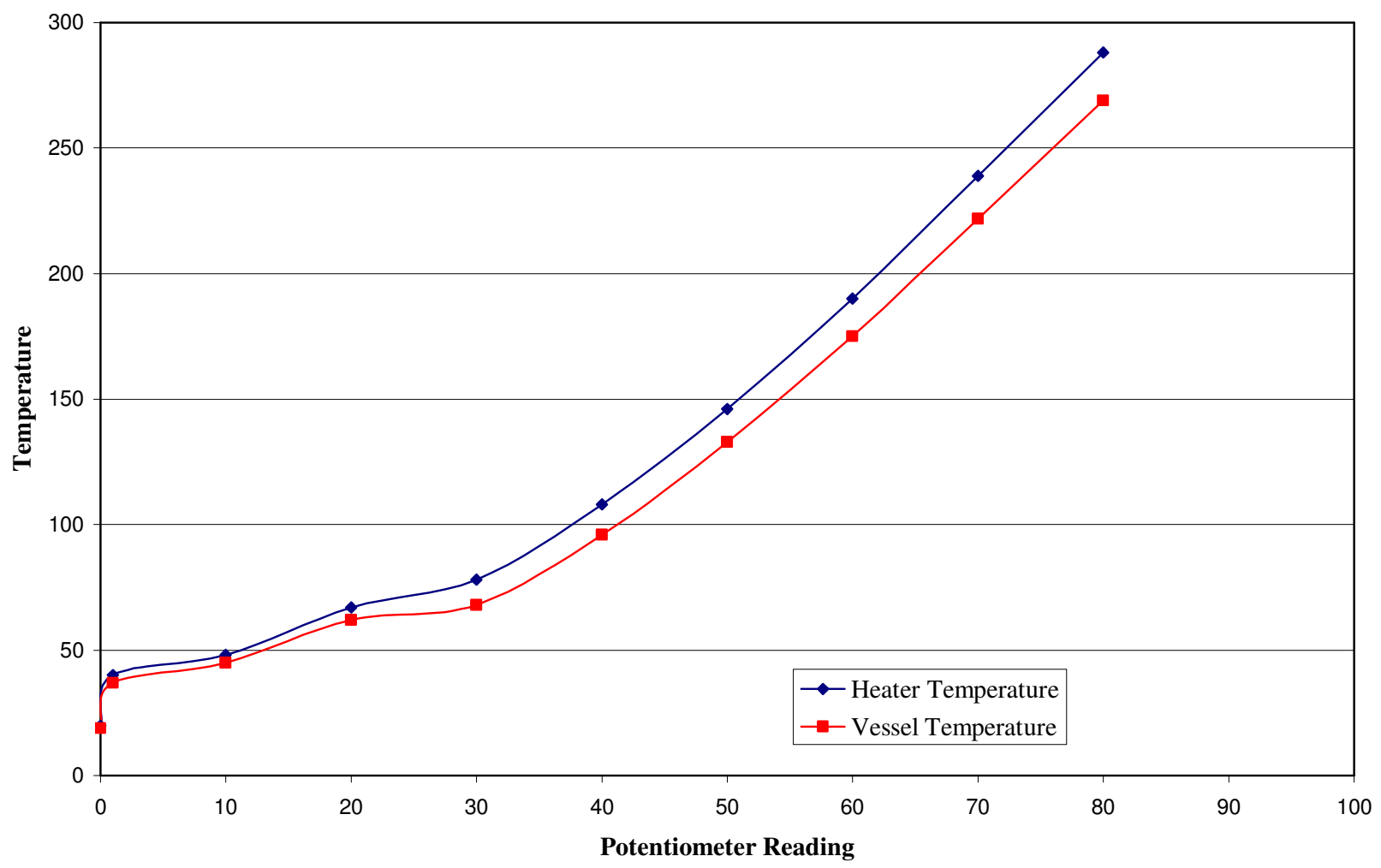

Figure 27 Heater Calibration

The preceding graph describes the calibration of the control unit with the heater temperature. As it can clearly be seen from the graph, the control potentiometer was not taken through the full range of the unit. This was not necessary since the heaters were able to achieve the desired operating temperatures at less than the full range of the controller. With the exception of one set of data points, the temperature curve of the heaters is an exponential curve.

As previously mentioned, after each adjustment of the controller, the system was allowed to come to equilibrium for an hour. This includes the initial start up of the heaters. The temperature readings of the heaters and the interior of the vessel were 
recorded as soon as the unit was turned on. Since the heaters are still powered at the zero mark on the controllers, the system was held at zero for an hour as well as after each adjustment.

\subsubsection{Calibration of Pressure Control System}

A pressure regulating valve was purchased from McMaster Carr along with a vacuum gauge. The combination of the two of these items allowed control over the pressure in the system. Further discussion of the pressure control system will be addressed in the Experimental Shakedown.

\subsection{Modeling and Calibration of Flow Rate}

A wiped film evaporator is a liquid liquid separator. The separation that occurs is a separation of the more volatile material from the less volatile material. These will be referred to as the light fraction and the heavy fraction. For the proper operation of the WFE it was necessary to determine the proper flow rate through the system.

The maximum flow rate that the WFE can process can be estimated by doing an energy balance across the WFE. The heating mantle on the WFE has a rating of 1500 watts total, or 750 watts per half. The latent heat of vaporization for the coal liquid was estimated at $100 \mathrm{~kJ} / \mathrm{Kg}$. Assuming that the coal liquid enters the WFE at separation temperature, the equation would be: 


$$
q=m c_{p}
$$

Equation 2

Rearranging to solve for $\mathrm{m}$

$$
m=q / c_{p}
$$

Equation 3

$$
m=\frac{(1500 W * 60 s)}{100000 J}
$$

Equation 4

$$
m=0.9 \mathrm{Kg}
$$

Equation 5

The density of the coal liquid is $1.2 \mathrm{~g} / \mathrm{cc}$, so $0.9 \mathrm{Kg}$ of the coal liquid equates to

$$
\rho=\frac{m}{V}
$$

Equation 6

$$
V=\frac{900 g}{1.2 g / c c}
$$

\section{Equation 7}




$$
V=750 c c=750 m L
$$

\section{Equation 8}

According to this calculation, the maximum flow rate into the WFE is $750 \mathrm{~mL}$ per minute. This assumes that the heat transfer is $100 \%$ efficient and that all of the heat from the heating mantle heats the WFE and not the surrounding air.

The previous calculation was for the rated wattage, however, as a result of measuring the amperage and the voltage supplied to the heater, it was seen that the measured rating was slightly higher. The unit was calibrated against the calculated values and it was seen that rated value of the heating mantle was slightly less than the calculated value. Using the data collected as a result of experimentation and using Ohm's Law and the power equation, the adjusted power rating can be calculated.

$$
\begin{aligned}
& V=I R \\
& P=I^{2} R \\
& P=I^{2}\left[\frac{V}{I}\right] \\
& P=I V
\end{aligned}
$$

\section{Equation 9}

The measured voltage and amperage per half of the heating mantle was $117.5 \mathrm{~V}$ and $7.1 \mathrm{~A}$ respectively. Solving the equations with the values listed above yields a power rating of 834.25 W per half, or 1668.5 total watts. It was expected that the voltage applied to the heating mantle would decrease as the mantle temperature approached the temperature set 
point. However, it was noticed that this was not the case. Once the mantle was turned on, the voltage was constant to within $2 / 10$ of a volt until the mantle was turned off by the controller. The circuit was either on or off.

Recalculating the maximum flow rate into the WFE yields a volume of 834.12 $\mathrm{mL}$. This was of course, the theoretical value assuming $100 \%$ efficiency. To calculate the actual values, an energy balance needed to be performed on the heating mantle once again, factoring in the energy required to bring the WFE to temperature and the convective losses to the environment. Subtracting the sum of these two values from the theoretical value gave the energy lost in the system. From there the efficiency of the heater was calculated.

The first step was to calculate the convective heat loss. From (12) the following values were found in table A.7

$$
\begin{aligned}
& k=0.0331 \mathrm{~W} / \mathrm{mK} \\
& v=25.5 \times 10^{-6} \mathrm{~m}^{2} / \mathrm{s} \\
& \operatorname{Pr}=0.69 \\
& \beta=1 / 400
\end{aligned}
$$

The mean fluid temperature was

$$
(500+300) / 2=400 K
$$

\section{Equation 10}

The next step was to calculate the Rayleigh number. This number was used to calculate the convective heat transfer coefficient. 


$$
R a_{D}=G r_{D} \operatorname{Pr}
$$

\section{Equation 11}

$$
G r_{D}=\frac{\beta \Delta T_{g} D^{3}}{v^{2}} \operatorname{Pr}
$$

Equation 12

$$
\begin{gathered}
=\frac{(1 / 400)(200)(9.81)(0.0635)^{3}(0.69)}{\left(25.5 * 10^{-6}\right)^{2}} \\
=1332689.32
\end{gathered}
$$

From here, the Nusselt number was calculated

$$
N u_{D}=0.36+\frac{0.518 R a_{D}^{1 / 4}}{\left[1+(0.559 / \operatorname{Pr})^{9 / 16}\right]^{4 / 9}}
$$

Equation 13

$$
=0.36+\frac{0.518(1332689.32)^{1 / 4}}{\left[1+(0.559 / 0.69)^{9 / 16}\right]^{4 / 9}}
$$

\section{Equation 14}

$$
\begin{gathered}
=42.05 \\
h_{c}=\left(\frac{k}{D}\right) N u_{D}=\left(\frac{0.0331}{0.060}\right) * 42.05
\end{gathered}
$$

Equation 15 


$$
=23.19 \mathrm{~W} / \mathrm{m}^{2} \mathrm{~K}
$$

Using this as the value of the heat transfer coefficient, the total heat loss was then calculated using the following equation,

$$
\begin{gathered}
\dot{Q}=h_{c} A\left(T_{S}-T_{E}\right) \\
\text { Equation 16 } \\
=(23.19)(\pi)(0.0635)(1)(500-300) \\
=924.771 \mathrm{~W} / \mathrm{m}
\end{gathered}
$$

The preceding calculation was the amount of heat lost per meter of length. However, since the WFE is much less than one meter long, a correction factor needed to be used. The WFE body is eight inches long, or $0.2032 \mathrm{~m}$ in length. Multiplying the length by the energy lost per meter yields an energy loss of 187.9 watts. This decreases the amount of energy that was used to heat the material in the WFE, as well as the WFE body. The measured rating of the heating mantle was $1668.5 \mathrm{~W}$, subtracting what was lost to the air yields an effective rating of 1480.6 watts.

The next step was to calculate the amount of energy required to heat up the WFE body to temperature. The mass of the WFE body was calculated by finding the volume of the stainless steel from which the WFE body was constructed. The WFE body was $0.2032 \mathrm{~m}$ in length, a diameter of $0.0635 \mathrm{~m}$, and wall thickness of $0.00635 \mathrm{~m}$. This equated to 231.67 cubic centimeters of stainless steel at 8.0 grams per cubic centimeter, or 1.853 kilograms. This mass was for the cylindrical portion of the WFE body only and did not include the mass of the bearings or of the seal for the end of the cylinder. The rotor, or vanes, in the WFE weighed three lbs, or 1.36 kilograms. The specific heat of stainless steel was $500 \mathrm{~J} / \mathrm{kg} \mathrm{K}$. The assumed mass in the system that needed to be heated 
to temperature was $3.213 \mathrm{~kg}$. The amount of energy required to heat this mass up to temperature was calculated from the following formula

$$
Q=m C_{p} \Delta T
$$

Equation 17

$$
\begin{gathered}
=3.213 * 500 * 200 \\
=321300 \mathrm{~J}
\end{gathered}
$$

In order to convert this to watts, a time frame needed to be established. This time frame was the amount of time that it took to heat the body of the WFE to temperature.

However, if the WFE body was assumed to be at steady state, i.e., at temperature, and the WFE body transferred the heat perfectly, any heat added would either be lost to the surroundings, or be transferred to the material in the WFE. Using the modified rating of the heating mantle reduces the maximum volume of material that was able to be processed in the WFE to $740 \mathrm{ml}$. This assumed $100 \%$ efficiency, so it was understood that the value was high, but gave an upper boundary for the operation of the system.

\subsection{Calibration of Flow Control}

\subsubsection{Initial Design}

In the initial design of the WFE system the vacuum was used to pull the material from the holding tank through the WFE. A precise metering valve was purchased to control the flow. Metering valves control the flow of a fluid based on the pressure difference across the valve and a constant know as the "Cv" factor. The equation for calculating the flow rate is as follows 


$$
\frac{\text { Turnsopen }}{\text { fullyopenturns }} * C v \sqrt{\frac{\text { pressuredrop }}{\text { specificgravity }}} * 3.89
$$

Equation 18(14)

Since the flow rate through the WFE had already been calculated, it was necessary to select a valve that would give a large range of flow rates and yet not exceed the maximum flow rate of the WFE. The following is a graph of the flow rates from four valves available from Mcmaster Carr.

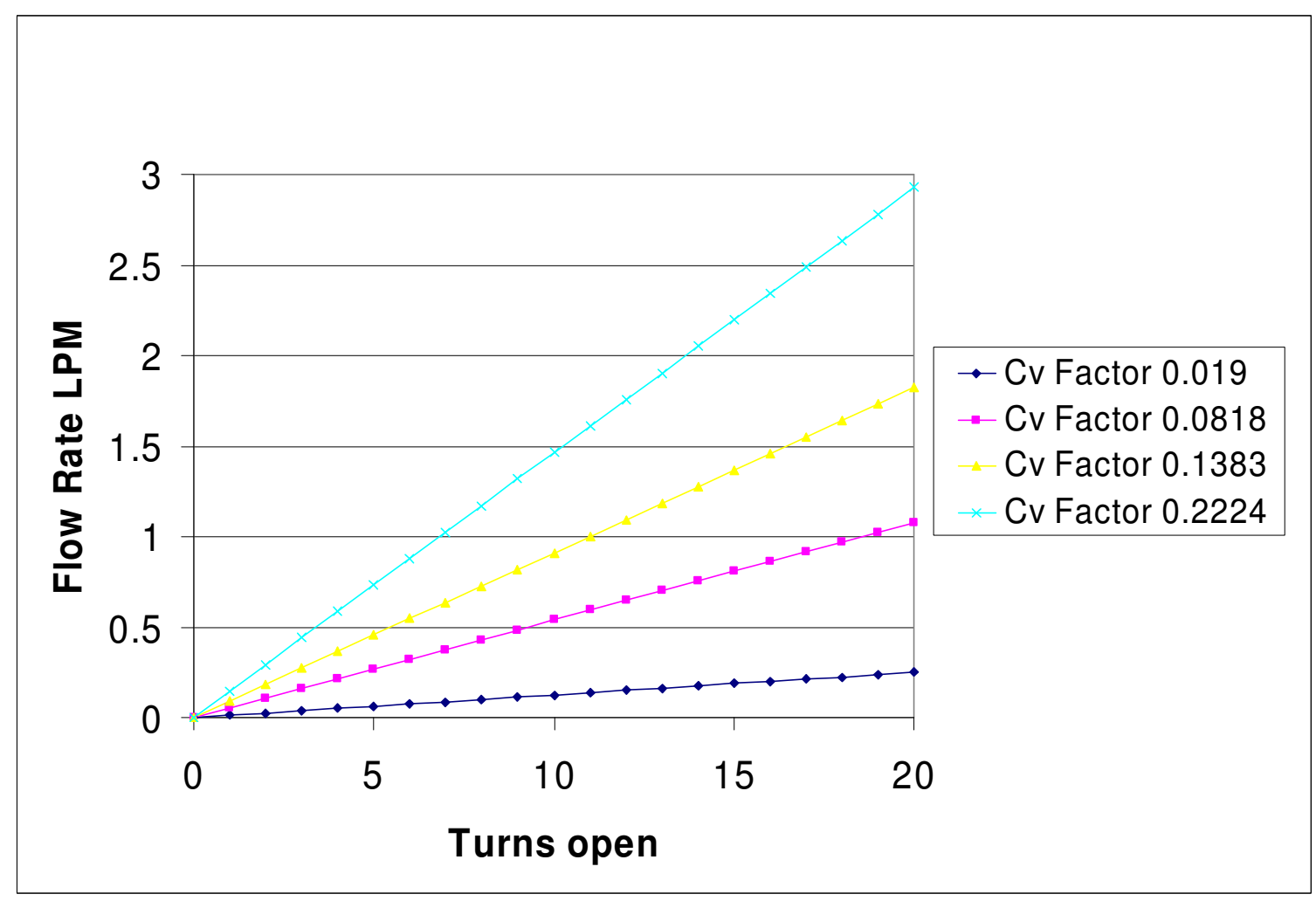

Figure 28 Metering Valve flow rates

The valve with the smallest $\mathrm{Cv}$ factor would not exceed the capacity of the WFE, but would not provide the range of flow rates that would be needed to conduct this research. 
Therefore, the valve with a $\mathrm{Cv}$ factor of 0.0818 was chosen. Even though the maximum flow rate though the valve exceeded the capacity of the WFE, the range was more suited to the parameters of the research.

The system was designed, constructed and calibrated. The system was run through all its operations in an initial shakedown. From the test, any need for changes and alterations for the system was determined.

\subsection{Flow Control}

\subsubsection{Second Design}

One of the design criteria for the stand was to be portable. As the stand was originally built, it would fit through a standard sized doorway. With the motor and the pump installed on the unit, this condition could not be met. Additional alterations were to accommodate the control unit for the pump and the heaters. While this limited the mobility of the stand, it was necessary in order to carry out the experiment.

To add the pump and motor to the stand, a platform needed to be built to support them. Also the vertical spacing of the reactor and the WFE needed to be adjusted. The Unistrut enabled these adjustments.

The second problem was locating available power to run the motor and heaters for the pump. The heaters required $230 \mathrm{~V}$, the motor required $90 \mathrm{~V} \mathrm{DC}$, and the control unit required $110 \mathrm{~V}$. The motor was connected to the control unit which provided the power for the motor. There were several outlets available that provided the required power. 
However, these outlets were currently in use for other equipment. Most of the equipment was not in continuous use so this was a rather minor issue.

\subsubsection{Pump Calibration}

Even though this particular pump was marketed as a precision metering pump, calibration runs were performed to verify the accuracy of the pump. Before this calibration was performed, the pump and the controller needed to be connected and powered.

The manual for the controller was clear and concise; however, no wiring manual was supplied with the motor for the pump. Fortunately, the pump manufacturer's website provided wiring diagrams for each of the models they manufacture.

The pump was a 0.5 horsepower shunt wound variable speed motor. The pump was connected to a 300 to 1 reducing differential. One of the operating guidelines provided by the pump supplier was that the differential cannot exceed $100 \mathrm{rpm}$. The variable controller was similar to the control unit on the WFE so the adjustments were quite simple. Just as the stirred vessel's heaters were powered in the "off" position on the controller, the pump was also powered when the controller was in the zero position. The same min and max adjustment knobs illustrated previously were used to calibrate the pump motor to meet the operating parameters of the reducing differential.

The calibration was to adjust the controller so that the zero setting was actually zero and the maximum setting corresponded to the maximum operating parameter of the reducing differential. However, at the maximum dial setting, the motor could not be 
slowed to $100 \mathrm{rpm}$ as intended. The following graph illustrates the calibrated speed of the pump.

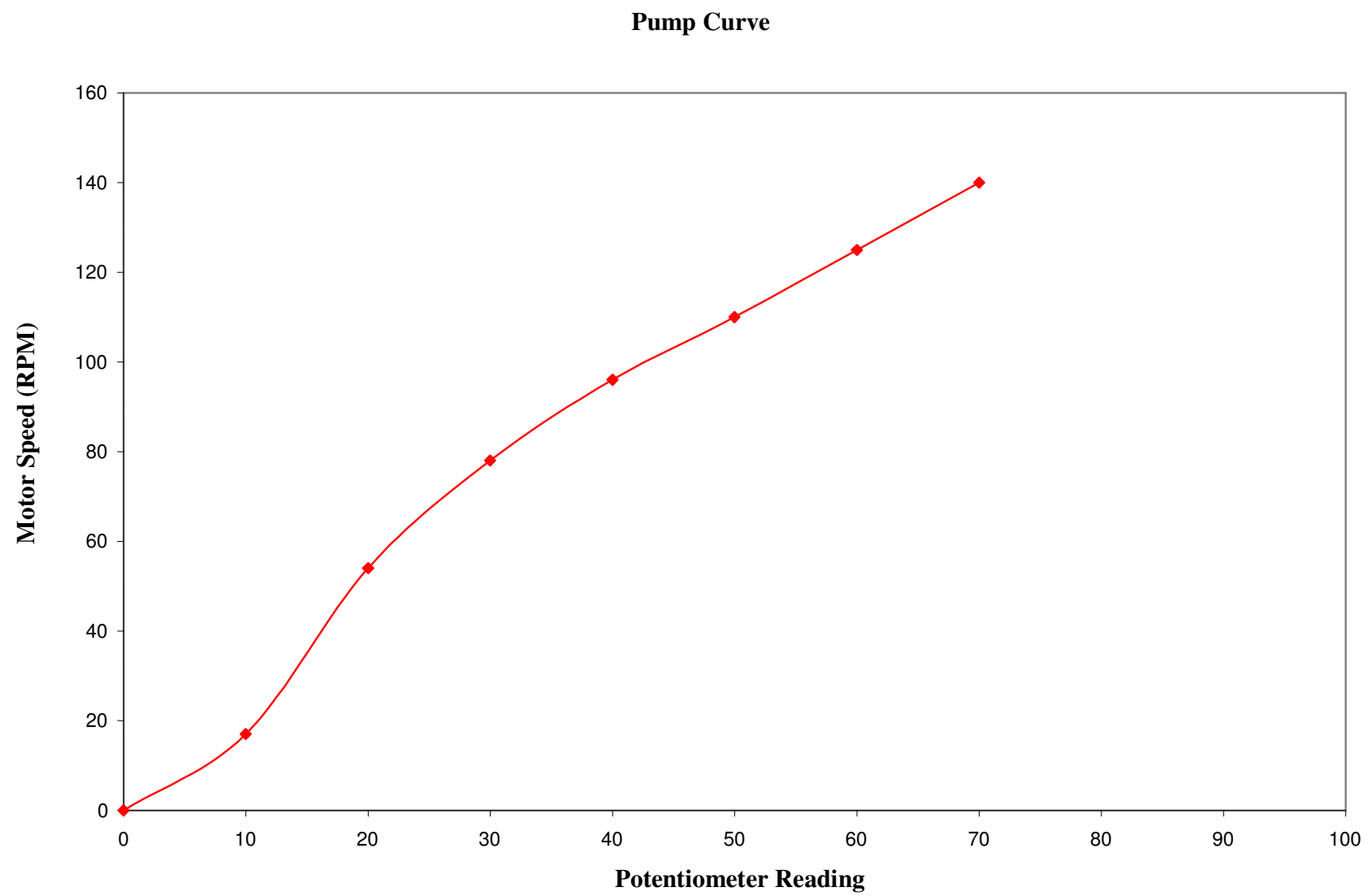

Figure 29 Metering pump RPM curve

As it can be seen from the graph, the maximum speed of the pump is exceeded before the potentiometer reaches half of its operational range. The calibration was stopped after the $70 \%$ potentiometer reading since the two previous speed values exceeded the maximum speed at which the differential can operate. To prevent future researchers from unintentionally damaging the pump and/or differential by exceeding the operational range, an additional page was be added to the manual for the pump, and a tag was attached to the controller that will make note of the limiting RPM value. 


\subsection{Re-Design Wrap Up}

There were several aspects of the stand, and WFE system design that needed to be re-evaluated and re-designed before the research could move forward. The stand remained relatively unchanged, only requiring the addition of one more cross member to the back of the stand to accommodate the pump. The pump and motor assembly were mounted on a piece of 12 ' C-channel. This channel was more than adequate to support the motor and pump. The channel also provided the means by which the pump could be incorporated into the stand. The inside measurement of the $\mathrm{C}$ - channel was such that adding one cross member to the back side of the stand allowed the channel to straddle two cross members and be anchored in place securely.

\section{$7 \quad$ Experimental Part I}

\subsection{First Shakedown Using the Gate Valve}

The first run through the mini-WFE was done with just the heavy oil. This was done to check the plumbing and to familiarize the researcher with the operation of the WFE. Since the heavy oil is the material that is going to be distilled from the coal tar pitch, running the system with just the heavy oil gave the opportunity to determine the operating parameters that would distill off most of the heavy oil.

Since the speed of the WFE was the easiest parameter to control, that was the first variable that was changed for the various runs.

The first run operating parameters were as follows,

$10,200 \mathrm{~mL}$ of heavy oil 
WFE heater temp $225 \mathrm{C}$

WFE speed $50 \%$

Reactor heaters $242 \mathrm{C}$

Internal reactor temp $234 \mathrm{C}$ (heat time of $2 \mathrm{hr} 10 \mathrm{~min}$ )

Vacuum -28 in./Hg

Valve open one full turn

Run time $\sim 15$ minutes

The parameters for the second run

$10,200 \mathrm{~mL}$ of heavy oil

WFE heater temp $224 \mathrm{C}$

WFE speed $50 \%$

Reactor heaters $234 \mathrm{C}$

Internal reactor temp $224 \mathrm{C}$ (heat time of $2 \mathrm{hr} 10 \mathrm{~min}$ )

Vacuum -26 in./Hg

Valve open one full turn

Run time $\sim 9$ minutes

After each of these two runs were completed, it was noticed that a vacuum had been created inside the reactor. This was not completely unexpected since the WFE was run under a vacuum. However, as the pressure was decreasing in the reactor it was opposing 
the vacuum that was pulling the heavy oil from the reactor into the WFE. To correct this problem, a hole was drilled in the lid of the reactor and a pressure release valve was welded in place. This valve was set to break open at $0.5 \mathrm{psi}$, with the air flow going into the reactor. This would prevent any vapor from escaping into the high bay which would have created a safety hazard.

Once the valve had been installed, the first two runs were repeated. The two runs took less than one minute each to complete. The flow rate was estimated to be $15,000 \mathrm{ml}$ a minute. This huge flow rate overloaded the WFE. When the collection tanks were drained, there was material in each of the tanks. It was realized that the material was being pulled through the system too quickly by the vacuum. There was material in the light fraction tank because the material could not flow out of the WFE into the heavy fraction tank fast enough. The flex hose connected to the light fraction tank was filling up and overflowing into the light fraction tank.

\subsection{Second Flow Control Design Using the Gate Valve}

It was obvious from the above data that a better method to control the flow was needed. The metering valve(s) that were intended to control the flow did not function as anticipated. The orifice in the valve through which the fluid was intended to flow was too small for the viscosity of the material. For any of the material to flow through the valve, the valve needed to be completely opened. Also, while calibrating the valve to determine the flow rate, it was noticed that the flow rate varied by up to $200 \mathrm{~mL}$ in a time frame of 30 seconds. This amount of fluctuation was not acceptable in this research, therefore a more accurate means of controlling the flow was needed. 


\section{2b The Precision Metering Pump}

A constant controllable flow could be achieved with a precise metering pump. The metering pump that was used was a Zenith Heated head pump. This pump provided $1.2 \mathrm{cc} /$ revolution. This allowed the flow to be controlled with precision. There were two problems with incorporating the pump into the design. The first was space. The pump would need to be placed in the line between the reactor and the WFE. The pump head would fit with minimal difficulty, but installing the unit with the motor attached needed further alterations.

The second problem was the pump was not operational. Professor Stansberry had an old Zenith heated head pump but coal tar had been run through it a number of years ago and solidified in the pump. The motor for the pump and the control unit for both the heaters and the motor had been taken to be used on another piece of equipment. These could be replaced, but cleaning the pump proved to be more difficult. The pump was sent to Thomas Pumps to be rebuilt and fitted with a motor and control unit.

The main concern was whether the pump could be cleaned up and made to function again. The first attempt to clean the pump was to fill the pump with N-methyl2-pyrrilidone, a super solvent that had been previously used to dissolve coal. Since the pump had a rather small capacity, $1.2 \mathrm{cc}$ per revolution, it could not hold very much solvent. This pump was so finely machined that it was assembled with out gaskets. According the company that sold the pump, Thomas Pumps located in Pittsburgh PA, the tolerance was 1/30 the width of a human hair, about 1 ten thousandth of an inch. There was concern that in the process of disassembly and re-assembly, any small nick or burr 
that might be created would prevent the pump from operating properly. With these tight tolerances, it took the NMP overnight to soak completely through the pump, and produced little results. The NMP had gone from a clear light yellow to almost black, which indicated that it was dissolving the pitch, but the process was extremely time consuming.

The procedure used by the repair shop to refresh similar pumps at Thomas Pumps was to bake them in a vacuum oven overnight. Baking the pump should convert the material in the pump into a fine powder and allow the pump to turn. While this seemed like a reasonable approach, the issue of altering the crystalline structure of the metal, or possible warping the metal, was a concern. Since baking was the method recommended by the repair shop the possibility of damaging the pump seemed remote, but better to err on the side of caution. Dr. Stansberry's lab had purchased an ultra sonic bath which could be used to clean various instruments. Our approach was to immerse the pump in NMP and put it in the ultrasonic bath. The NMP and the metal would not react, and there were no gaskets in the pump that the solvent could destroy. This method proved remarkably effective. After ninety minutes in the bath, one of the shafts in the pump could be removed. After an additional two hours, the entire pump could be disassembled. As a result, his method of cleaning a pump was recommended to the representative from Thomas Pumps.

After the pump was made operable it had to be built into the apparatus. Since the stand had originally been designed and constructed without a pump in the system, slight alterations needed to be made to incorporate the pump into the stand. However the depth of the pump and motor assembly made fitting the stand through a doorway much more 
difficult. Supplying power for the pump and the heaters on the pump was more challenging. The heaters ran on $240 \mathrm{~V}$, and the bus bar in the mezzanine of the high bay only had a few outlets of this voltage, and they were taken by other pieces of equipment. The only solution was to unplug the equipment when it was not in use and then plug it back in when the run was finished.

A small concern about adding the pump to the stand was the dimensions of the stand with the pump attached. Some disassembly may be required in order to meet one of the fundamental design conditions; the apparatus shall fit through a standard size door. Without the pump attached the stand fit easily, however, once the pump, motor and two control panels were added, the stand did not fit well, and became a little bit more difficult to manage. With some minor disassembly, the system can be made to meet that criteria.

\subsection{Experimental Part II}

After the incorporation of the metering pump into the system and its calibration, a second shakedown run was attempted. In this attempt, only the heavy oil (solvent) was run through the system.

\subsubsection{Second Shakedown}

During the second run a problem with the WFE occurred. The wiper blades froze in place and the fuse in the controller blew. Once all the power was shut off to the system, the blades were turned manually. There did appear to be a point in the rotation that the blades caught. It was hypothesized that a nick in either the blade or the cylinder 
wall caused the problem. The WFE was then disassembled and inspected for nicks and burrs. None were found on the blades, but the inspection of the cylinder wall was more difficult. The cylinder was too small to fit a hand in for a complete manual inspection. The depth that the walls of the WFE that could be inspected by hand was about three inches, or the length of an index finger. Since material had already been through the WFE, the walls were discolored and a visual inspection proved inconclusive.

Since no nicks or burrs were found, the blades were cleaned and the WFE was reassembled and the fuse replaced. Before the power was turned back on, the blades were turned manually. The rotation was smooth, and did not catch, so the power was turned back on. The WFE motor was turned on and the speed was gradually increased until the dial reached about $55 \%$. At this point the wiper blades came to a complete halt, and the fuse blew again. The blades could be rocked back and forth and turned manually for several turns and would seize up again. The WFE was disassembled again and inspected. Once again the blades were free of nick and burrs, so it was assumed that the cylinder wall was the culprit. To fix the cylinder wall, an engine hone needed to be purchased. There were two styles of hones available, so both were purchased since it was impossible to determine which would be more effective in this case. Here are pictures of the hones. 


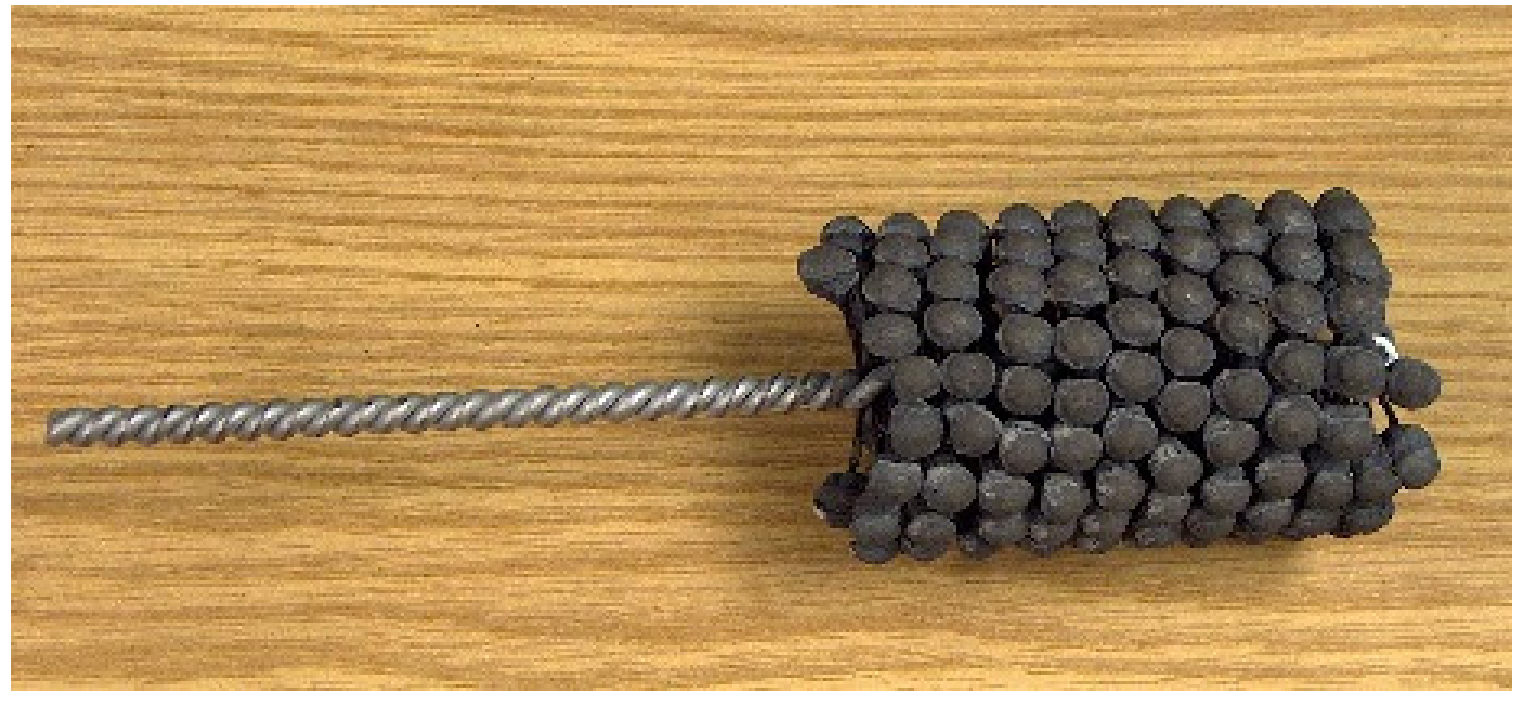

Figure 30 Cylinder hone

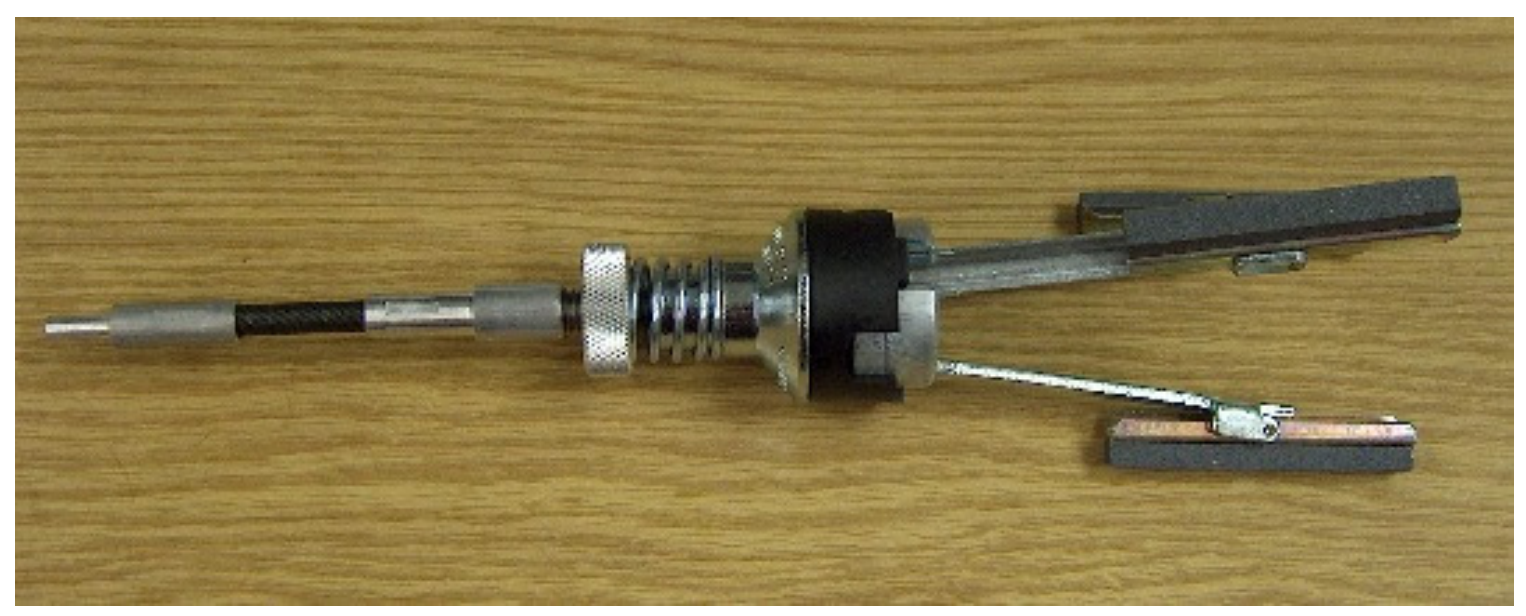

Figure 31 Cylinder hone

Both of these hones could be powered by an ordinary hand drill, corded or otherwise.

The second of the two hones had a more abrasive surface than the first. As a precaution, the first hone was used to prevent the removal of too much of the cylinder wall. 
The hone was attached to a cordless drill and inserted into the WFE once the drill was turned on. The hone was kept in the WFE for a few seconds and then removed. The cylinder wall was inspected as much as the space allowed and then the process was repeated. This process was repeated a total of four times until the area of the wall that could be felt was smooth to the touch.

After the honing was complete, the WFE was reassembled. The wiper blades were turned by hand, and again about halfway through the rotation, the blades hung up again. Once again, the WFE was disassembled and inspected. In the process of the disassembly, one of the mechanical seals slipped off of the shaft.

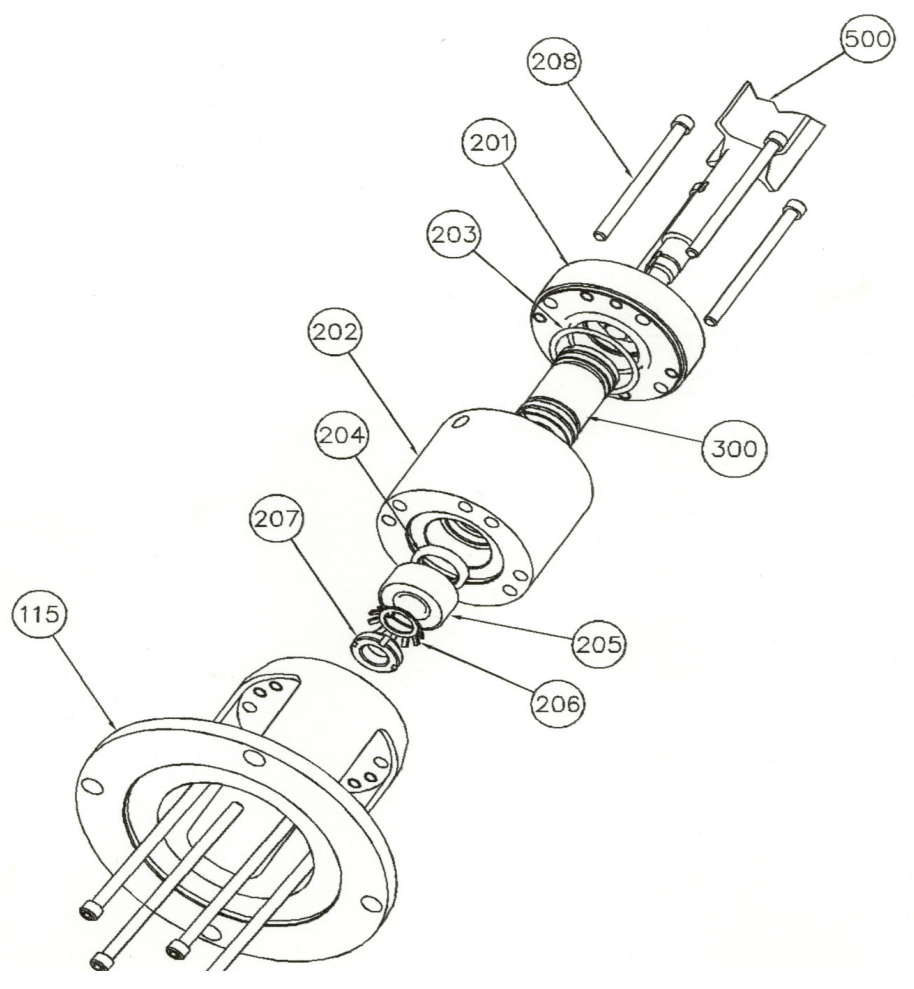

Figure 32 (25) WFE assembly 
The seal in question is number 300 in the illustration above. Although it can not be seen from the illustration, there are two set screws in the seal, located $90^{\circ}$ apart. An expanded view of the seal can be seen below.

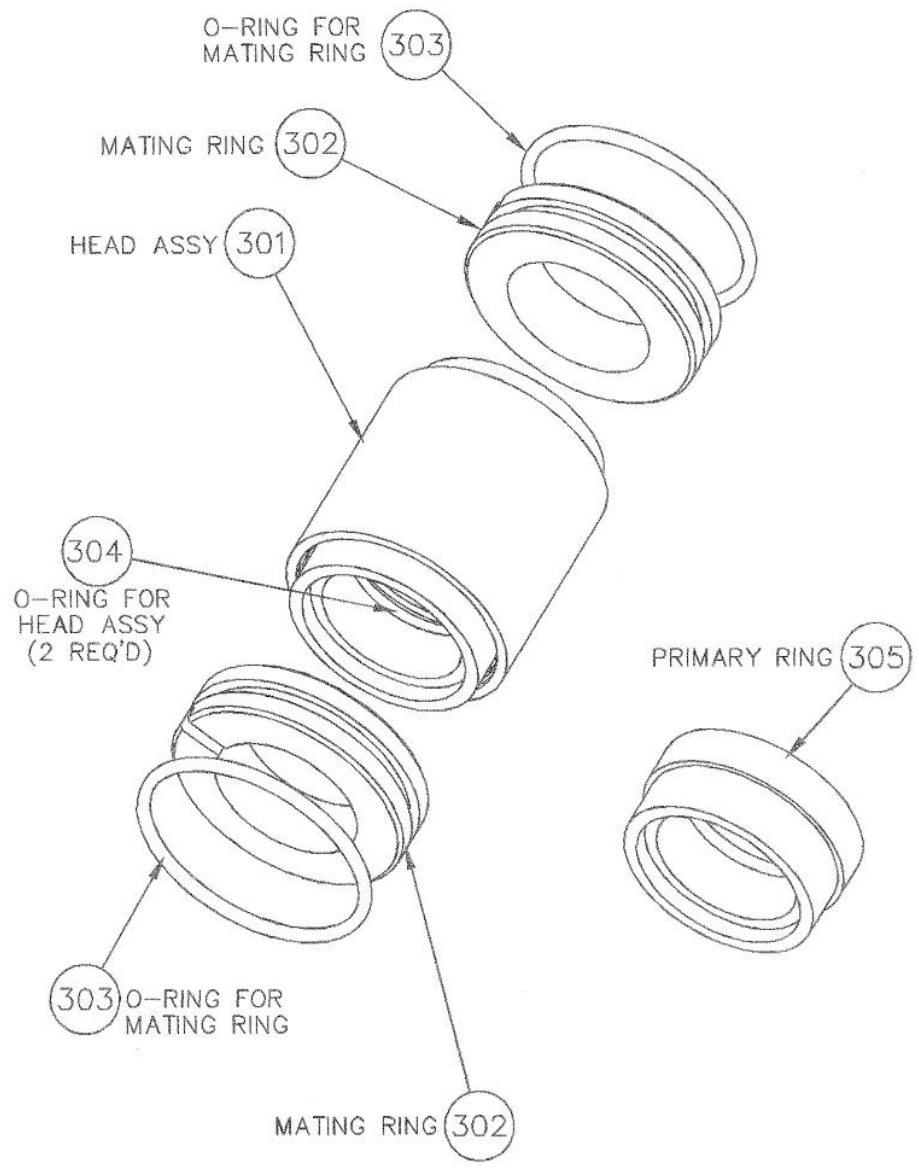

Figure 33 (25) WFE mechanical seal assembly

One of these set screws from the head assembly, part \# 301, had come loose and gotten lodged in one of the cooling water ports located in 202 (Figure 15), the bearing and seal housing. This area of the WFE needed to be cooled due to the bearings and seals in this portion of the device. The seal kept the water out of the WFE and from leaking out around the shaft on the motor side.

The set screw had backed itself out by its threads and lodged itself in the water ports and locked the system. During operation it had become very deformed and needed 
to be replaced. Set screws were readily available from various manufacturers. The concern was that the set screw had done some damage to the seal or to the water ports. A visual inspection of the seal and the ports revealed no damage to either. The reason that the blades could be rocked back and forth and then turned was that the set screw would fall out of the water port and allow the blades to turn, as a response to the rocking. In response to the centripetal force during rotation the screw slipped out and seized the system. To prevent this type of occurrence from happening again, the new set screws had to be purchased and threaded into place with Loktite applied to them. Once the parts were assembled, the experiment could continue.

\section{Experimental Part III}

Once the WFE had been reassembled, the pump incorporated and calibrated, the research continued. The first part of the research was complete. A working system incorporating a small scale WFE had been designed and constructed. Some shakedown runs were done to insure the system was operational. The next step was to perform a trial run to evaluate the operating parameters.

\subsection{Experimental Design}

After the design construction and shakedown of the mini-WFE system was complete, the goal of this work was to evaluate the operation of the mini-WFE so the importance of various parameters effecting separation of the solvent and $\mathrm{H}$-coal could be established. With this information the operation of the pilot scale WFE could be made 
more efficient. It was not practical to determine these parameters on the pilot scale WFE because of the amount of material needed to make the runs and the hazardous potential of handling so much material.

In order to accomplish this task a sensitivity analysis was required. A sensitivity analysis can be conveniently done using a two level factorial experimental design by which two parameters can be compared simultaneously. The system is analyzed and the effect of two parameters on a dependent variable is tested. This reduces the number of experiments needed to establish parameter sensitivity.

The ultimate goal of this work was to enable the production of large quantities of binder pitch from a mixture of solvent and hydrogenated coal solution using the pilot scale WFE. Large quantities of binder pitch, over $1500 \mathrm{lbs}$. needed to be made to meet a contractual obligation of the Carbon Products Group. This was to be done by evaporating the low boiling point solvent from the higher boiling point $\mathrm{H}$-coal solution. By the removal of a quantity of solvent the softening point of the resulting pitch could be increased.

There were two important dependent variables for this experiment: (1) the amount of solvent evaporated and (2) the softening point of the pitch produced. In the experiments for this research the quantity of solvent evaporated could easily be determined while the softening point determination was a more involved analytical procedure. The quantity of solvent evaporated could be collected in the light fraction vessel and weighted. Thus the quantity of solvent evaporated was the dependent variable. Others have related the quantity of solvent removed to the softening point of the pitch so measuring that parameter would be redundant. Also from these previous 
measurements we knew the quantity of solvent to be removed for the production of binder pitch.

According to Arlidge there are four parameters that have the most impact on the operation of a WFE. They are

(1) Vacuum level

(2) Feed temperature

(3) Jacket temperature

(4) Feed rate

The technicians at LCI have added another

(5) Wiper RPM

Because the goal is to correlate effects from the mini-WFE to the pilot scale WFE and the pilot scale WFE and feed material conditions have limitations, some of the variables defined by Aldrich can be eliminated. First the vacuum level was kept as high as possible. This was because the pilot scale WFE had no easy way to control the pressure in the system and since we were trying to remove as much of the solvent as possible, we kept the vacuum as high as possible. The goal was to enable refinement to take place in a single run rather than do repeated runs. The lower the pressure the more solvent evaporated so this variable was not tested. It was only imperative that the pressure in the mini-WFE system be as low as that in the pilot scale WFE.

The feed temperature could be varied but only slightly. The viscosity of the fluid was strongly dependent upon the feed temperature. At low feed temperatures flow was restricted so only higher temperatures would be used in these experiments. Therefore this variable was not tested. 
The jacket temperature, as a variable, could be varied over some range but this was also not practical. This was because the feed temperature must be kept high for the fluid to flow freely. At that temperature some of the solvent was already evaporating as evidenced by the fumes escaping from the system. The upper jacket temperature of the pilot scale system was fixed by the heater's ability to supply enough hot oil to keep the cylindrical surface at its maximum temperate. The range of temperature difference between the feed temperature and jacket temperature was small. Thus the jacket temperature was the highest temperature obtainable in the pilot scale WFE.

The feed rate could be varied significantly. Through some calculations an approximate feed rate was determined but this was based on $100 \%$ effectiveness of heat transfer. This was impossible, but that parameter could be varied widely and the effectiveness on feed rate on separation efficiency could be evaluated.

Wiper speed that affects heat transfer could also be varied significantly. Since the goal was to produce large quantities of synpitch it was desirable to have the greatest feed rate but that would require the most effective heat transfer. One of the parameters that affect heat transfer rate was wiper rpm. This parameter could also be varied widely.

The experimental matrix for the mini-WFE had the following fixed conditions. The pressure was be the lowest pressure obtainable from the vacuum pump. This duplicated the pressure condition of the pilot scale WFE. The temperature of the jacket was as close to the maximum temperature of the pilot scale WFE as possible, so it was fixed. The feed temperature was fixed to the input temperature of the feed into the pilot scale WFE system. 
The test matrix tested the two remaining parameters: wiper speed and feed rate. The range of wiper speeds of the mini-WFE could duplicate the range of the pilot scale system. The evaluation of high and low effects could be evaluated. The second parameter that could be varied was the feed rate. Since we have metering pumps for both systems and we know the relative surface areas we can use feed rates to calculate residence times. The residence time in the WFE could be varied with feed rate. The mini-WFE was tested with feed rates so the residence time in the WFE systems were comparable. These define the ranges of the adjustable parameter that could affect the efficiency of solvent evaporation for the mixture.

The sensitivity of the evaporation process from the WFEs could be established using the following experimental structure. The boundaries were divided into Low, and High - each in equal divisions of range. The Lows and Highs in the mini-WFE were related to similar Lows and Highs in the pilot scale WFE. They were set up in sets of two level experiments. The parametric study of this type, commonly called a multi-variable optimization. This process involved selecting two variables and changing one at time while the other remained constant. Each selection of two variables resulted in four runs through the system. The effects of the parameters were determined by direct measurement of the dependent variable. The results were placed in two groups; the two results from one variable being held constant, and the two results from the other variable being held constant. The results from each of the four runs were plotted on a graph. The first group of results were averaged and plotted, as was the second group. The two averaged points were connected with a line. The slope of that line illustrated which of 
the two variables had the greatest impact on the dependent variable. A generic illustration of a complete set of four runs is shown on the following graph.

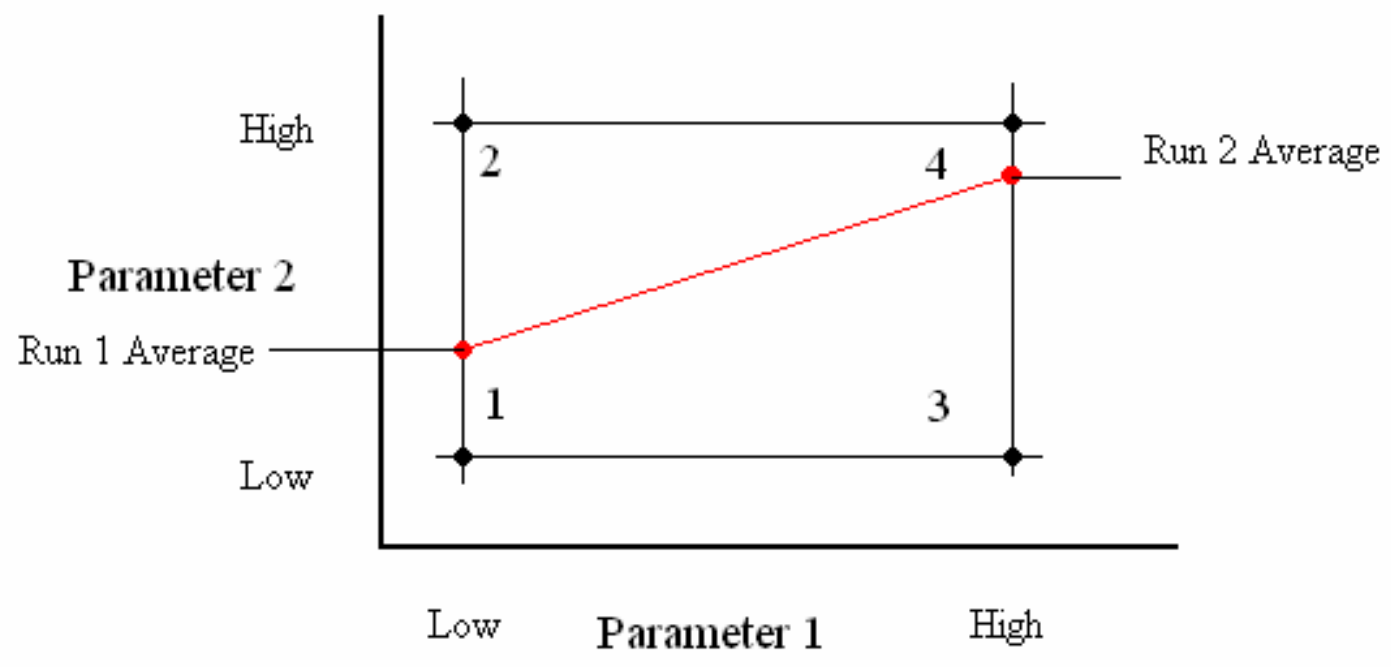

Figure 34 Parametric optimization

If the slope of the line is positive, as is illustrated above, parameter one has more of an impact on performance than parameter two. If the slope is negative, then parameter two has the larger impact on performance. Once the parametric study was complete, the optimum sensitivity of the operating parameters was determined. This optimization approach allowed the determination of the variable that had the most impact on the separation of the material as it passes through the WFE. While these results could be used to operate the WFE for other applications, another parametric study would need to be conducted to determine the optimum operating parameters for that specific application.

By using two two-level experiments, the effectiveness of changing the various parameters on the WFE function could be established. Since the parameters were related 
to the performance ranges of the pilot scale WFE, the results were nearly directly transferable to the pilot scale system. Remember, the differences: the wiper structure and vertical vs. horizontal structures will have some effect on the system efficiencies so direct transference was not possible but the information from the experimental system greatly helped in the refinement processes using the pilot scale system.

In the experiments a specific quantity of blend was put in the CSTR. It was heated to the appropriate temperature. It was then pumped through the WFE at high and low ranges, and (More discussion will follow concerning the pumping procedure) at high and low wiper rotation rates. Samples of the volatiles were collected and weighted. The mass of the collected, condensed, volatiles were used to evaluate the relative efficiencies of the parameters.

\subsubsection{Preliminary Experiment:}

Before the two level factorial experiment was begun the hypothesis that wiper speed should be one of the parameters that needed to be tested had to be verified.

Although Ariledge did not have this listed as one of the variable parameters affecting the performance of the WFE, LCI, in response to one of our inquiries, suggested that varying the wiper speed would vary the yield. Arlidge (13) suggested a wiper rpm of 1700, which corresponded to a wiper blade speed of $15 \mathrm{ft} / \mathrm{sec}$. [The only parameter tested in this experiment was wiper speed all other parameters were held constant.] The recommended wiper speed corresponded to $100 \%$ reading on the speed indicator. A quantity of blend was run though the mini-WFE system for 60 minutes. Two tests: one at $50 \%$ and the other at $100 \%$ were tested. The distillate was collected and weighted. The mass of the distillate was plotted against wiper speed and indeed by increasing the wiper speed the 
mass of distillate increased. This is seen in the following figure. This supported the hypothesis that wiper speed should be one of the variables to be tested.

WFE Speed vs. Mass Out (5/4 \& 5/5)

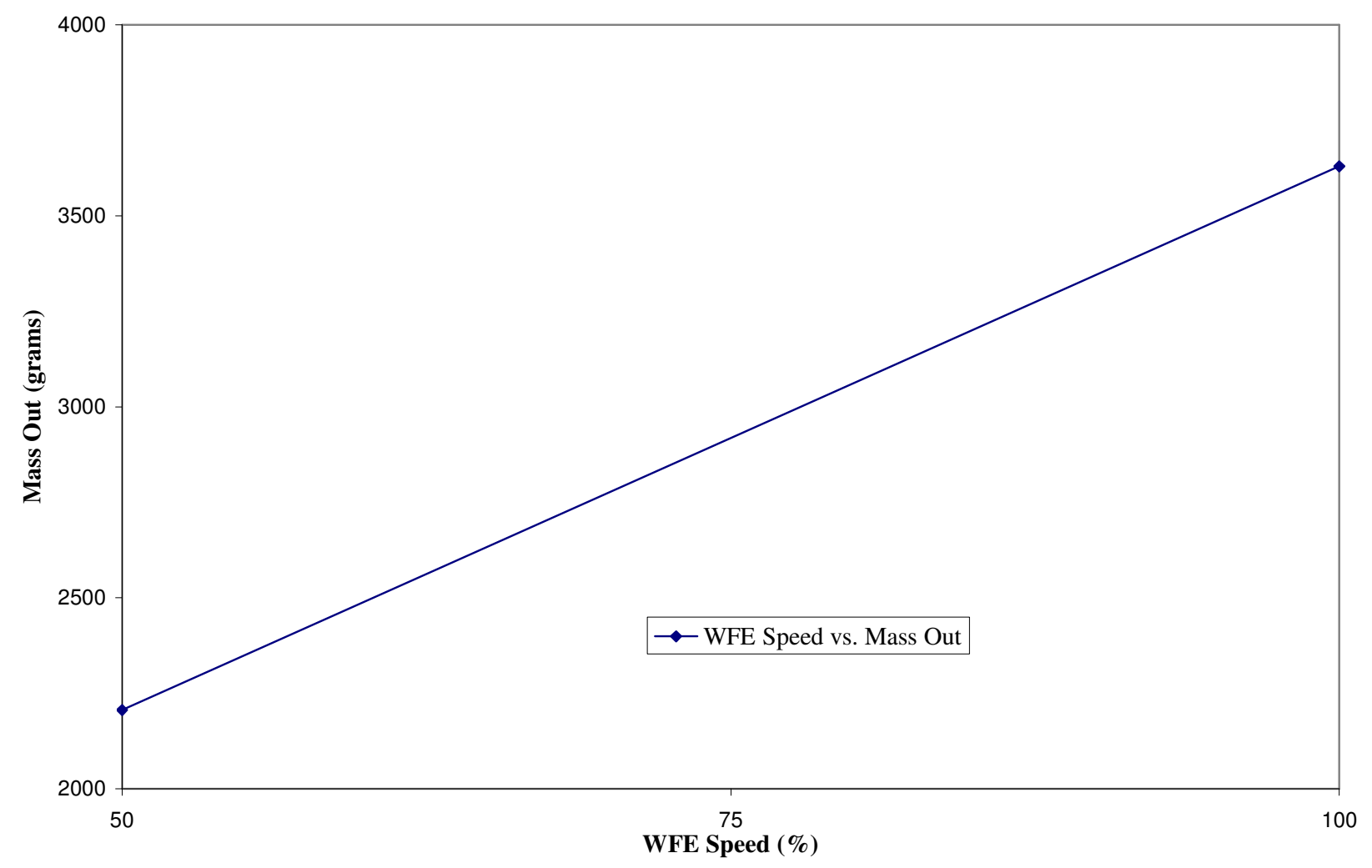

Figure 35 WFE speed vs mass out

\subsubsection{The Two Level Factorial Experiments}

In these experiments the fluid blend was fed in at a flow rate of $98.4 \mathrm{~mL} / \mathrm{min}$ and $49.2 \mathrm{~mL} / \mathrm{min}$ into the mini-WFE system. The pressure was $-28 \mathrm{in} / \mathrm{Hg}$. This was done at two pump speeds $30 \%$ and $15 \%$, based on the readout on the controller. These two pump speeds were tested at two wiper speeds $50 \%$ and $100 \%$ based on the controlled to the wiper. The distillate was collected and weighted for each experiment. The data is listed in 
Appendix A. The percent separation was calculated and the average value at the two pump speeds was plotted against two wiper speeds. The plot is seen below. The source data can be seen in Figure 31 in Appendix II.

\section{Wiper Speed vs. Separation \%}

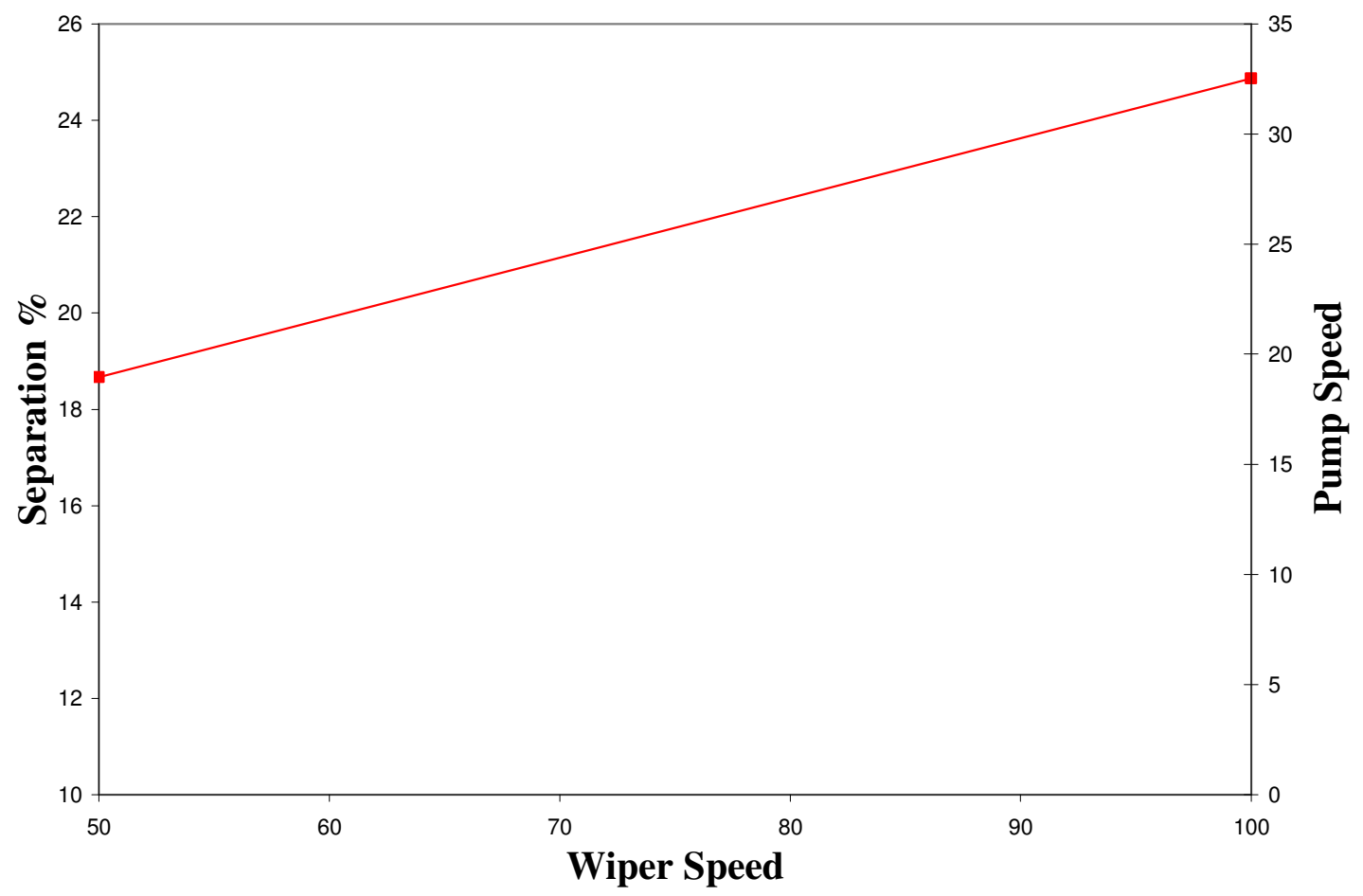

Figure 36 Separation vs pump speed and WFE RPM

The data used for this and other plots was selected due to it's presumed repeatability. Several of the mass balances exceeded $100 \%$, or were less than $95 \%$, and as a result, those data points were not used for plotting purposes.

The only important fact that can be extracted from the plot is that since the slope is positive with respect to wiper speed. The wiper speed has a more dramatic positive effect on percent separation than the pump speed. The question remains "will lowering the pump speed further increase the efficiency of separation?" Logic tells us the lower 
the pump speed the greater the residence time and therefore the better the separation. That conjecture further implies the greater importance of wiper speed.

That hypothesis was examined using a second two level experiment. In that experiment, the pump speed was halved again but the wiper range speed was retained. The raw data can be seen in Figure 32 in Appendix II. That data is plotted below. It can be seen that wiper speed has the dominant effect on percent separation. Now to maximize the combination of parameters that produces the most effective separation the data was rearranged so the slope of the line was the most positive. When the pump speed was plotted inversely with respect to the wiper speed the slope of the line was much more positive. Thus the conclusion that can be drawn was that the higher the wiper speed and lower the pump speed the more effective the separation. This was the information fed to the pilot plant operating the pilot scale WFE. 


\section{$\%$ Separation vs Pump SPeed}

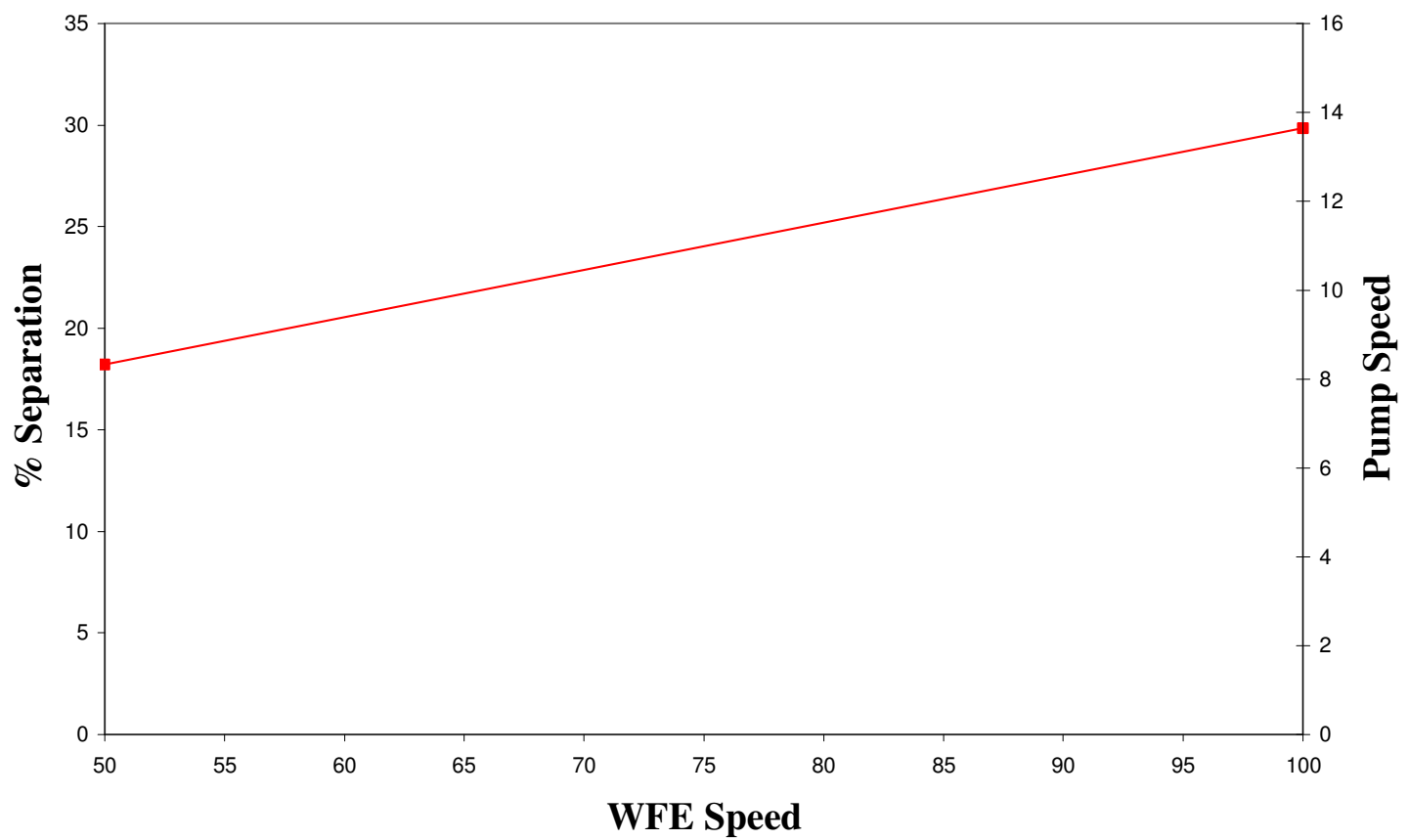

Figure 37 Separation vs pump speed and WFE RPM

In this experiment the pump speed was halved again. If lowering the pump speed has no increased effect the slope should be the same as the first plot. Comparison of the slope change from the first plot to the second plot shows that the slope is greater when the pump speed is lowered. Therefore it can be said that the lower the pump speed the more efficient the separation will be. So the conclusion to be drawn is that the most effective separation can be obtained by decreasing the pump speed to as low as feasible and increasing the wiper speed to as high as possible. The recommendation for the pilot plant operation was to lower the pump speed and increase the wiper speed as much as possible to get the best separation efficiency. 
WFE Separation

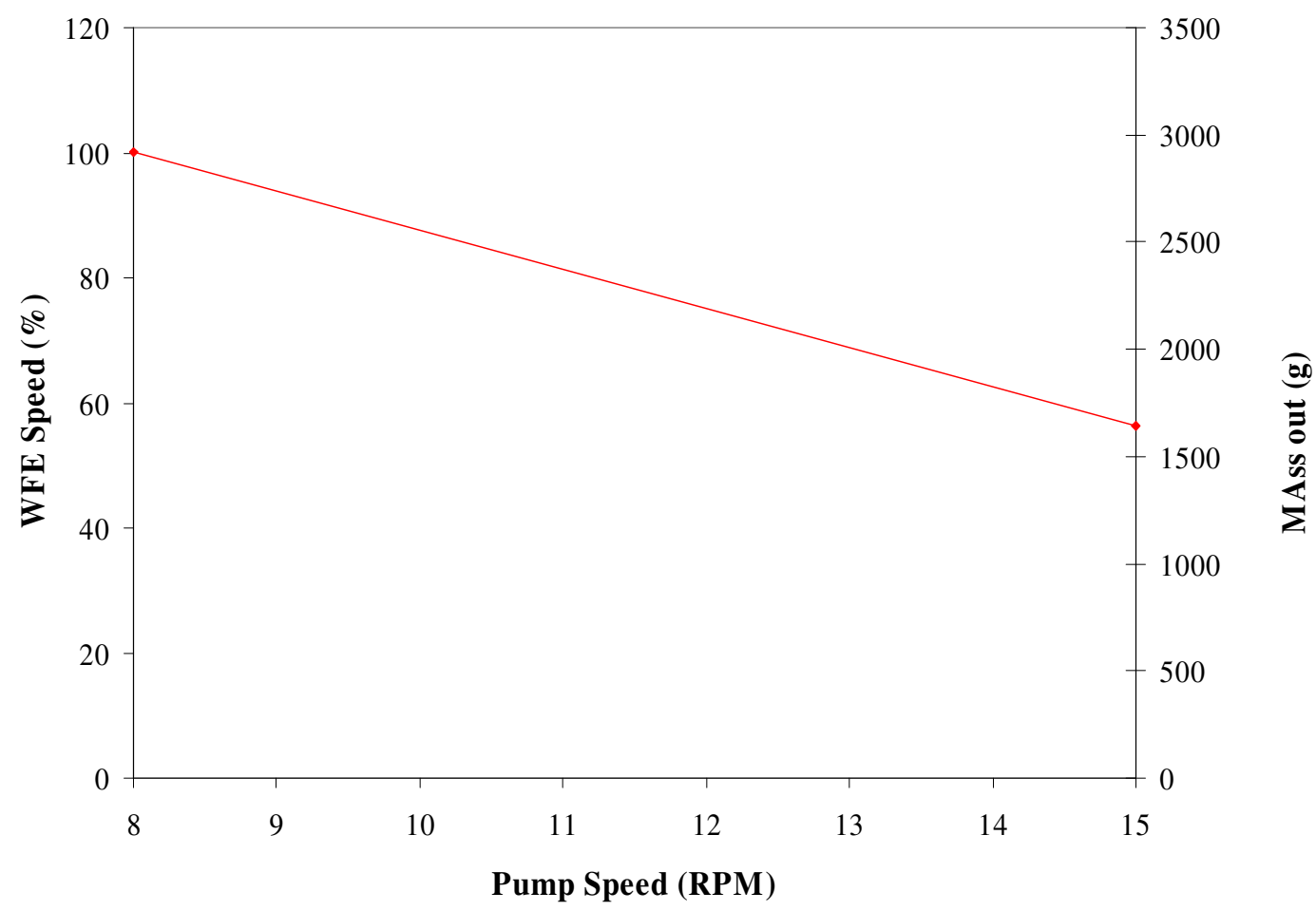

Figure 38 Separation vs pump speed and WFE RPM

Further experimentation was limited because of the pump operation. The feed rate into the WFE was controlled by the Zenith metering pump. It is necessary to explain that even though the pump is machined to output $1.2 \mathrm{cc} / \mathrm{rev}$, the pump actually outputs more than that amount of material. This was due to a phenomenon known as slippage. Slippage occurs due to the pressure difference across the pump. This is when material 'slips' through the internal workings of the pump. However, this slippage remains constant and can be accounted for.

The amount of separation appeared to be the most dependent on pump speed. The following is a graph of pump speed versus separation. 
Pump Speed vs. Separation \%

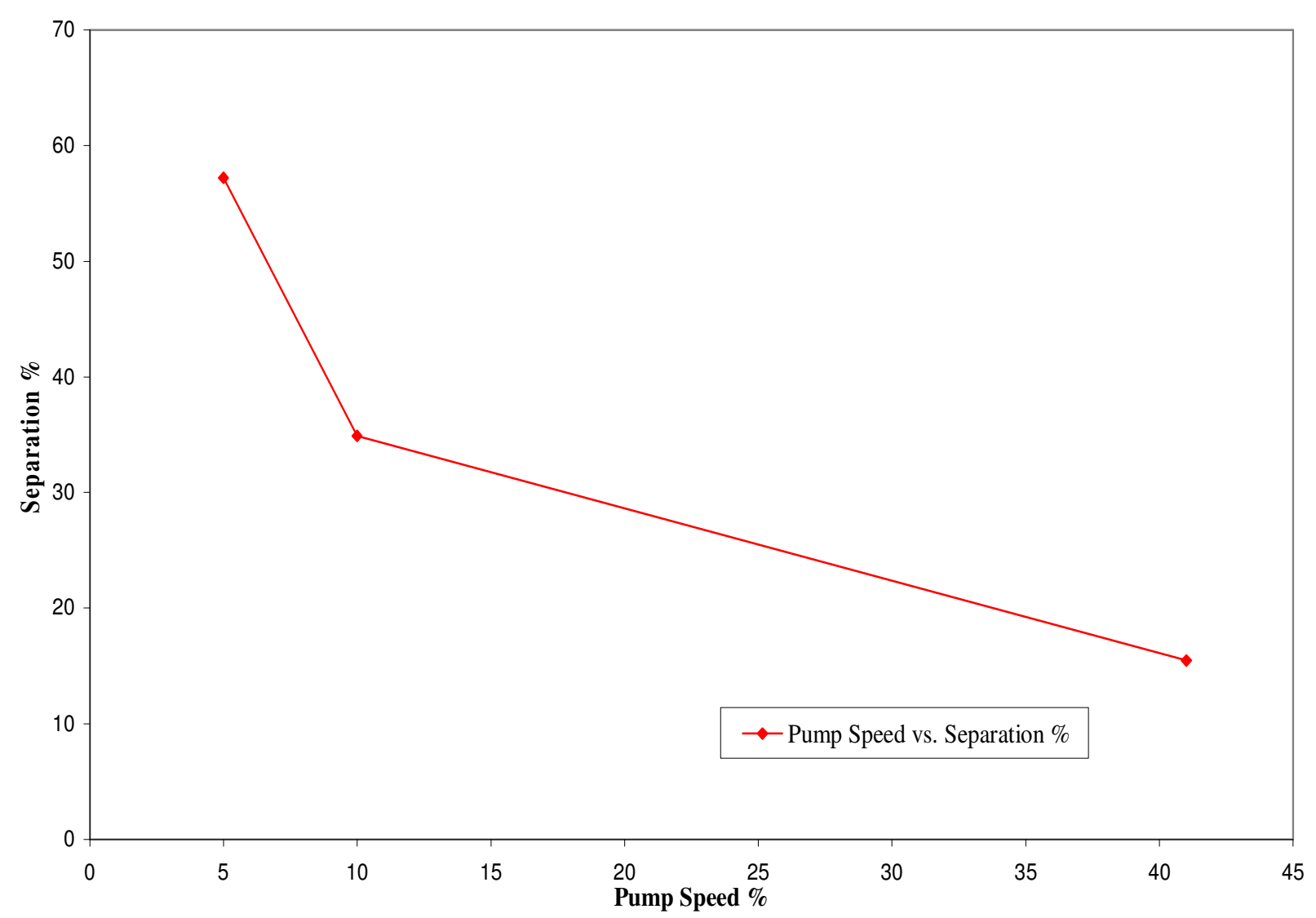

Figure 39 Separation vs pump speed

It can be seen from the graph that slower feed rates into the WFE yielded a higher separation rate. The result was determined experimentally and was also verified by a representative at LCI Corporation. The flow rate LCI used in their laboratories, for water, given in $\mathrm{lbs} / \mathrm{hr}$, was $3-4$. While it is possible in theory to achieve this flow rate with the Zenith pump, there were several factors that limit this.

The first factor that limited the minimal flow rate in this system was the slippage in the pump. Due to the nature of the Zenith pump, the amount of slippage remains 
constant for given operation parameters. Because of this, the amount of slippage could be determined and factored into the flow rate.

The second limiting factor was the controller. The controller used a dial rheostat to adjust the speed of the pump. While this was effective, it was not precise and made consistent adjustments difficult. This limited the accurate reproducibility of a given set of parameters. Another small accuracy problem arose with the photo tachometer as well. The speed range needed for the pump to achieve the flow rate desired was outside the operation range of the photo tachometer. It was then necessary to determine the speed manually, which also introduced human error into the measurement.

At very slow speeds, less than four RPM, the rotation of the pump became discontinuous. At certain points in the rotation, the pump would catch and cease to turn. After several seconds the rotation would continue. With this type of performance from the pump, it was impossible to quantify the amount of material flowing through the pump in small time intervals. Once the run was completed, the average flow rate could be determined over the course of the run, but there was no way to tell how much the flow varied on a minute to minute basis due to the discontinuous operation of the pump. As a result of this, the pump could not be slowed enough to achieve the flow rate needed for the desired separation to occur. It would be expected the separation would continue to increase as the flow rate was decreased until complete separation occurred. 


\section{Results and Discussion}

The data from all of the runs through the WFE are listed in Appendix II. Although the results are not as consistent as would be desired, the general trend is that the separation increased as the research continued. The mass balance over the course of the experiment was very good. In several instances it can be seen that the mass balance is over $100 \%$. This is not unexpected and easily explained. The moment this material begins to cool, it solidifies and sticks to whatever surface it's in contact with at the time. Over the course of the runs, material coated the plumbing. Some of this material would then be re-melted during the next run. If the amount of material that was re-melted exceeded that amount deposited, then the mass balance was over $100 \%$, but by a very small amount.

The best separation occurred on the final run. The separation achieved in the final run was $86 \%$. This was achieved with a WFE wiper speed of $100 \%$, a pump speed of $7 \%$, reactor temperature of $260^{\circ} \mathrm{C}$, and a WFE temperature of $335^{\circ} \mathrm{C}$. This run was the final run due to yet another failure of the heating mantle on the WFE. While $100 \%$ separation was not achieved, this research can still be considered a success. The general operating parameters have been determined for the operation of the WFE for the separation of a heavy oil solvent from synpitch.

The operating parameters are as follows; WFE temperature as hot as can be achieved with the heating devices, WFE speed at maximum, vacuum as low as possible, feed rate on the order of a couple pounds per hour, and a reactor temperature 20-30 
degrees below the boiling point of the material. The slightly lower reactor temperature prevents the material from flashing, or violent spontaneous boiling. As previously mentioned, with the current equipment, the needed flow rate could not be achieved.

It should be noted that concurrent with this research a second group of researchers was preparing the pilot plant WFE for separation runs of synpitch. Their goal was to make binder pitch from coal tar distillate and hydrogenated coal. Based on the results of the mini-WFE runs, parameters were set. The basic limitations of that system are the temperature at the cylinder wall and flow rates. With the guidance from the mini-WFE runs, separation in the pilot scale WFE was accomplished. However the production rate was only $1 \mathrm{gallon} / \mathrm{hr}$. This is far to slow to meet contractual obligations. Koppers Corp has permitted the Carbon Products Group to use their distillation facility at their pilot plant which can easily fulfill the production requirements. This research did complete its objective by determining the parameters of maximum importance for the separation of coal tar distillate and hydrogenated coal liquids needed for the refinement of binder pitch In conclusion a small mini-WFE system was designed and constructed. It underwent a shake down test for suitability. A two level factorial experiment was designed and run to evaluate the parameters that could be varied in both the pilot scale WFE and mini-WFE system. From those evaluations the general efficiency of the parameters were determined. These were used to set the conditions of the pilot scale WFE where the successful separation of solvent and hydrogenated coal for the production of binder pitch was completed. 


\section{Recommendations for Further Research}

The research done for this thesis completes the goals outlined in the thesis, but is by no means complete. Additional research can, and should be done on this and other materials to provide baseline operating parameters for the WFE unit. Before that research is continued, several modifications to the design would be beneficial.

The first change that should be made is the control units for the metering pump and for the heating ropes for the reactor. A digital controller would allow accurate and precise duplication of operation parameters from run to run. The metering pump needs to be able to operate continuously down to $0.5 \mathrm{RPM}$ for smaller flow rates. Thomas Pumps should be consulted to see how this might be possible. A digital controller for the heaters on the reactor should be acquired as well for more reliable temperature settings.

The amount of time required to complete a run with the small flow rates will increase dramatically if the current storage vessels are used at full capacity. It would be prudent to replace the current vessels with significantly smaller stainless steel ones. The stainless steel should prevent corrosion (rust) from contaminating the system. The smaller vessels would decrease the heat up time and allow for more data to be collected in the same amount of time. The plumping could also be upgraded at the same time to switch all of it over to Swagelok. This would allow all of the segments on the plumbing to be removed and "baked out" if fouling or plugging became an issue. It would also enable the new vessels to be removed and interchanged with ease. 


\section{$11 \underline{\text { References }}$}

1. U. Mannweiler. "The Development of the World Aluminum Market." RDC Internal Publication 1994

2. N.R. Turner. "Recent Trends In Binder Pitches for Reduction Anodes." JOM November 1993

3. W.K. Fischer, R.C. Perruchoud. "Pitch Evaluation." RDC Internal Publication 1995

4. U. Mannweiler. "Anode Manufacturing: An Introduction." RDC Internal Publication

5. F. Keller, R. Engelsmann, A. Kooijmann, W. Schmidt-Hatting.

"Workers' Hygiene and Environmental Protection in Anode Plants." Light Metals 1989

6. F. Keller. "Waste Materials in Anode Manufacturing: An Overview." Light Metals 1994

7. F. Keller. "Anode Quality Figures." RDC Internal Publications 1995

8. "Constructing and Operating Anode Plants: What Top Management Needs to Know." Keller, F., Mannweiler, Ulrich, Knall, Egon Original Publication ARABAL 1993, Cairo, Egypt

9. Mukherjee, Rajiv. "Does Your Application Call for an F-Shell Heat Exchanger." CEP Magazine, April 2004

10. Lodes, T. W. "Challenge of Shell and Tube Heat Exchanger Mechanical Design." American Society of Mechanical Engineers, Volume 118, 1986 pgs. 103-110

11. Poddar, Tarun K., Polley, Graham T. "Optimize Shell-and-Tube Heat Exchanger Design." Chemical Engineering Progress, Sept 2000

12. A.F. Mills. Basic Heat \& Mass Transfer Second Edition. 1999 Prentice Hall Inc.

13. Arlidge, Dean B. "Wiped Film Evaporators as Pilot Plants." Chemical Engineering Process, Volume 79, Aug 1983

14. McMaster Carr, Catalog 107 pg 348. 
15. Jones, Samuel S. "Anode-carbon usage in the Aluminum Industry." Petroleum-Derived Carbons, pgs 234-250, 1986.

16. Wright, Kenton B. Alcoa "Pitch Content Optimization Model for Anode Mixes." Warrick Operations, Newburgh, IN 47630

17. Uthaniporn Suriyapraphadilok, Colin Jennis-McGroarty, Adam Zel, and John Anderson "The use of Gasification Pitch and Coal Tar Pitch in Carbon Anodes."

18. Wombles, Robert H.., Kiser, Melvin D. "Developing coal tar/petroleum pitches." Light Metals, 2000, pps 537-541

19. Mantell, Charles L "Carbon and Graphite Handbook." Robert E. Krieger Publishing Company. Huntington, New York, 1979

20. Wikipedia website. http://en.wikipedia.org/wiki/Coal. May 2005

21. Brian Bland. "Design, Construction, and Evaluation of Coal Extraction Pilot Plant to Manufacture Coal Based Carbon Pitch." Masters Thesis, 2000

22. Newman, J.W. "Manufactured Petroleum Pitch-A Versatile Carbon Precursor." Light Metals, 1980 pg 503-508

23. Baron, J.T., Kraynok, C.E., Wombles, R.H. "Strategies for a declining North American Coal Tar Supply.” Light Metals, 1998 pg. 203-216

24. Swann, Philip D., Davies, Clive, Berber, John S. "Extraction of Useful Chemical Derivatives From Coal." MSS Information Corporation New York, New York.

25. LCI LabVap Benchtop WFE operations manual.

26. Merriam Webster website. http://www.m-w.com/. May 2005.

27. Oxford Advanced Learners Dictionary website. http://www.oup.com/elt/catalogue/teachersites/oald7/?cc=global. May 2005. 


\section{Appendix I: Safety Concerns}

There are some safety concerns with the materials that are being used in this experiment as well as the equipment that is being used. The coal liquid and coal tar pitch that are being used in this research are irritants, both to the skin and the respiratory tract. To safeguard against this type of exposure, none of the material will be handled with out basic precautions in place.

Any person(s) that will be handling the material will use latex gloves and a respirator equipped with an organic vapor cartridge to protect the researcher from both skin exposure and inhalation hazards. In addition to the latex gloves, once the system is operating at temperature, heat resistant Kevlar reinforced "hot gloves" will be worn over the latex gloves to guard against exposure to the heated parts of the system. In addition to the gloves, most of the system plumbing is wrapped in insulation also to protect the researcher from the possibilities of burns. This is the primary purpose for the insulation, not for the reduction of heat loss that the insulation provides.

In addition to the concerns listed above, perhaps the greatest concern is the fact that coal tar pitch, and most other coal derived liquids, are known carcinogens. The MSDS for coal tar pitch is listed in the appendix IV. While the above mentioned precautions will provide some protection to the researcher, limiting the exposure to the hot vapors and liquids will be the safest course of action. To this end, the material will not be handled at operating temperature as much as is allowed. Some limited exposure may be encountered when draining the fraction collection tanks. This is unavoidable due to the softening point of the heavy fraction being above room temperature. The material 
will need to be heated above the softening point of the material in order for the material to flow from the tank. 


\section{Appendix II: WFE Data}

\begin{tabular}{|c|c|c|c|c|c|c|c|c|c|c|c|c|c|c|}
\hline Date & Mass In & $\begin{array}{l}\text { WFE } \\
\text { Set } \\
\text { Temp }\end{array}$ & $\begin{array}{l}\text { WFE } \\
\text { temp }\end{array}$ & $\begin{array}{l}\text { WFE } \\
\text { speed }\end{array}$ & high/low & $\begin{array}{l}\text { Pump } \\
\text { Speed }\end{array}$ & high/low & $\begin{array}{l}\text { Pump } \\
\text { RPM }\end{array}$ & $\begin{array}{c}\text { Reactor } \\
\text { Temp }\end{array}$ & $\begin{array}{l}\text { Light } \\
\text { Fraction }\end{array}$ & $\begin{array}{l}\text { Heavy } \\
\text { Fraction }\end{array}$ & $\begin{array}{c}\text { Mass } \\
\text { Out }\end{array}$ & $\begin{array}{c}\text { Mass } \\
\text { Balance }\end{array}$ & $\begin{array}{c}\% \\
\text { Separation }\end{array}$ \\
\hline $4 / 25 / 2005$ & 11000 & 315 & 307 & 50 & I & 30 & $\mathrm{~h}$ & 82 & 285 & 2500 & 8500 & 11000 & * & 22.73 \\
\hline $4 / 26 / 2005$ & 11000 & 315 & 303 & 100 & $\mathrm{~h}$ & 30 & $\mathrm{~h}$ & 82 & 292 & 3500 & 7500 & 11000 & * & 31.82 \\
\hline 4/27/2005 & 11321.2 & 315 & 309 & 50 & I & 15 & I & 41 & 292 & 3587.12 & 7388.25 & 10975 & 96.95 & 31.69 \\
\hline 4/28/2005 & 10986.8 & 315 & 306 & 100 & $\mathrm{~h}$ & 15 & I & 41 & 297 & 1969.36 & 8951.29 & 10921 & 99.4 & 17.92 \\
\hline 4/29/2005 & 10920.7 & 335 & 303 & 100 & $\mathrm{~h}$ & 15 & I & 41 & 300 & 1694.01 & 8998.62 & 10693 & 97.91 & 15.51 \\
\hline 4/30/2005 & 10889.5 & 335 & 305 & 50 & 1 & 15 & 1 & 41 & 302 & 1597.33 & 9145.06 & 10742 & 98.65 & 14.67 \\
\hline $5 / 2 / 2005$ & 10338.4 & 335 & 309 & 50 & I & 15 & I & 41 & 300 & 1244.06 & 8865.82 & 10110 & 97.79 & 12.03 \\
\hline $5 / 3 / 2005$ & 8865.82 & 335 & 312 & 50 & I & 15 & I & 41 & 300 & 618.21 & 8277.85 & 8896 & 100.34 & 6.97 \\
\hline $5 / 4 / 2005$ & 10526.9 & 315 & 309 & 50 & I & 8 & $\mathrm{vl}$ & 10 & 300 & 2205.71 & 8176.6 & 10382 & 98.63 & 20.95 \\
\hline $5 / 5 / 2005$ & 10369.6 & 315 & 309 & 100 & $\mathrm{~h}$ & 8 & $\mathrm{vl}$ & 10 & 285 & 3629.29 & 5710.99 & 9340 & 90.07 & 35 \\
\hline 5/6/2005 & 9666.15 & 315 & 309 & 100 & $\mathrm{~h}$ & 8 & $\mathrm{vl}$ & 5 & 291 & 1704.46 & 1273.71 & 2978 & & 57.23 \\
\hline $5 / 6 / 2005$ & 6747.02 & 335 & 312 & 100 & $\mathrm{~h}$ & 8 & $\mathrm{vl}$ & 5 & 291 & 2824.7 & 3922.32 & 6747 & 100.61 & 41.87 \\
\hline $5 / 8 / 2005$ & 9603.31 & 335 & 323 & 100 & $\mathrm{~h}$ & 7 & $\mathrm{vl}$ & 4 & 293 & 2724.06 & 6337.91 & 9770 & 101.74 & 28.37 \\
\hline $5 / 10 / 2005$ & 4058.43 & 335 & 323 & 100 & $\mathrm{~h}$ & 7 & $\mathrm{vl}$ & 4 & 260 & 3512.84 & 551.14 & 4064 & 100.14 & 86.56 \\
\hline
\end{tabular}




$\begin{array}{cccc}\text { Rows } & \text { Wiper } & \text { Pump } & \\ 2 & \text { Speed } & \text { Speed } & \text { \% Separation } \\ 3 & 50 & 30 & 22.73 \\ 5 & 100 & 30 & 31.82 \\ 7 & 100 & 15 & 17.92 \\ & 50 & 15 & 14.6 \\ \text { Avg } & 50 & 18.66 & \\ & 100 & 24.87 & \\ & & & \end{array}$

$\begin{array}{cccc}\text { Rows } & \text { Wiper } & \text { Pump } & \\ 5 & \text { Speed } & \text { Speed } & \text { \% Separation } \\ 7 & 100 & 15 & 17.92 \\ 13 & 50 & 15 & 15.51 \\ 10 & 100 & 8 & 41.8 \\ & 50 & 8 & 20.9 \\ \text { Avg } & 50 & 18.2 & \\ & 100 & 29.85 & \end{array}$

Figure 41 Separation Comparison 


\section{Appendix III: MSDS Carbon Black Base}

Material Safety Data Sheet

MATERIAL K O P P E R S MEDICAL EMERGENCIES: 1800 553-5631

SAFETY

OUTSIDE U.S.A.: $\quad 412$ 227-2001

DATA

GENERAL INFORMATION: 412 227-2424

SHEET

KOPPERS INC.

436 SEVENTH AVENUE

PITTSBURGH, PA. 15219-1800

CHEMTREC ASSISTANCE 1800 424-9300

CANUTEC: $\quad 1613$ 996-6666

\section{SECTION I - PRODUCT IDENTIFICATION}

PRODUCT NAME: Carbon Black Base \#1

SYNONYM: None

PRODUCT USE: Burned to produce carbon black.

CHEMICAL FAMILY: Coal tar distillate

FORMULA: Complex mixture of hydrocarbons

CAS NUMBER: 65996-92-1

NFPA 704M/HMIS RATING: 2/2 HEALTH 1/1 FLAMMABILITY $1 / 1$ REACTIVITY

$0=$ Least $\quad 1=$ Slight $\quad 2=$ Moderate $3=$ High $\quad 4=$ Extreme

CANADIAN PRODUCT CLASSIFICATION: Class D, Division 2, Subdivision A, Very Toxic

Material

SECTION II - HEALTH/SAFETY ALERT

WARNING

MAY BE FATAL IF SWALLOWED 


\section{HARMFUL TO THE SKIN OR IF INHALED}

CAUSES EYE AND SKIN IRRITATION

AVOID PROLONGED OR REPEATED CONTACT

OBSERVE GOOD HYGIENE AND SAFETY PRACTICES WHEN HANDLING THIS

PRODUCT DO NOT USE THIS PRODUCT UNTIL MSDS HAS BEEN READ AND

UNDERSTOOD

WARNING: THIS PRODUCT CONTAINS A CHEMICAL KNOWN TO THE

STATE OF CALIFORNIA TO CAUSE CANCER.

\section{SECTION III - HEALTH HAZARD INFORMATION}

EYE: Direct contact with liquid or vapor may cause moderate irritation.

SKIN: Contact with skin can result in severe irritation which when accentuated by sunlight may result in phototoxic skin reaction. This material or similar materials when administered throughout the major portion of their lifetime has caused cancer in laboratory animals.

INHALATION: Acute overexposure to vapor may result in respiratory tract irritation. Repeated and/or prolonged contact to high concentrations of vapor may result in respiratory difficulties, central nervous system (CNS) effects by headache, drowsiness, dizziness, weakness, characterized incoordination, circulatory collapse, coma and possible death.

INGESTION: Ingestion of material may cause gastrointestinal disturbances including irritation, nausea, vomiting, abdominal pain. Systemic effects are similar to those described under INHALATION.

OTHER: See Section XIII (Comments) for additional information on heatlh effects.

\section{SECTION IV - EMERGENCY AND FIRST AID PROCEDURES}

EYE CONTACT: Immediately flush with large amounts of water for 15 minutes. Seek medical aid.

SKIN CONTACT: Remove contaminated clothing. Wipe material from skin. Wash thoroughly with soap and water or waterless hand cleaner. If irritation persists, seek medical aid.

INHALATION: Remove from exposure. If breathing has stopped or is difficult, administer artificial respiration or oxygen as indicated. Seek medical aid. 
INGESTION: Give 1 to 2 glasses of milk or water to victim if conscious and alert. Induce vomiting OR give 1 to $2 \mathrm{oz}$ (30 to $60 \mathrm{~g}$ ) activated charcoal in water to victim if conscious and alert. If vomiting occurs, repeat treatment. Seek medical aid.

NOTE TO PHYSICIAN: Due to the possibility of sensitization of the myocardium following extreme acute overexposures, cardiorespiratory support should be available.

DO NOT ATTEMPT TO GIVE ANYTHING BY MOUTH TO AN UNCONSCIOUS PERSON.

SECTION V - FIRE AND EXPLOSION HAZARD INFORMATION

FLASH POINT \& METHOD: $243 \mathrm{~F}$

AUTOIGNITION TEMP: ND

FLAMMABLE LIMITS (\% BY VOLUME/AIR): LOWER: ND IPPER: ND

TDG FLAMMABILITY CLASSIFICATION: None

EXTINGUISHING MEDIA: Use dry chemical, carbon dioxide, foam or water spray. Water or foam may cause frothing, if molten.

FIRE-FIGHTING PROCEDURES: Wear complete fire service protective equipment, including full-face MSHA/NIOSH approved self-contained breathing apparatus. Use water to cool fire-exposed container/structure/protect personnel. Toxic vapors may be given off in a fire.

FIRE AND EXPLOSION HAZARDS: When heated (fire conditions), vapors/decomposition products may be released forming flammable/explosive mixtures in air. Closed containers may explode when exposed to extreme heat(fire).

SENSITIVITY TO MECHANICAL IMPACT: ND

SENSITIVITY TO STATIC DISCHARGE: ND

\section{SECTION VI - SPILL, LEAK AND DISPOSAL INFORMATION}

SPILL OR LEAK PROCEDURES (PRODUCT): Stop leak if no risk involved. Stay upwind. Solidified spills: Shovel into dry containers and cover. Flush area with water.

Small wet spills: Take up with sand or other noncombustible absorbent material. Flush area with water. Dike large spills for later disposal. Contain runoff from fire control and dilution water. This product released into the environment must be reported to the National Response Center (1 800-424-8802). 
When this product is spilled or leaked, the CERCLA reportable quantity is 17 gallons or more. DOT REPORTABLE QUANTITIES

1 pound Benzo(b)fluoranthene

1 pound Benzo(a)pyrene

WASTE DISPOSAL: Dispose of as such in accordance with local/state/federal regulations.

\section{SECTION VII - RECOMMENDED EXPOSURE LIMIT/HAZARDOUS INGREDIENTS}

EXPOSURE LIMIT (PRODUCT): n 8 hour work shift, benzene soluble fraction of total particulate including dust, fumes and mists.

** Suspected Human Carcinogen.

Percent by weight are the maximum level of ingredients.

HAZARDOUS INGREDIENTS CAS NUMBER \%BY WT. EXPOSURE LIMIT (PPM;MG/M3)

\begin{tabular}{|c|c|c|c|}
\hline Coal Tar Distillate & $65996-92-1100$ & OSHA-TWA & $0.2 *$ \\
\hline Benzene & $71-43-2 \quad 0.012$ & OSHA-TWA 1 & $* *$ \\
\hline Toluene & $108-88-3 \quad 0.026$ & OSHA-TWA 200 & $* *$ \\
\hline Ethylbenzene & $100-41-4 \quad 0.03$ & OSHA-TWA 100 & 435 \\
\hline M \& P Xylene & mixture 0.028 & OSHA-TWA 100 & 435 \\
\hline O-Xylene & $95-47-6$ & OSHA-TWA 100 & 435 \\
\hline Naphthalene & $91-20-3$ & OSHA-TWA 10 & 50 \\
\hline Quinoline & $91-22-5$ & None & \\
\hline Acenaphthene & $83-32-9$ & None & \\
\hline Dibenzofuran & $132-64-9 \quad 2.368$ & None & \\
\hline Fluorene & $86-73-7 \quad 4.112$ & None & \\
\hline Phenanthrene & $85-01-8$ & OSHA-TWA & $0.2 *$ \\
\hline Anthracene & $120-12-7 \quad 4.354$ & OSHA-TWA & $0.2 *$ \\
\hline Fluoranthene & $206-44-0 \quad 12.474$ & None & \\
\hline Pyrene & $129-00-0 \quad 8.222$ & OSHA-TWA & $0.2 *$ \\
\hline Benzo(a)anthracene & $56-55-3 \quad 2.082$ & None & \\
\hline Chrysene & $218-01-9 \quad 2.208$ & OSHA-TWA & $0.2^{*}$ \\
\hline Benzo(a)pyrene & $50-32-8 \quad 0.546$ & OSHA-TWA & $0.2^{*}$ \\
\hline Benzo(b)fluoranthene & $205-99-2 \quad 0.62$ & None & \\
\hline Benzo(j)fluoranthene & $205-82-3 \quad 0.44$ & None & \\
\hline Benzo(k)fluoranthene & $207-08-9 \quad 0.41$ & None & \\
\hline
\end{tabular}


Benzene

Toluene

Ethylbenzene

M \& P Xylene

O-Xylene

Naphthalene

Quinoline

Dibenzofuran

Phenanthrene

Anthracene

Fluoranthene

Benzo(a)anthracene

Chrysene

Benzo(a)pyrene

Benzo(b)fluoranthene

Benzo(j)fluoranthene

Benzxo(k)fluoranthene

\section{SECTION VIII - PERSONAL PROTECTION INFORMATION}

EYE PROTECTION: Industrial safety glasses, minimum. As necessary to comply with 29 CFR 1910.133 and work area conditions: use side shields, goggles or face shield. Chemical goggles; face shield (if splashing is possible).

SKIN PROTECTION: As required, industrial resistant flexible-type gloves. Depending on working conditions, i.e., contact potential, wear impervious protective garments such as head/neck cover, aprons, jackets, pants, coveralls, boots, etc. See Section XIII - Comments for additional information on skin protection recommendations.

RESPIRATORY PROTECTION: Not required under normal use conditions. If ventilation does not maintain inhalation exposures below TLV(PEL), use MSHA/NIOSH approved units as per current 29 CFR1910.134 and manufacturers' "Instructions" and "Warnings". Combination filter/organic vapor cartridges or canister may be used.

VENTILATION: Provide sufficient general/local exhaust ventilation in pattern/volume to control inhalation exposures below current exposure limits and areas below flammable vapor concentrations. Local exhaust is necessary for use in enclosed or confined spaces. See OSHA 29 CFR 1910.146 Permit Required Confined Space. 


\section{SECTION IX - PERSONAL HANDLING INSTRUCTIONS}

HANDLING: Avoid prolonged or repeated breathing of vapors, mists or fumes. Avoid prolonged or repeated contact with skin or eyes. Observe good personal hygiene practices and recommended procedures. Application of certain protective creams (sun screens for coal tar products) before working/several times during work may be beneficial.

STORAGE: Keep in a closed, labeled container within a cool (well shaded), dry ventilated area. Protect from physical damage. Keep containers closed when material is not in use. Maintain good housekeeping.

OTHER: Not for use or storage in or around the home. DO NOT TAKE INTERNALLY. Do not use until manufacturer's precautions have been read/understood. Wash exposed areas promptly and thoroughly after skin contact and before eating, drinking, using tobacco products or rest rooms.

SECTION X - REACTIVITY DATA

CONDITIONS CONTRIBUTING TO INSTABILITY: Overheating

INCOMPATIBILITY: none known

HAZARDOUS REACTIONS/DECOMPOSITION/COMBUSTION PRODUCTS: Oxides of carbon

CONDITIONS CONTRIBUTING TO HAZARDOUS POLYMERIZATION: none

SECTION XI - PHYSICAL DATA

BOILING POINT: $\quad$ 295C TO 453C SPECIFIC GRAVITY: $1.13 \mathrm{~g} / \mathrm{cc} 3$

MELTING POINT: NA NOLATILE BY VOL: NA

VAPOR PRESSURE: $\quad$ 0.066mm Hg @ 30C EVAPORATION RATE(ETHER=1): NA

VAPOR DENSITY(AIR=1): NA VISCOSITY: $\quad 35$

SOLUBILITY: $\quad$ slight $\quad \mathrm{pH}: \quad 6.2$

(WATER)

VOC: NA

COEFFICIENT OF WATER/OIL DISTRIBUTION: slightly H2O soluble 
APPEARANCE/ODOR: brown to black liquid with tarry odor

*lbs/gal

SECTION XII - TRANSPORT INFORMATION

\author{
PRODUCT PACKAGED IN BARGE \\ RQ OTHER REGULATED SUBSTANCES,LIQUID,N.O.S. \\ (CONTAINS BENZO(A)PYRENE, BENZO(B)FLUORANTHENE) \\ CLASS 9 NA3082 PG III \\ CRUDE COAL TAR OIL \\ PLACARDED: CLASS 9 \\ PRODUCT PACKAGED IN TANK CAR \\ RQ OTHER REGULATED SUBSTANCES,LIQUID,N.O.S. \\ (CONTAINS BENZO(A)PYRENE, BENZO(B)FLUORANTHENE) \\ CLASS 9 NA3082 PG III \\ CRUDE COAL TAR OIL \\ PLACARDED: CLASS 9 \\ -------- PRODUCT PACKAGED IN TANK TRUCK -------- \\ RQ OTHER REGULATED SUBSTANCES,LIQUID,N.O.S. \\ (CONTAINS BENZO(A)PYRENE, BENZO(B)FLUORANTHENE) \\ CLASS 9 NA3082 PG III \\ CRUDE COAL TAR OIL \\ PLACARDED: CLASS 9
}

\title{
SECTION XIII - COMMENTS
}

Persons with pre-existing disease in or a history of ailments involving the skin may be at a greater risk of developing adverse health effects when exposed to this material.

The application of a commercially available sun-blocking lotion is recommended to greatly reduce the phototoxicity of coal tar associated sun burning. The lotion should be applied prior to the application of the barrier cream and should have a sun protection factor(SPF) greater than 15. Application of a general purpose protective cream or a cream specifically formulated for preventing coal tar containing products from contacting skin before working/several times during work may be beneficial.

The IARC monographs ( Vol 32 and 35) state that there is sufficient evidence for the carcinogenicity of benz(a)anthracene and similar materials in experimental animals. The NTP 
Annual Report on Carcinogens states that benz(a)anthracene and similar coal-derived liquids are carcinogenic in animals. Benz(a)anthracene appears on the OSHA Carcinogen List.

Similar or identical materials have produced skin tumors when tested on laboratory animals in lifetime skin painting studies. The following compounds have been placed in Group 3 as having inadequate evidence of carcinogenicity: fluorene, phenanthrene, anthracene, carbazole, fluoranthene, pyrene, and chrysene.

Reviewed and revised April 2001.

No known ingredients which occur at greater than $0.1 \%$, other than those listed above, are listed as a carcinogen in the IARC Monographs on the Evaluation of the Carcinogenic Risk of Chemicals to Humans, the NTP Annual Report on Carcinogens or OSHA 29 CFR 1910.10011047 subpart Z Toxic and Hazardous Substances (Specifically Regulated Substances).

SKIN PROTECTION (protective material): Permeation/degradation values of chemical mixtures cannot be predicted from pure components or chemical classes. Thus, these materials are normally best estimates based on available pure component data. A significant difference in chemical breakthrough time has been reported for generically similar gloves from different manufacturers (AIHA J., 48, 941-947 1987).

Do not use until manufacturer's precautions have been read/understood. Wash exposed areas promptly and thoroughly after skin contact from working with this product and before eating, drinking, using tobacco products or rest rooms.

Prepared By: Safety and Health Department

REVISION DATE: 02/02

CODE NUMBER: IND00116FE0219

SPECIFICATION SHEET NUMBER:

REPLACES SHEET: IND00116MY0118

SUPPLIER INFORMATION: Same as manufacturer.

NOTICE: While the information and recommendations set forth herein are believed to be accurate as of the date hereof, Koppers makes no warranty with respect thereto and disclaims all liability from reliance thereon. 


\section{Appendix IV: MSDS Coal Tar Pitch}

Material Safety Data Sheet

MATERIAL K O P P E R S MEDICAL EMERGENCIES: 1800 553-5631

SAFETY

OUTSIDE U.S.A.: $\quad 412$ 227-2001

DATA

GENERAL INFORMATION: 412 227-2424

SHEET

KOPPERS INC.

436 SEVENTH AVENUE

PITTSBURGH, PA. 15219-1800

CHEMTREC ASSISTANCE 1800 424-9300

CANUTEC: $\quad 1613996-6666$

\section{SECTION I - PRODUCT IDENTIFICATION}

PRODUCT NAME: Carbon Pitch Soft

SYNONYM: Coal Tar Pitch, Pencil Pitch

PRODUCT USE:

CHEMICAL FAMILY: Aromatic Hydrocarbons

FORMULA: See Section XIII - Comments for FORMULA.

CAS NUMBER: 65996-93-2

NFPA 704M/HMIS RATING: $\quad$ 2/2 HEALTH $\quad$ 1/1 FLAMMABILITY $\quad 1 / 1$ REACTIVITY

$0=$ Least $\quad 1=$ Slight $\quad 2=$ Moderate $\quad 3=$ High $\quad 4=$ Extreme

CANADIAN PRODUCT CLASSIFICATION: Class D, Division 2, Subdivision A

\section{SECTION II - HEALTH/SAFETY ALERT}

WARNING

MAY CAUSE EYE IRRITATION AND BURNING. MAY CAUSE SKIN IRRITATION, A PHOTOTOXIC SKIN REACTION IN SUNLIGHT, AND SKIN DAMAGE. MAY CAUSE RESPIRATORY TRACT IRRITATION IF INHALED.

MAY CAUSE DIGESTIVE TRACT IRRITATION IF INGESTED.

CONTACT WITH HEATED MATERIAL MAY CAUSE THERMAL BURNS. CHRONIC OVEREXPOSURE (as defined by OSHA recommended standards) 
CAN CAUSE CANCER.

TARGET ORGANS ARE THE SKIN, BLADDER, SCROTUM, LUNGS.

RISK OF CANCER DEPENDS ON DURATION AND LEVEL OF EXPOSURE.

AVOID PROLONGED OR REPEATED CONTACT

WITH SKIN OR BREATHING DUST/FUMES/VAPORS.

OBSERVE GOOD HYGIENE AND SAFETY PRACTICES WHEN HANDLING THIS

PRODUCT

DO NOT USE THIS PRODUCT UNTIL MSDS HAS BEEN READ AND

UNDERSTOOD

THIS PRODUCT CONTAINS A CHEMICAL KNOWN TO THE STATE OF CALIFORNIA

TO CAUSE CANCER AND REPRODUCTIVE HAZARDS.

\section{SECTION III - HEALTH HAZARD INFORMATION}

EYE: Exposure to fumes, vapors, or dust may cause irritation and burning to the eyes.

Reversible symptoms may include irritation, a burning sensation,

intolerance to light, redness/swelling/tearing, and possible erosion of the surface of the cornea. Contact with heated material may cause thermal burns.

SKIN: Contact with the skin can result in irritation which, when accentuated by sunlight, may result in a phototoxic skin reaction. Contact with heated material may cause thermal burns. Hot/molten pitch is a severe burn hazard. Prolonged and repeated skin contact in the absence of recommended hygiene practices may cause acne, folliculitis and more serious skin disorders such as changes in skin pigmentation, ulcerations, benign skin growths and skin cancer.

INHALATION: Inhalation of fumes, vapors, or dust may cause temporary respiratory irritation.Acute respiratory effects caused by overexposure to coal tar pitch volatiles may include coughing, sneezing, and swollen or irritated nasal mucosa or sinuses. See "Other" below for "Inhalation Continued".

INGESTION: Ingestion of coal tar pitch may cause irritation of the gastrointestinal tract followed by one or more of the following: nausea, vomiting, and abdominal discomfort.

OTHER: Inhalation Continued: Inhalation of fumes or vapors in significant excess of the PEL/TLV may lead to systemic symptoms such as salivation; vomiting; respiratory difficulties; headache; loss of pupillary reflexes; central nervous system (CNS) effects such as dizziness, weakness, possible loss of coordination and collapse; cyanosis; hypothermia; and convulsions.

\section{SECTION IV - EMERGENCY AND FIRST AID PROCEDURES}

EYE CONTACT: Flush eyes immediately with large amounts of water for at least 15 
minutes, occasionally lifting the eyelids. Seek medical aid immediately.

SKIN CONTACT: For contact with molten product, do not remove contaminated clothing. Flush skin immediately with large amounts of cold water. If possible, Submerge area in cold water. Pack with ice. Seek medical aid immediately. For other contact, remove all contaminated clothing and wash exposed area thoroughly with nonabrasive soap and water, or a mild detergent.

INHALATION: Remove subject from exposure area to fresh air immediately. If breathing is difficult, give oxygen. If breathing has stopped, administer artificial respiration (e.g., mouth-to-mouth). Seek medical aid immediately.

INGESTION: If the person is conscious, first induce vomiting to prevent further absorption. DO NOT ATTEMPT TO GIVE ANYTHING BY MOUTH TO AN UNCONSCIOUS PERSON.

Give oxygen if respiration is shallow. Immediately seek medical aid.

\section{SECTION V - FIRE AND EXPLOSION HAZARD INFORMATION}

FLASH POINT \& METHOD: >190C (374F) PMCC AUTOIGNITION TEMP: >399C$750 \mathrm{~F}$

\section{FLAMMABLE LIMITS (\% BY VOLUME/AIR): LOWER: NA UPPER: NA}

EXTINGUISHING MEDIA: Use dry chemicals, carbon dioxide, sand, foam, steam, or water fog.

FIRE-FIGHTING PROCEDURES: Wear complete fire service protective equipment, including full-face MSHA/NIOSH approved self-contained breathing apparatus. Use water or water spray to cool fire-exposed containers and structures and to protect personnel. Water/fog can control unconfined pitch fires, but water may cause frothing or eruption in closed tanks.

FIRE AND EXPLOSION HAZARDS: Coal tar pitch at elevated temperatures may generate vapors that may ignite in the presence of air and a source of ignition. Burning may emit hazardous fumes/vapors which can form flammable/explosive mixtures in air and which may be in concentrations greater than the recommended PEL/TLV. Air-borne pitch dust may form explosive mixtures with air. Cloud ignition temperature is $710 \mathrm{C}(1310 \mathrm{~F})$ minimum. Explosion concentration (dust) is 0.035 ounces/ft 3 (1000 mg/0.03 m3). Closed containers may explode when exposed to extreme heat. Liquid (molten) pitch at elevated temperatures will sustain combustion.

SENSITIVITY TO MECHANICAL IMPACT: no 
SENSITIVITY TO STATIC DISCHARGE: yes for solid pitch dust

\section{SECTION VI - SPILL, LEAK AND DISPOSAL INFORMATION}

SPILL OR LEAK PROCEDURES (PRODUCT): Avoid breathing vapors or contact with skin and eyes. Remove all ignition sources. Try to stop the source of the leak if possible without hazard. Ventilate the area if spill occurs indoors. Release or spillage of solid can be treated as a coal spillage and recovery made avoiding skin and eye contact. Shovel into dry, labeled containers and secure cover. Contain runoff of fire control water. If hot liquid is spilled, contain by diking/berming with absorbent solids, such as sand, ashes, earth, or other inert material as necessary to prevent entry into sewers or open bodies of water. Avoid contact with hot liquid/fumes/vapors. Provide cleanup personnel with appropriate protective clothing. In cases involving release to the environment in the U.S., report the release to The National Response Center at 1-800-424-8802. In Canada, report releases to provincial authorities, municipal authorities, or both, as required. Due to the concentration of Benzo(a)pyrene in coal tar pitch as determined from the analyses presented in Section VII and the reportable quantity for Benzo(a)pyrene of one pound, a CERCLA (Superfund)release of approximately 7 gallons (74 pounds) of coal tar pitch requires National Response Center notification. See Section 7 for listing of additional hazardous substances.

WASTE DISPOSAL: If disposing in a state other than California, dispose of as an industrial waste in accordance with local, state, and federal regulations. Place in tightly sealed labeled containers. This product contains coal tar constituents, which have been determined by IARC to be a carcinogen. According to California hazardous waste regulations, substances posing a hazard to human health because of carcinogenicity are hazardous wastes. Dispose of as a hazardous waste in the state of California. In Canada, dispose of the material in accordance with provincial regulations.

\section{SECTION VII - RECOMMENDED EXPOSURE LIMIT/HAZARDOUS INGREDIENTS}

\section{EXPOSURE LIMIT (PRODUCT):}

*For coal tar pitch volatiles, OSHA-PEL is $0.2 \mathrm{mg} / \mathrm{m} 3$ averaged over an 8 hour work shift, benzene soluble fraction of total particulate including dust, fumes and mists.

\begin{tabular}{lll}
$\begin{array}{l}\text { HAZARDOUS INGREDIENTS } \\
\text { (PPM;MG/M3) }\end{array}$ & \multicolumn{1}{c}{ CAS NUMBER \% } & \\
\multicolumn{1}{c}{ - } & & \\
& & \\
Coal Tar Pitch & $65996-93-2100$ & $* 0.2 \mathrm{Mg} / \mathrm{M}$ \\
1-Nitropyrene & $5522-43-0$ & $<2$
\end{tabular}




$\begin{array}{lcc}\text { Benzo(a)anthracene } & 56-55-3 & <1 \\ \text { Benzo(b)fluoranthene+ } & 205-99-2 & \\ \text { Benzo(k)fluoranthene+ } & 207-08-9 & \\ \text { Benzo(j)fluoranthene+ } & 205-82-3 & \\ \text { 7,12-Dimethylbenz(a)anthracene } & 57-97-64 & <4 \\ \text { Dibenz(a,j)acridine } & 224-42-0 & <1 \\ \text { Dibenz(a,h)acridine } & 226-36-8 & <1 \\ \text { Benzo(g,h,i)pyrene+ } & & \\ \text { 7H Dibenzo(c,g)carbazole } & 194-59-2 & <1 \\ \text { Dibenzo(a,l)pyrene } & 191-30-0 & <1 \\ \text { Dibenzo(a,e)pyrene } & 192-65-4 & <1 \\ \text { Dibenzo(a,h)pyrene } & 189-64-0 & <1 \\ \text { Benzo(a)pyrene } & 50-32-8 & <2 \\ \text { Chrysene } & 218-01-9 & <2 \\ \text { Dibenz(a,h)anthracene } & 53-70-30 & <1 \\ \text { Indeno(1,2,3-cd)pyrene } & 193-39-5 & <1\end{array}$

- SARA TITLE III SECTION 313 CHEMICALS (SEE SECTION VII FOR CAS NUMBERS AND PERCENTAGES)

1-Nitropyrene

Benzo(a)anthracene

Benzo(b)fluoranthene

Benzo(k)fluoranthene

Benzo(j)fluoranthene

7,12-Dimethylbenz(a)anthracene

Dibenz(a,j)acridine

Dibenz(a,h)acridine

Benzo(g,h,i)pyrene

7H Dibenzo(c,g)carbazole

Dibenzo(a,1)pyrene

Dibenzo(a,e)pyrene

Dibenzo(a,h)pyrene

Benzo(a)pyrene

Chrysene

Dibenz(a,h)anthracene

Indeno(1,2,3-cd)pyrene

\section{SECTION VIII - PERSONAL PROTECTION INFORMATION}

EYE PROTECTION: Wear chemical/industrial safety glasses (with side shields), goggles, or face shields to prevent eye contact. Do not wear contact lenses when handling this material. Chemical splash goggles or face shields are highly recommended if handling molten material. 
SKIN PROTECTION: Wear full body, industrial-type work clothing closed at the neck and sleeves. As required to prevent skin contact, wear chemical resistant gloves, footwear, and coveralls; wear heat resistant gloves, if molten. See Section XIII - Comments for "Skin Protection Continued".

RESPIRATORY PROTECTION: The need for respiratory protection depends on the type and magnitude of exposure. Use MSHA/NIOSH approved respirator. Approved MSHA/NIOSH respirators include either of the following, as required: a half-face piece or full-face piece respirator with a particulate cartridge or organic vapor/particulate cartridge; or, a full-face piece continuous flow, positive pressure air supplied respirator.

VENTILATION: Provide sufficient general/local exhaust ventilation in pattern/volume to maintain concentrations below the recommended PEL/TLV and to maintain areas below flammable vapor/explosive dust concentrations.

\section{SECTION IX - PERSONAL HANDLING INSTRUCTIONS}

HANDLING: Avoid prolonged or repeated contact with skin or breathing of dust/fumes/vapors. Observe good personal hygiene practices and recommended procedures. Avoid contact with molten material. Wear appropriate protective equipment when performing maintenance on contaminated equipment. Closed system handling of liquid pitch could create excessive vapor concentrations in confined spaces; e.g., tanks, rail cars, tank trailers. When entering a confined space that has been in liquid pitch service, follow confined space entry procedures set forth in the OSHA Permit-Required Confined Spaces Standard, 29 CFR 1910.146.

STORAGE: Store in a labeled container in a clean, dry, well-ventilated area away from all sources of ignition. Protect containers from physical damage. Maintain good housekeeping.

OTHER: Wash exposed areas thoroughly with soap \& water after handling and especially before eating, drinking, using tobacco products or restrooms. Take a complete soap and water shower at the end of each workday. Do not smoke or eat in areas where this material is handled. Work clothes should be laundered before reuse. Remove and launder contaiminated clothing separate from other laundry before reuse.

SECTION X - REACTIVITY DATA

CONDITIONS CONTRIBUTING TO INSTABILITY: None known.

INCOMPATIBILITY: Avoid contact with water when confined and in a molten state. Avoid contact with strong oxidizing agents. 
HAZARDOUS REACTIONS/DECOMPOSITION/COMBUSTION PRODUCTS: Does not decompose at ambient temperatures. May emit hazardous fumes/vapors in concentrations greater than the PEL/TLV upon heating or burning. REACTIVITY:None.HAZARDOUS COMBUSTION

PRODUCTS:C02, C0, N0x,S02,\& PAHs.

CONDITIONS CONTRIBUTING TO HAZARDOUS POLYMERIZATION: None

SECTION XI - PHYSICAL DATA

BOILING POINT: $\quad$ >240C (>464F) $\quad$ SPECIFIC GRAVITY: $1.3+/-0.04$ @ 15.5C

MELTING POINT: NA $\quad$ \% VOLATILE BY VOL: NA

VAPOR PRESSURE: none @ 20C EVAPORATION RATE(ETHER=1): NA

VAPOR DENSITY $(A I R=1):>1 \quad$ VISCOSITY: NA

SOLUBILITY: negligible $\quad \mathrm{pH}: \quad$ NA

(WATER)

VOC: NA

COEFFICIENT OF WATER/OIL DISTRIBUTION: NA

APPEARANCE/ODOR: Temperature dependent. Black solid when allowed to cool. Black viscous liquid with aromatic odor when heated.

SECTION XII - TRANSPORT INFORMATION

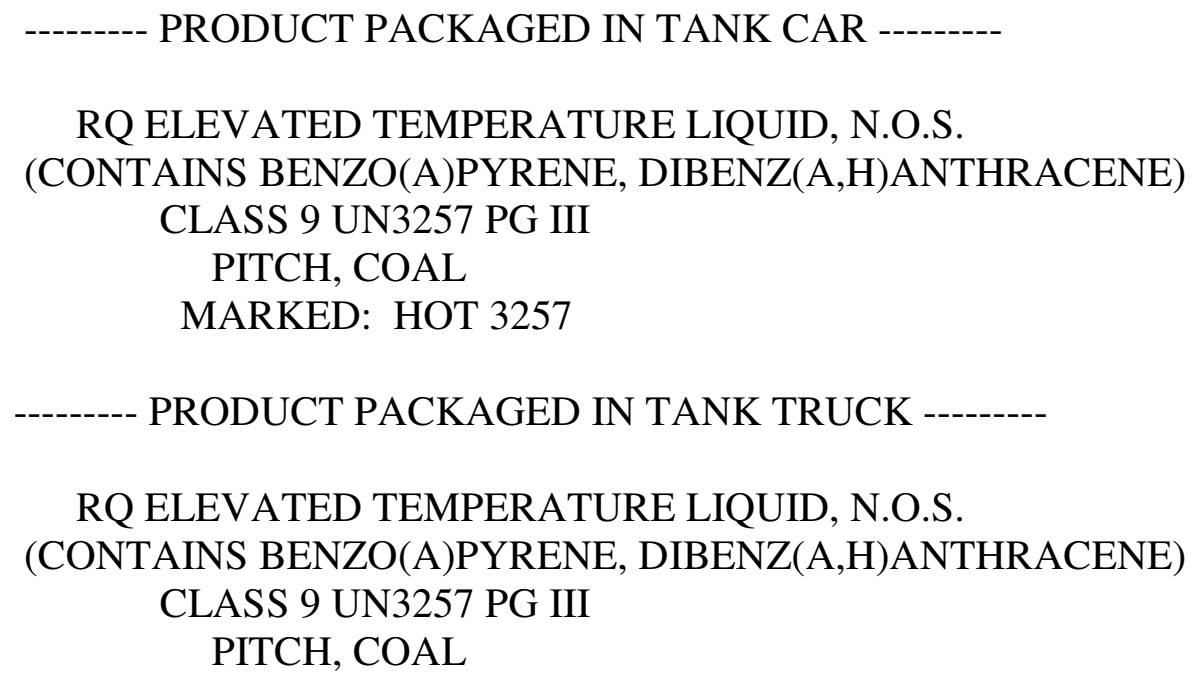


MARKED: HOT 3257

\section{SECTION XIII - COMMENTS}

Carcinogenicity: NTP(X) IARC(X) OSHA(X) ACGIH(X). This product contains coal tar pitch. The IARC monographs (Vol.35) state that there is sufficient evidence that coal tar pitches are carcinogenetic in humans. There is also sufficient evidence that chronic occupational overexposure to coal tars may cause skin cancer. Historical studies and anecdotal reports show an association between coal tar pitch overexposure and scrotal cancer in the absence of good hygiene practices. No recent studies support an association between coal tar pitch overexposure and scrotal cancer in the workplace. Epidemiological studies of aluminum reduction workers in the Soderberg process showed an excess risk of developing bladder cancer for workers with chronic overexposure to coal tar pitch volatiles in excess of the recommended threshold limit value. Studies also suggest an excess risk of developing lung cancer among workers with chronic overexposure to coal tar pitch volatiles in excess of the recommended threshold limit value.

Mutagenicity: Available data characterizes coal tar pitch as a mutagen.

Reproductive Toxicity and Teratogenicity: None known. Although coal tar pitch does contain substances considered to be reproductive hazards by the State of California, no scientific study supports an association between coal tar pitch exposures and human reproductive hazards. Persons More Susceptible to Exposure: Individuals with chronic respiratory disorders may be more susceptible to the effects of exposure to any airborne material. Individuals with pre-existing skin disorders may be more susceptible to irritation, dermatitis, and phototoxic reactions. Persons with a history of central nervous system (CNS) functional illness may be more susceptible to the effects when working with this product (see "Effects of Acute Exposure"above).

There are no known ingredients other than those listed above which occur at a concentration greater than 0.01 percent and are listed as a carcinogen in the IARC Monographs on the report on Carcinogens or OSHA 29 CFR 1910.1001-1004 subpart Z Toxic and Hazardous Substances (Specifically Regulated Substances).

FORMULA: A complex hydrocarbon mixture which includes polynuclear aromatic hydrocarbons (PAH's).

Skin Protection Continued: Application of certain protective creams for coal tar products and sunscreens before and during work may be beneficial and are recommended. Remove and launder contaminated clothing separately from other laundry before reuse.

No known ingredients which occur at greater than $0.1 \%$ are listed as a carcinogen in the IARC Monographs on the Evaluation of the Carcinogenic Risk of Chemicals to Humans, the NTP Annual Report on Carcinogens or OSHA 29 CFR 1910.1001-1047 subpart Z Toxic and Hazardous Substances (Specifically Regulated Substances).

SKIN PROTECTION (protective material): Permeation/degradation values of 
chemical mixtures cannot be predicted from pure components or chemical classes. Thus, these materials are normally best estimates based on available pure component data. A significant difference in chemical breakthrough time has been reported for generically similar gloves from different manufacturers (AIHA J., 48, 941-947 1987).

Do not use until manufacturer's precautions have been read/understood. Wash exposed areas promptly and thoroughly after skin contact from working with this product and before eating, drinking, using tobacco products or rest rooms.

Prepared By: Safety and Health Department

REVISION DATE: $11 / 00$

CODE NUMBER: IND00150NO0014

SPECIFICATION SHEET NUMBER:

REPLACES SHEET: IND00150FE0013

SUPPLIER INFORMATION: Same as manufacturer.

NOTICE: While the information and recommendations set forth herein are believed to be accurate as of the date hereof, Koppers makes no warranty with respect thereto and disclaims all liability from reliance thereon. 


\section{Appendix V: MSDS Creosote Oil}

Material Safety Data Sheet

MATERIAL K O P P E R S MEDICAL EMERGENCIES: 1800 553-5631

SAFETY OUTSIDE U.S.A.: 412 227-2001

DATA

GENERAL INFORMATION: 412 227-2424

SHEET

KOPPERS INC.

436 SEVENTH AVENUE

PITTSBURGH, PA. 15219-1800

CHEMTREC ASSISTANCE 1800 424-9300

CANUTEC: $\quad 1613996-6666$

SECTION I - PRODUCT IDENTIFICATION

PRODUCT NAME: Creosote (Manufacturing Use)

SYNONYM: P1/P13 Manufacturing Use

PRODUCT USE: Wood preservative

CHEMICAL FAMILY: Coal tar distillate

FORMULA: Complex mixture of aromatic and heterocyclic hydrocarbons

CAS NUMBER: 8001-58-9

NFPA 704M/HMIS RATING: 2/2 HEALTH 1/1 FLAMMABILITY $1 / 1$ REACTIVITY

$0=$ Least $\quad 1=$ Slight $\quad 2=$ Moderate $3=$ High $\quad 4=$ Extreme

CANADIAN PRODUCT CLASSIFICATION: Class D, Division 2, Subdivision A, Very Toxic

Material

SECTION II - HEALTH/SAFETY ALERT

CHRONIC OVEREXPOSURE (as defined by OSHA recommended standards)

MAY CAUSE CANCER

WARNING

MAY BE FATAL IF SWALLOWED

HARMFUL TO THE SKIN OR IF INHALED 


\begin{abstract}
CAUSES EYE AND SKIN IRRITATION
AVOID PROLONGED OR REPEATED CONTACT

OBSERVE GOOD HYGIENE AND SAFETY PRACTICES WHEN HANDLING THIS PRODUCT

DO NOT USE THIS PRODUCT UNTIL MSDS \& PRODUCT LABEL HAVE BEEN

READ/UNDERSTOOD.

WARNING: THIS PRODUCT CONTAINS A CHEMICAL KNOWN TO THE STATE

$\mathrm{OF}$
\end{abstract}

\title{
CALIFORNIA TO CAUSE CANCER.
}

\section{SECTION III - HEALTH HAZARD INFORMATION}

EYE: Direct contact with liquid or vapor may cause moderate irritation.

SKIN: Contact with skin can result in severe irritation which when accentuated by sunlight may result in phototoxic skin reaction. This material or similar materials when administered throughout the major portion of their lifetime has caused cancer in laboratory animals. Contact with heated material may cause thermal burns.

INHALATION: Acute overexposure to vapor may result in respiratory tract irritation. Repeated and/or prolonged contact to high concentrations of vapor may result in respiratory difficulties, central nervous system (CNS) effects characterized by headache, drowsiness, dizziness, weakness, incoordination, circulatory collapse, coma and possible death.

INGESTION: Ingestion of material may cause gastrointestinal disturbances including irritation, nausea, vomiting, abdominal pain. Systemic effects are similar to those described under INHALATION.

OTHER: See Section XIII (Comments) for additional information on health effects.

\section{SECTION IV - EMERGENCY AND FIRST AID PROCEDURES}

EYE CONTACT: Immediately flush with large amounts of water for 15 minutes. Seek medical aid.

SKIN CONTACT: Remove contaminated clothing. Wipe material from skin. Wash thoroughly with soap and water or waterless hand cleaner. If irritation persists, seek medical aid.

INHALATION: Remove from exposure. If breathing has stopped or is difficult, administer artificial respiration or oxygen as indicated. Seek medical aid.

INGESTION: If victim is conscious and alert, give 1-2 glasses of water or milk. 
Induce vomiting using ipecac syrup as directed on the label. After vomiting, the victim may be given a slurry of $100 \mathrm{~g}$ of activated charcoal in $8 \mathrm{oz}$. of water. Seek medical aid.

NOTE TO PHYSICIAN: Due to the possibility of sensitization of the myocardium following extreme acute overexposures, cardiorespiratory support should be available.

INGESTION: DO NOT INDUCE VOMITING OR GIVE ANYTHING BY MOUTH TO AN

UNCONSCIOUS PERSON.

SECTION V - FIRE AND EXPLOSION HAZARD INFORMATION

FLASH POINT \& METHOD: >93 C (>200 F)PMCC AUTOIGNITION TEMP: Not Deter

FLAMMABLE LIMITS (\% BY VOLUME/AIR): LOWER: ND IPPER: ND

TDG FLAMMABILITY CLASSIFICATION: None

EXTINGUISHING MEDIA: Use dry chemical, carbon dioxide, foam or water spray. Water or foam may cause frothing, if molten.

FIRE-FIGHTING PROCEDURES: Wear complete fire service protective equipment, including full-face NIOSH certified Self-Contained breathing apparatus. Use water to cool fire-exposed container/structure/protect personnel. Toxic vapors may be given off in a fire.

FIRE AND EXPLOSION HAZARDS: When heated (fire conditions), vapors/decomposition products may be released forming flammable/explosive mixtures in air. Closed containers may explode when exposed to extreme heat(fire).

SENSITIVITY TO MECHANICAL IMPACT: ND

SENSITIVITY TO STATIC DISCHARGE: ND

\section{SECTION VI - SPILL, LEAK AND DISPOSAL INFORMATION}

SPILL OR LEAK PROCEDURES (PRODUCT): Stop leak if no risk involved. Stay upwind. Solidified spills: Shovel into dry containers and cover. Flush area with water. Small wet spills: Take up with sand or other noncombustible absorbent material. Flush area with water. Dike large spills for later disposal. Contain runoff from fire control and dilution water. This product released into the environment must be reported to the National Response Center (1 800-424-8802). When this product is spilled or leaked, the CERCLA reportable quantity is 1 pound. 
1 pound Creosote

1 pound Benzo(b)fluoranthene

WASTE DISPOSAL: This product is a US EPA defined toxic waste. Dispose of as a toxic waste in accordance with local, state and federal regulations.

\section{SECTION VII - RECOMMENDED EXPOSURE LIMIT/HAZARDOUS INGREDIENTS}

\section{EXPOSURE LIMIT (PRODUCT):}

*For coal tar pitch volatiles, OSHA-PEL is $0.2 \mathrm{mg} / \mathrm{m} 3$ averaged over an 8 hour work shift, benzene soluble fraction of total particulate including dust, fumes and mists.

$* *$ skin

***OSHA-Action Level - 0.5 ppm 8-hr. TWA

\#Suspected Human Carcinogen. Percent by weight are the maximum levels of constituents.

HAZARDOUS INGREDIENTS (PPM;MG/M3)

CAS NUMBER \%BY WT. EXPOSURE LIMIT

Creosote

Phenanthrene

Fluoranthene

Pyrene

Acenaphthene

Fluorene

Naphthalene

Dibenzofuran

Anthracene

Benzo(a)anthracene

Chrysene

Biphenyl

1 Indeno(1,2,3-c,d)pyrene

Quinoline

Benzo(a)pyrene

Benzene

Benzo(g,h,i)perylene

M \& P Xylene

mixture 0.13

Styrene

\begin{tabular}{|c|c|}
\hline $8001-58$ & $3-9100$ \\
\hline $85-01-8$ & 14.13 \\
\hline 206-44-0 & $\begin{array}{ll}0 & 7.41\end{array}$ \\
\hline $29-00-0$ & 5.14 \\
\hline $83-32-9$ & 6 \\
\hline $86-73-7$ & 4.39 \\
\hline $91-20-3$ & 16.11 \\
\hline $132-64-9$ & 3.13 \\
\hline $120-12-7$ & $\begin{array}{l}7 \\
3.76\end{array}$ \\
\hline $56-55-3$ & 1.40 \\
\hline S-018-018 & $\begin{array}{ll}9 & 1.22\end{array}$ \\
\hline $95-52-4$ & 1.03 \\
\hline 193-39 & $\begin{array}{ll}-5 & 0.12\end{array}$ \\
\hline $91-22-5$ & 0.90 \\
\hline $50-32-8$ & 0.39 \\
\hline $71-43-2$ & 0.13 \\
\hline
\end{tabular}

191-24-2 0.17

108-38-3\&106-42-3

$100-42-5 \quad 0.06$
OSHA-TWA $0.2^{*}$

OSHA-TWA $0.2^{*}$

None

OSHA-TWA $0.2 *$

None

None

OSHA-TWA $10 \quad 50$

None

OSHA-TWA $0.2 *$

None

OSHA-TWA $0.2 *$

OSHA-TWA 0.2

None

None

OSHA-TWA $0.2 *$

OSHA-TWA $13^{* * *}$

OSHA-STEL 5

None

OSHA-TWA $100 \quad 435$

OSHA-TWA 100 


Dibenzo(a,h)anthracene
Phenol
Toluene
Benzofuran (Coumarone)
Ethylbenzene
O Xylene
Indene
2 Methylnaphthalene
1 Methylnaphthalene
Benzo(b)fluoranthene
Benzo(j)fluoranthene
Benzo(k)fluoranthene

$\begin{array}{cc}53-70-3 & 0.04 \\ 108-95-2 & 0.06 \\ 108-88-3 & 0.15 \\ & \\ 271-89-6 & 0.19 \\ 100-41-4 & 0.04 \\ 95-47-6 & 0.04 \\ 95-13-6 & 1.02 \\ 91-57-6 & 4.84 \\ 90-12-0 & 1.80 \\ 205-99-2 & 0.42 \\ 205-82-3 & 0.30 \\ 207-08-9 & 0.28\end{array}$

OSHA-STEL 200

None

OSHA-TWA $519 * *$

OSHA-TWA 100

OSHA-STEL 150

None

OSHA-TWA 100435

OSHA-TWA $100 \quad 435$

None

None

None

None

None

None

\section{SECTION VIII - PERSONAL PROTECTION INFORMATION}

EYE PROTECTION: Industrial safety glasses, minimum. As necessary to comply with OSHA 1910.133 and work area conditions: use side shields, goggles or face shield. Chemical goggles; face shield (if splashing is possible).

SKIN PROTECTION: As required, chemical resistant gloves. Depending on working conditions, i.e., contact potential, wear chemical resistant protective garments such as head/neck cover, aprons, jackets, coveralls, or long sleeved shirts and long pants, boots, long pants, chemical resistant overshoes, etc. See Section XIII - Comments for additional information on skin protection recommendations. 
RESPIRATORY PROTECTION: Not required under normal use conditions. If ventilation does not maintain inhalation exposures below TLV(PEL), use NIOSH certified air purifying respirators equipped with combination filter/organic vapor cartridge in accordance with OSHA Respiratory Protection Standard 1910.134 and manufacture's "Instructions" and "Warnings".

VENTILATION: Provide sufficient general/local exhaust ventilation in pattern/volume to control inhalation exposures below current exposure limits and areas below flammable vapor concentrations. Local exhaust is necessary for use in enclosed or confined spaces. See OSHA 29 CFR 1910.146 Permit Required Confined Space.

\section{SECTION IX - PERSONAL HANDLING INSTRUCTIONS}

HANDLING: Avoid prolonged or repeated breathing of vapors, mists or fumes. Avoid prolonged or repeated contact with skin or eyes. Observe good personal hygiene practices and recommended procedures. Application of certain skin creams (sun screen in conjunction with a general purpose protective cream) before working/several times during work may be beneficial.

STORAGE: Keep in a closed, labeled container. Protect from physical damage. Keep containers closed when material is not in use. Maintain good housekeeping.

OTHER: Not for use or storage in or around the home. DO NOT TAKE INTERNALLY. Do not use until manufacturer's precautions and product label have been read and understood. Wash exposed areas promptly and thoroughly after skin contact and before eating, drinking, using tobacco products or rest rooms.

SECTION X - REACTIVITY DATA

CONDITIONS CONTRIBUTING TO INSTABILITY: Overheating

INCOMPATIBILITY: none known

HAZARDOUS REACTIONS/DECOMPOSITION/COMBUSTION PRODUCTS: Oxides of carbon

CONDITIONS CONTRIBUTING TO HAZARDOUS POLYMERIZATION: none

SECTION XI - PHYSICAL DATA

BOILING POINT: $\quad>180 \mathrm{C}(>355 \mathrm{~F}) \quad$ SPECIFIC GRAVITY: $1.060 \mathrm{~g} / \mathrm{ml} @ 20 \mathrm{C}^{*}$

MELTING POINT: NA NOLATILE BY VOL: NA

VAPOR PRESSURE: $\quad$ 0.42mm Hg @70f EVAPORATION RATE(ETHER=1): slow 


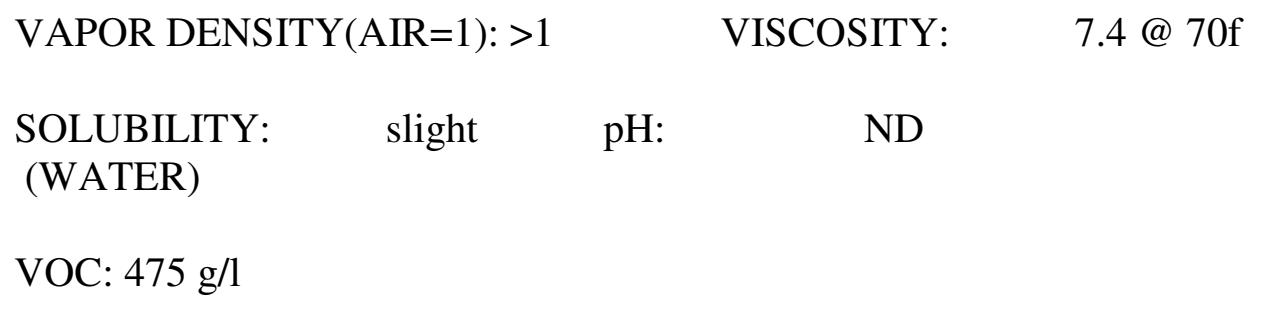

COEFFICIENT OF WATER/OIL DISTRIBUTION: slightly H2O soluble

APPEARANCE/ODOR: brown to black liquid with creosote or tarry odor

$*$ Specific Gravity +8.76 lb/gal

SECTION XII - TRANSPORT INFORMATION

-------- PRODUCT PACKAGED IN BARGE ---------

RQ ENVIRONMENTALLY HAZARDOUS SUBSTANCES, LIQUID, N.O.S. (CONTAINS BENZO(A)ANTHRACENE,BENZO(B)FLUORANTHENE) CLASS 9 UN3082 PG III

COAL TAR CREOSOTE, OR DISTILLATE, OR SOLUTION

PLACARDED: CLASS 9

--------- PRODUCT PACKAGED IN TANK CAR ---------

RQ ENVIRONMENTALLY HAZARDOUS SUBSTANCES, LIQUID, N.O.S. (CONTAINS BENZO(A)ANTHRACENE,BENZO(B)FLUORANTHENE) CLASS 9 UN3082 PG III

COAL TAR CREOSOTE, OR DISTILLATE, OR SOLUTION

PLACARDED: CLASS 9

PRODUCT PACKAGED IN TANK TRUCK ---------

RQ ENVIRONMENTALLY HAZARDOUS SUBSTANCES, LIQUID, N.O.S. (CONTAINS BENZO(A)ANTHRACENE,BENZO(B)FLUORANTHENE)

CLASS 9 UN3082 PG III

PLACARDED: CLASS 9

PRODUCT PACKAGED IN DRUM (TIGHT HEAD) 


\section{RQ ENVIRONMENTALLY HAZARDOUS SUBSTANCES, LIQUID, N.O.S. (CONTAINS BENZO(A)ANTHRACENE,BENZO(B)FLUORANTHENE) CLASS 9 UN3082 PG III \\ PLACARDED: CLASS 9}

\section{SECTION XIII - COMMENTS}

Persons with pre-existing disease in or a history of ailments involving the skin or blood-forming organs may be at a greater risk of developing adverse health effects when exposed to this material.

The IARC monographs (Vol. 35) states that there is sufficient evidence for the carcinogenicity of creosote in experimental animals. The NTP Annual Report on Carcinogens states that creosote oils are carcinogenic in experimental animals. Creosote does not appear in the OSHA Subpart Z Table.

Epidemiological studies of workers in the woodtreating industry have shown no significant health effects due to occupational exposure to creosote. The application of a commercially available sun-blocking lotion is recommended to greatly reduce the phototoxicity of coal tar derived materials associated sun burning. The sun block should be applied prior to the application of a protective cream and should have a sun protection factor(SPF) greater than 15 . Application of a general purpose protective cream or a cream specifically formulated for protection coal tar based products from contacting skin before working/several times during work may be beneficial.

EPA Reg. No. 61468-6.

Coal Tar Creosote (Pressure Applications) is an EPA registered pesticide regulated by the Federal Insecticide Fungicide Rodenticide Act (FIFRA) and failure to follow the label directions is a violation of Federal Law. The label addresses issues of personal hygiene practices, personal protective equipment use, the use, care and disposal of protective clothing and material handling precautions. Please refer to the label for more details.

This product containes benzene. The IARC monographs (vol. 29) states that there is sufficient evidence for the carcinogenicity in humans and limited evidence for the carcinogenicity in animals. Benzene is also listed in the NTP Annual Report on Carcinogens and in the OSHA Subpart Z Table (Specifically Regulated Substances).

Reviewed and revised May 2001.

No known ingredients which occur at greater than $0.1 \%$, other than those listed above, are listed as a carcinogen in the IARC Monographs on the Evaluation of the Carcinogenic Risk of Chemicals to Humans, the NTP Annual Report on Carcinogens or OSHA 29 CFR 1910.1001-1047 subpart Z Toxic and Hazardous Substances (Specifically Regulated Substances).

SKIN PROTECTION (protective material): Permeation/degradation values of chemical mixtures cannot be predicted from pure components or chemical classes. Thus, these materials are normally best estimates based on available pure 
component data. A significant difference in chemical breakthrough time has been reported for generically similar gloves from different manufacturers (AIHA J., 48, 941-947 1987).

Do not use until manufacturer's precautions have been read/understood. Wash exposed areas promptly and thoroughly after skin contact from working with this product and before eating, drinking, using tobacco products or rest rooms.

Prepared By: Safety and Health Department

REVISION DATE: 05/01 CODE NUMBER: IND00211MY0107

SPECIFICATION SHEET NUMBER: TP-1203-10 REPLACES SHEET:

IND00211AP0106

SUPPLIER INFORMATION: Same as manufacturer.

NOTICE: While the information and recommendations set forth herein are believed to be accurate as of the date hereof, Koppers makes no warranty with respect thereto and disclaims all liability from reliance thereon. 